\title{
Oligodendrogliopathy in neurodegenerative diseases with abnormal protein aggregates: The forgotten partner
}

\author{
Isidro Ferrer ${ }^{\mathrm{a}, \mathrm{b}, \mathrm{c}, \mathrm{d}, *}$ \\ ${ }^{a}$ Department of Pathology and Experimental Therapeutics, University of Barcelona, Hospitalet de Llobregat, Spain \\ ${ }^{\mathrm{b}}$ Service of Pathology, Bellvitge University Hospital, IDIBELL, Hospitalet de Llobregat, Spain

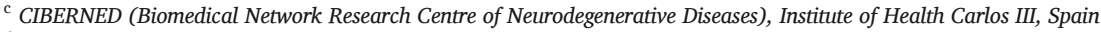 \\ ${ }^{\mathrm{d}}$ Institute of Neurosciences, University of Barcelona, Spain
}

\section{ARTICLE INFO}

\section{Keywords:}

Oligodendrocytes

Multiple system atrophy

Lewy body diseases

Tauopathy

Alzheimer's disease

Amyotrophic lateral sclerosis

Frontotemporal lobar degeneration

Creutzfeldt-Jakob's disease

Tau

$\alpha$-synuclein

\begin{abstract}
A B S T R A C T
Oligodendrocytes are in contact with neurons, wrap axons with a myelin sheath that protects their structural integrity, and facilitate nerve conduction. Oligodendrocytes also form a syncytium with astrocytes which interacts with neurons, promoting reciprocal survival mediated by activity and by molecules involved in energy metabolism and trophism. Therefore, oligodendrocytes are key elements in the normal functioning of the central nervous system. Oligodendrocytes are affected following different insults to the central nervous system including ischemia, traumatism, and inflammation. The term oligodendrogliopathy highlights the prominent role of altered oligodendrocytes in the pathogenesis of certain neurological diseases, not only in demyelinating diseases and most leukodystrophies, but also in aging and age-related neurodegenerative diseases with abnormal protein aggregates. Most of these diseases are characterized by the presence of abnormal protein de-
\end{abstract}

Abbreviations: 5-HT, 5-hydroxytryptamine; A $\beta$, $\beta$-amyloid; ABCA8, ATP binding cassette subfamily A member 8; AD, Alzheimer's disease; ADP, adenosine diphosphate; AGD, ar-

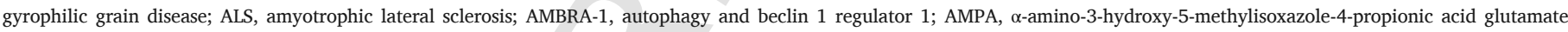

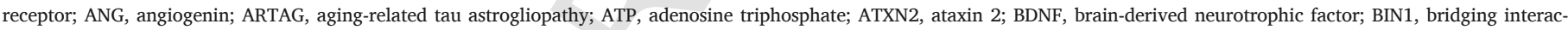

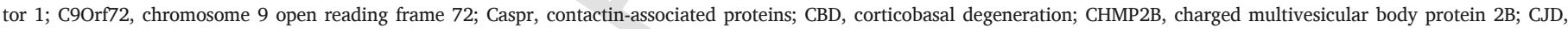

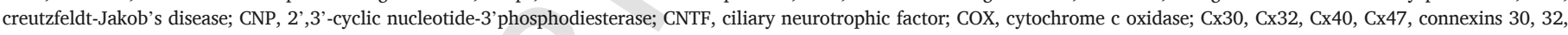

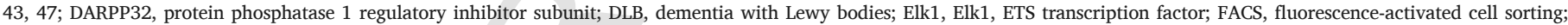

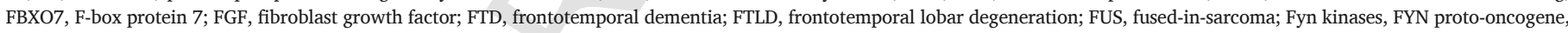

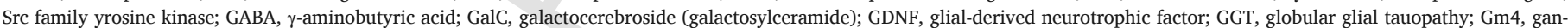

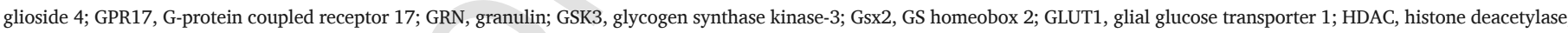

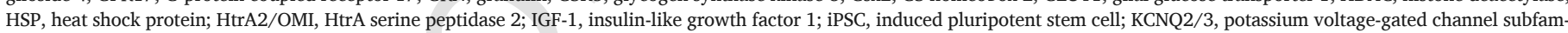

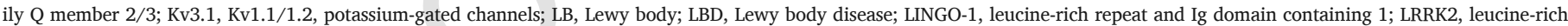

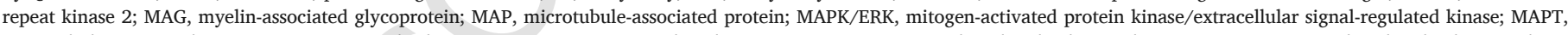

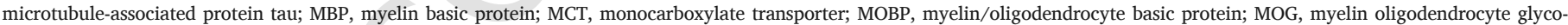

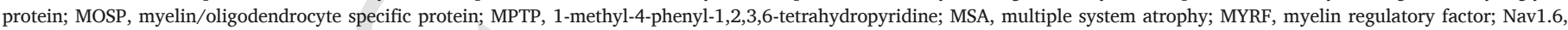

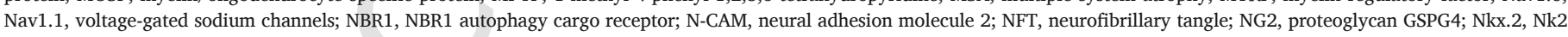

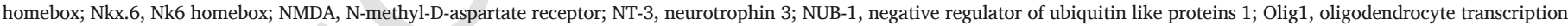

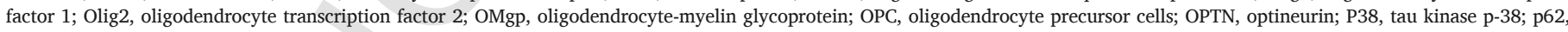

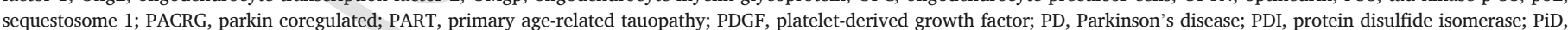

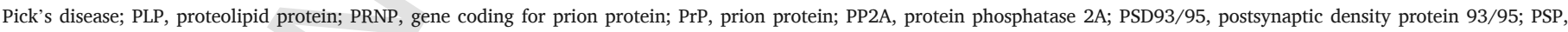

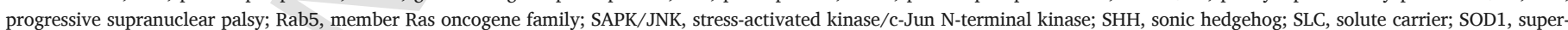

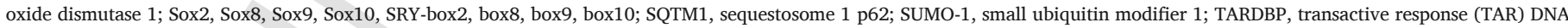

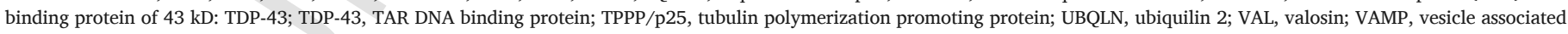
membrane protein; Wnt, Wnt family; XIAP, X-linked inhibitor of the apoptosis; Znf488, Znf536, zinc finger proteins 488 and 536.

* Correspondence to: Department of Pathology and Experimental Therapeutics, University of Barcelona, Campus Bellvitge, Feixa Llarga sn, Hospitalet de Llobregat, 08907, Spain.

Email address: 8082ifa@gmail.com (I. Ferrer) 
TDP-43

Prion posits, forming characteristic and specific inclusions in neurons and astrocytes but also in oligodendrocytes, thus signaling their involvement in the disease. Emerging evidence suggests that such deposits in oligodendrocytes are not mere bystanders but rather are associated with functional alterations. Moreover, operative modifications in oligodendrocytes are also detected in the absence of oligodendroglial inclusions in certain diseases. The present review focuses first on general aspects of oligodendrocytes and precursors, and their development and functions, and then introduces and updates alterations and dysfunction of oligodendrocytes in selected neurodegenerative diseases with abnormal protein aggregates such as multiple system atrophy, Lewy body diseases, tauopathies, Alzheimer's disease, amyotrophic lateral sclerosis, frontotemporal lobar degeneration with TDP-43 inclusions (TDP-43 proteinopathies), and Creutzfeldt-Jakob's disease as a prototypical human prionopathy.

\section{Oligodendrocytes: general aspects}

In addition to neurons and astrocytes, other cells, smaller in size, are present in the nervous system. These cells, called the "third element" turned out to be two different cell types after pioneering studies by Del Rio-Hortega (1921); one of these was microglia, the other oligodendroglia. The two cell types have different origins, morphology and functions; processes in some subtypes of oligodendroglial cells run in parallel to myelin thus suggesting a relationship between oligodendroglia and myelin (Penfield, 1924; Boullerne, 2016). Four different types were described by Pio del Rio-Hortega as detailed in a recent review (Perez-Cerda et al., 2015). Type I have small round cell bodies and large numbers of very fine cellular processes associated with thin myelinated fibers in the grey matter and interfascicular white matter; Type II are cuboidal with few and thick processes which trap axons longitudinally in the white matter; Type III have one or two long cellular processes and they are present in the brain stem and spinal cord; Type IV have an elongated cell body and unique long processes running in parallel to thick axons in the white matter of the brain stem and spinal cord. Perineuronal oligodendroglial cells are called "perineuronal satellites" whereas another subtype includes oligodendroglial cells localized in the proximity of small blood vessels and are called, for this reason, "perivascular satellites". Functions of perivascular oligodendrocytes are barely known although endothelial cell-oligodendrocyte interactions are altered in small vessel disease and aging (Rajani and Williams, 2017). Oligodendrocytes represent $75 \%$ of glial cells in the adult human brain (Pelvig et al., 2008).

Substantial knowledge about oligodendroglia and myelin in the central nervous system came out of electron microscopy observations and made it clear that oligodendrocytes are the only cells producing myelin in the central nervous system (Bunge, 1968; Raine, 1984; Hildebrand et al., 1993). Individual axons are myelinated by consecutive oligodendrocytes arranged in line; eachsegment or internode is separated from the next by a node of Ranvier. The myelin sheath is made up of thick membrane bi-layers of about $12 \mathrm{~nm}$ in periodicity formed by alternating electron-dense (major dense line of myelin) and electron-light (intra-period line of cytoplasm) tightly connected at their edges by thigh junctions between the electron-dense layers (Baumann and Pham-Dinh, 2001; Sherman and Brophy, 2005; Ozgen et al., 2016; Li and Richardson, 2016). This structure is not homogeneous along the internode but has non-compact regions such as the outer and inner periaxonal lips, the paranodal loops and interconnected cytoplasmic pockets (Pedraza et al., 2001; Traka et al., 2002; Poliak and Peles, 2003; Möbius et al., 2008; Hartline, 2008; De Monasterio-Schrader et al., 2012; Velumian et al., 2011; Aggarwal et al., 2011a; Nave and Werner, 2014).

Myelin sheaths protect the axonal membrane, promote the spread of electric signal along the axon, and decrease the capaci- tancy thus increasing the speed of the action potential with more efficiency (Rosenbluth, 2009; Bakiri et al., 2011; Harris and Attwell, 2012; Babbs and Shi, 2013). The nodes of Ranvier separate internodes. Axons at the site of nodes are enriched in voltage-gated sodium channels and potassium-gated channels Nav 1.6, Nav 1.1, KCNQ2/3, Kv 3.1, Kv1.1/ 1.2; and postsynaptic density protein 93/95 (PSD 93/95) which are all crucial for saltatory nerve conduction. In addition, cytoskeletal scaffolding proteins ankyrin $\mathrm{G}$ and $\mathrm{B}, \alpha \mathrm{II} / \beta \mathrm{II}$-spectrin and $\beta \mathrm{IV}$-spectrin participate in the transport of ion channels and contribute to the assembling of axonal proteins at the node of Ranvier (Rosenbluth, 1976; Rasband et al., 1999; Rios et al., 2003; Devaux et al., 2003, 2004; Chen et al., 2004; Hartline and Colman, 2007; Duflocq et al., 2008; Susuki et al., 2013; Battefeld et al., 2014; Arancibia-Carcamo and Attwell, 2014; Barry et al., 2014). Astrocytes are often located at the vicinity of the nodes of Ranvier (Hildebrand, 1971a, b), but their role is not known.

Oligodendrocytes can generate between 20 and 60 myelinating processes with internodal lengths of about $20 \mu \mathrm{m}-200 \mu \mathrm{m}$ (Hildebrand et al., 1993). The estimated surface area of one oligodendrocyte, once the myelin membrane is "unfolded", is $5-50 \times 10^{3} \mu \mathrm{m}^{2}$ (Baron and Hoekstra, 2010). Therefore, oligodendrocytes are one of the cell types in the body with the largest surface membrane.

Oligodendrocytes are connected with each other and with astrocytes through gap junctions thus forming a glial syncytium in the white matter tracts (Bedner et al., 2012; Nualart-Marti et al., 2013).

Myelin is composed of cholesterol (26\%); glycosphingolipids, in particular galactocerebrosides and sulphatides (31\%); plasmalogens (20\%); phospholipids and gangliosides, particularly GM4; and proteins (30\%) (Kursula, 2001, 2008; Chrast et al., 2011; Saher and Stumpf, 2015; Schmitt et al., 2015). The principal proteins are myelin basic protein (MBP), proteolipid protein (PLP) and its isoform DM20, 2',3'-cyclic nucleotide-3'phosphodiesterase (CNP), myelin-associated glycoprotein (MAG), myelin oligodendrocyte glycoprotein (MOG), myelin/oligodendrocyte specific protein (MOSP), myelin/oligodendrocyte basic protein (MOBP), oligodendrocyte-myelin glycoprotein (OMgp), transferrin, carbonic anhydrase, claudin 11, connexins 32 and 47 (Cs32 and Cx47) and tetraspan-2, among other minority proteins (Chen et al., 2006; Jahn et al., 2009; Harauz et al., 2009; Llorens et al., 2011; Raasakka and Kursula, 2014; McKerracher and Rosen, 2015). MBP and PLP represent $80 \%$ of the total myelin protein.

Nodes of Ranvier are enriched in certain myelin- and axon-derived proteins-netrin, contactin 1 and 2, neurofascin 155, neurofascin 186, contactin-associated proteins (Caspr 1 and 2) -which interact to bind the myelin sheath to the axon at the free borders of myelin, together with extracellular matrix proteins such as brevican, versican and N-CAM variant (Rasband, 2011; Thaxton et al., 2011; Susuki et al., 2013; Arancibia-Carcamo and Attwell, 2014; Griggs et al., 2017). 
Because of the large area of oligodendrocytes and cellular processes including myelin, these cells would be very vulnerable to energy metabolism deficiencies. Oligodendrocytes and myelin in the developing brain are indeed very vulnerable to hypoxia. However, mature oligodendrocytes are equipped with metabolic mechanisms that can cope with metabolic insults. These include high levels of glutathione which protects oligodendrocytes from oxidative damage, switching from an oxidative to a glycolytic metabolism; myelin compaction and low turn-over of myelin proteins; and axon-myelin interactions which are mutually supportive (Back et al., 1998; Brown et al., 2001; Morland et al., 2007; Funfschilling et al., 2012; Toyama et al., 2013; Hirrlinger and Nave, 2014; Roth and Núñez, 2016).

Oligodendrocytes have an elaborate network of microtubules composed of microtubule-associated proteins MAP2 and tau whose assembly depends on the interaction of several kinases including Fyn kinases and microtubule-severing proteins such as stathmin (Richter-Landsberg, 2000). Alteration of the cytoskeleton in oligodendroglial cells occurs in tauopathies in which hyper-phosphorylated tau is accumulated and disrupts oligodendroglial microtubules (Richter-Landsberg, 2008). Since the oligodendroglial microtubules participate in the translocation and sorting of MBP and CNP, their alteration may render myelin vulnerable (Bauer et al., 2009). Abnormal tau inclusions in glial cells in tauopathies have functional consequences (Kahlson and Colodner, 2016).

\section{Development of oligodendroglia and myelin}

Oligodendrocyte precursor cells (OPCs) proliferate in the neuroepithelium of the subventricular zone and migrate to the future white matter through extending and retracting cell processes until their definitive placements (Baumann and Pham-Dinh, 2001; Kirby et al., 2006; Miller and Mi, 2007; Hughes et al., 2013). This process is modulated by self-repulsive movements which allow a certain separation between neighboring cells (Jarjour et al., 2003; Hughes et al., 2013). Oligodendrocytes during development are called pre-oligodendrocytes, immature oligodendrocytes, myelinating and mature oligodendrocytes, each one characterized by very specific morphological and biochemical properties. Differentiation of OPCs to oligodendrocytes depends on the availability of certain growth and survival factors such as platelet-derived growth factor A (PDGF)-A, fibroblast growth factor 2 (FGF-2), insulin-like growth factor 1 (IGF-1), ciliary neurotrophic factor (CNTF) and neurotrophin 3 (NT-3); some cells remain as OPCs whereas redundant cells are eliminated by apoptosis (Barres et al., 1992; Raff et al., 1993; Barres and Raff, 1993; Trapp et al., 1997; Miller, 2002).

Although OPCs can differentiate into oligodendrocytes in the absence of axons (Abney et al., 1981; Raff et al., 1985), axons control the development of oligodendroglia in vivo (Wender et al., 1980; Privat et al., 1981; David et al., 1984; Valat et al., 1988; Barres and Raff, 1993, 1999). Moreover, axon signals mediated by certain transcription factors and selected microRNAs, histone deacetylases and the Wnt/- $\beta$-catenin pathway modulate myelin gene expression and myelination (Fancy et al., 2009; Emery, 2010; Piaton et al., 2010; Taveggia et al., 2010; Budde et al., 2010; Dugas et al., 2010; Zhao et al., 2010; Kim et al., 2010; Nave, 2010; Twak et al., 2011).

Myelination is also triggered by functional activity of neurons, mediated by ATP and adenosine signals which regulate cross-information between axons, astrocytes and oligodendrocytes, in parallel with down-regulation of PSA-NCAM and LINGO-1 (Demerens et al., 1996; Charles et al., 2000; Mi et al., 2005; Ishibashi et al., 2006; Brinkmann et al., 2008; Gyllensten and Malmfors, 2009). Synaptic activity contributes to the regulation of myelination (Kukley et al.,
2007; Ziskin et al., 2007; Gibson et al., 2014; Hines et al., 2015; Mensch et al., 2015; Koudelka et al., 2016).

Myelination is a complex phenomenon which wraps the axon with concentric bilayers (Pedraza et al., 2001; Ffrench-Constant et al., 2004; Simons and Trotter, 2007; Bauer et al., 2009). The process of axon myelination is not uniform but varies along the segment of the involved axon. MBP is produced in the distal parts of oligodendrocytes closest to axons and then MBP progresses from the outside to the inside (Ainger et al., 1993, 1997; Snadeiro et al., 2014). PLP is transported to myelin by vesicular transport and interacts with MBP in the presence of neuronal signals; interaction between the neuron and MBP is necessary for myelin protein clustering (Fitzner et al., 2006). Galactocerebroside (galactosylceramide: GalC) is also incorporated at the same time; thus, neuron-oligodendroglial interactions are mandatory for proper myelin biogenesis (Trajkovic et al., 2006; Simons and Trajkovic, 2006).

Myelin compaction is regulated by several factors, among them CNP, the deficiency of which leads to increased myelin compaction (Snaidero et al., 2014). Conversely, over-expression of CNP leads to focal areas of loose myelin compaction (Gravel et al., 1996). MBP then aggregates and modifies its conformation, resulting in a very stable and resistant protein which limits the entry of other molecules (Aggarwal et al., 2011a, b; Aggarwal et al., 2013; Bakhti et al., 2013a, b). Myelin connects at their edges by tight junctions enriched in claudin-11 (Gow et al., 1999; Morita et al., 1999).

During myelination, molecular clustering occurs at the nodes of Ranvier which involves axonal adhesion molecule neurofascin 186, $\beta$ IV spectrin, $\beta$ II spectrin, ankyrin $G$, voltage-gated sodium channels, voltage-gated potassium channels, TAG-1 and actin, together with glial cell adhesion molecule neurofascin 155, axonal contactin and Caspr (Pan and Chan, 2017). Ankyrin deficiency alters the structure of the nodes of Ranvier and results in axonal degeneration (Saifetiarova et al., 2017). Caspr deficiency manifests by nodal disruption, disorganization of the microtubules and axonal swellings (Garcia-Fresco et al., 2006).

In addition to neuron-glia interactions, other extrinsic and intrinsic factors modulate OPC differentiation and myelination; these include hormones acting on specific receptors, cytokines and enzymes, some of them stimulators and others repressors (McTigue et al., 1998; Noble et al., 1988; Wang et al., 1998; Stolt et al., 2002; Calza et al., 2002; Valerio et al., 2002; Klein et al., 2002; Larsen et al., 2006; Kotter et al., 2006; Fancy et al., 2009; Emery et al., 2009; Meijer et al., 2012; Bankston et al., 2013).

\section{Diversity of OPCs/NG2-glia}

OPCs are also called NG2-glia because of their expression of proteoglycan GSPG4 (NG2). These cells are not only found during the development of the nervous system; OPCs are present in the adult brain and show particular features distinct from those seen in embryonic OPCs (Káradóttir et al., 2008; Tripathi et al., 2011; Clarke et al., 2012; Vigano et al., 2013; Crawford et al., 2016). OPCs/NG2-glia is considered the fourth element in the adult central nervous system constituting about $5-10 \%$ of the total cell population (Scolding et al., 1998; Horner et al., 2000; Dawson et al., 2003; Peters, 2004). Adult OPCs have the capacity to produce myelinating oligodendrocytes (Tripathi et al., 2010; Zawadzka et al., 2010), thus contributing to oligodendrocyte and myelin repair in the adult CNS (Tognatta and Miller, 2016). Indeed, NG2-glial cells are stem cells as they represent the major proliferative cell population in the adult CNS and have the capacity to differentiate into different cell types in addition to oligodendrocytes (Psachoulia et al., 2009; Simon et al., 2011; Dimou and Gotz, 2014; Crawford et al., 2016). OPCs can also generate astrocytes (Zhu et al., 2008, 
2011; Vigano et al., 2016). For example, a subset of OPCs in the CA1 region of the mouse hippocampus expresses S100 $\beta$, thus suggesting that these cells may act as precursors of astrocytes (Moshrefi-Ravasdjani et al., 2017). Human OPCs are also able to transform into astrocytes (Windrem et al., 2004; Sim et al., 2006, 2011). In addition, one NG2 can divide asymmetrically producing an oligodendrocyte and one NG2-glia (Hill et al., 2014). Whether adult OPCs are able to generate neurons is a matter of controversy. However, OPCs have been reported to be a source of pyriform pyramidal neurons in the adult rodent brain (Rivers et al., 2008; Guo et al., 2010), and adult OPCs removed from brain can transform into neurons in vitro or when inoculated into developing brains (Battefeld et al., 2014; Nunes et al., 2003). Furthermore, NG2 immunoreactivity is not restricted to a subpopulation of glial cells since pericytes also express NG2 (Ozerdem et al., 2001).

OPCs in the developing mouse brain arise from three waves and from different regions; progeny of the second and third waves persists until adulthood with a certain overlap and reconstructive capacities of the last generated OPCs (Kessaris et al., 2006; Dimou et al., 2005; Rowitch and Kriegstein, 2010; Tomassy et al., 2014). Regional heterogeneity of OPCs implies a different response to particular growth factors and sensitivity to determined signaling pathways even in close areas such as the ventral and dorsal spinal cord of the mouse (Cai et al., 2005; Fogarty et al., 2005; Vallstedt and Kullander, 2013). Important differences also exist between spinal, and cortical and white matter OPCs (Hildebrand et al., 1993; Chong et al., 2012; Hill et al., 2013; Vigano et al., 2013; Eugenin-von Bernhardi and Dimou, 2016; Naruse et al., 2017).

The region of origin also determines future functional capacities of the progeny as responses to demyelination and susceptibility to age-associated functional decline (Crawford et al., 2016; Ornelas et al., 2016). OPCs have the capacity to proliferate, migrate and differentiate following distinct insults, and they play some role in axon regeneration (Tan et al., 2005; Hughes et al., 2013). However, OPCs in the white matter differ from those of the grey matter in many ways including proliferation capacities, response to certain growth factors and plastic properties among others (Dimou et al., 2008; Kang et al., 2010; Young et al., 2013; Hill et al., 2013; Vigano et al., 2013; Serwanski et al., 2017; Hill et al., 2014; Dimou and Gotz, 2014). Certain OPCs express the G-protein coupled receptor 17 (GPR17) (Chen et al., 2009; Boda et al., 2011; Fumagalli et al., 2011) which is associated with higher capacity of differentiation into mature oligodendrocytes following cerebral injury (Vigano et al., 2016; Bonfanti et al., 2017).

Neurons can establish synaptic-like structures with NG2-glia, at least in particular regions and species (Bergles et al., 2000; Lin et al., 2005a, b), whose activation produces bursts of miniature potentials in NG2-glia mediated by $\alpha$-amino-3-hydroxy-5-methylisoxazole-4-propionic acid (AMPA) glutamate receptors (Bergles et al., 2000; Ziskin et al., 2007). In addition to AMPA receptors, NG2-glia expresses N-methyl-D-aspartate (NMDA) receptor, acetylcholine, $\gamma$-aminobutyric acid A $\left(\mathrm{GABA}_{\mathrm{A}}\right)$ and other receptors (Williamson et al., 1998; De Angelis et al., 2012; Dzamba et al., 2013). NG2-glia also expresses the post-synaptic density protein 95 (PSD-95) (Sakry et al., 2011). Therefore, neurons can regulate proliferation and differentiation of NG2-glia through synaptic signals (Lin et al., 2005a, b; Kukley et al., 2010; Mangin et al., 2012; Sun and Dietrich, 2013; Hill et al., 2014; Gibson et al., 2014; Dimou and Gallo, 2015).

\section{Expression of neurotransmitter, hormone receptors and ion channels in oligodendrocyte lineage}

A plethora of neurotransmitter and other receptors are expressed in OPCs and at different stages of oligodendroglial differentiation and maturation; these modulate, after specific ligand binding, various stages of oligodendrocyte development (Marinelli et al., 2016). GABA $_{B}$ receptors are expressed at early stages and their activation induces proliferation and migration of OPCs (Luyt et al., 2007). NMDA, AMPA and kainate receptors are expressed in immature and myelinating oligodendrocytes favoring differentiation and myelination in physiological conditions but also contributing to oligodendroglial damage in ischemia and excitotoxic injury (Salter and Fern, 2005; Micu et al., 2006; Káradóttir et al., 2005).

5-hydroxytryptamine (5-HT) receptor subtypes $1 \mathrm{~A}$ and $2 \mathrm{~A}$ are expressed in immature and myelinating oligodendrocytes (Fan et al., 2015). Its activation after exposure to serotonin interferes with oligodendroglial differentiation and myelinogenesis (Persico et al., 2000; Fan et al., 2015). Curiously, depression is accompanied by reduced oligodendroglia, expression of myelin-related genes and decreased MBP levels in various brain regions (Aston et al., 2005; Yamazaki et al., 2007; Regenold et al., 2007). Dopamine receptors D2 and D3 are expressed in oligodendrocyte precursors where they are probably involved in the regulation of differentiation and myelin formation (Bongarzone et al., 1998). Adult oligodendrocytres in rats also express D2 and D3 receptors but their function is not known (Rosin et al., 2005). Pre-oligodendrocytes express $\alpha$ - and $\beta$-adrenoreceptors whose activation inhibits their proliferation (Ghiani et al., 1999). Cholinergic receptors are present in OPCs and oligodendrocytes at different phases; acetylcholine via muscarinic receptors potentiates proliferation (De Angelis et al., 2012).

OPCs exhibit opioid receptors (Knapp et al., 1998). Dinorphin and pro-encephalin-derived peptides are produced at different stages of oligodendrocyte maturation, thus suggesting an autocrine/paracrine effect on cell survival and development (Knapp et al., 2011). However, perinatal exposure to methadone and bupremorphine alter myelination in the developing rat brain (Eschenroeder et al., 2012; Vestal-Laborde et al., 2014).

ADP and ATP stimulate OPC migration through specific receptors (Agresti et al., 2005) but ATP may also facilitate calcium-mediated excitoxicity and oligodendrocyte damage (Butt, 2006).

Prolactin activates proliferation, maturation and myelination of oligodendrocytes (Gregg et al., 2007). Dexametasone enhances myelination at early stages but reduces myelin formation at advanced stages of development (Almazan et al., 1996). Increased proliferation and oligodendroglial death, suggesting decreased lifespan, and increased oligodendroglial turnover are found in female and castrated male rats (Cerghet et al., 2009). Thyroid hormones activate the expression of myelin-related genes (Farsetti et al., 1991; Tosic et al., 1992; Rodriguez-Peña et al., 1993). Other factors influencing oligodendrocyte development are cannabinoids, liver $\mathrm{X}$ receptor, retinoic acid, prostaglandins and peroxisome proliferator activated receptor $\gamma$ (Marinelli et al., 2016).

Finally, different ion channels are expressed in OPCs and oligodendrocytes including voltage-gated sodium channels (Tong et al., 2009), voltate-gated calcium channels (Verkhratsky et al., 1990) and diverse potassium channels (Buttigieg et al., 2011; Wang et al., 2011; Hawkins and Butt, 2013; Moroni et al., 2015; Battefeld et al., 2016; Livesey et al., 2016; Fang et al., 2017; Brasko et al., 2017; Larson et al., 2018) which participate in glial cell proliferation, regeneration, oligodendroglia/neuronal and axonal interactions, and 
which modulate oligodendroglial responses to ischemia, excitotoxicity and seizures, among other pathological settings.

\section{Diversity of oligodendrocytes}

Transcriptomic profiles of neurons, astrocytes and oligodendroglia have been identified using high-throughput methods (Cahoy et al., 2008; Zhang et al., 2014; Moyon et al., 2015; van Bruggen et al., 2017). Single-cell RNA sequencing revealed different subpopulations of oligodendrocytes from several brain regions of juvenile and adult mouse brain (Zeisel et al., 2015; Marques et al., 2016). A single cluster of OPCs was found in the first studies (Marques et al., 2016; Hochgerner et al., 2017). However, several OPC clusters were recognized thereafter in the adult murine spinal cord (Habib et al., 2016). Likewise, several clusters of oligodendrocytes have been described in the mouse CNS (Tasic et al., 2016; Habib et al., 2017; Hochgerner et al., 2017).

Gene expression studies have also identified subpopulations of OPCs in human adult white matter and fetal forebrain (Sim et al., 2006, 2011), and in human (and murine) ventral midbrain during development (La Manno et al., 2016). Similar analysis has been extended to human oligodendrocytes, further confirming different clusters of oligodendrocytes and precursors in human brain (Darmanis et al., 2015; Spaethling et al., 2017; Habib et al., 2017; Lake et al., 2017).

All this information supports pioneering observations by Pio del Rio-Hortega describing different types of oligodendroglial cells. However, available information is not uniform and it is difficult, at present, to consolidate clear-cut profiles for different clusters/types of oligodendrocytes. There is probably a more complex scenario because transcription is modifiable depending on the function and physiological state of the cells.

\section{Signals involved in OPC generation, oligodendroglia differentiation and myelination}

Major knowledge of OPC generation comes from the study of the mouse spinal cord and forebrain. In the spinal cord, the first wave of generation occurs at embryonic day 12 , originates from the ventral neural tube and depends upon sonic hedgehog ( $\mathrm{SHH}$ ) and $N k x 6.1$ and $N k x 6.2$ regulation of Olig 1 and Olig2 transcription (Orentas et al., 1999; Lu et al., 2000; Vallstedt et al., 2005). A second wave originates at embryonic day 15 from the dorsal spinal cord; it is not dependent on SHH but it is regulated by $D b x 1$ and $A s 11$ and requires fibroblast growth factor enhancement and decreased bone morphogenic protein signaling (Vallstedt et al., 2005; Cai et al., 2005; Fogarty et al., 2005; Sugimori et al., 2008). A third wave occurs at birth (Rowitch and Kriegstein, 2010).

In the forebrain, the first wave comes from the medial ganglionic eminence upon SHH and Nkx.2 mediation (Nery et al., 2001; Tekki-Kessaris et al., 2001; Kessaris et al., 2006), and it spreads to the entire forebrain (Kessaris et al., 2006; Klambt, 2009). The second wave comes from the lateral ganglionic eminence under the control of Gs $x 2$ (Chapman et al., 2013) and it populates all the forebrain (Kessaris et al., 2006; Klambt, 2009). The third wave occurs at birth, and derives from dorsal and outer subventricular zones through Emxl extending to the corpus callosum and capsular white matter (Kessaris et al., 2006).

Such detail in human brain is not available although OPCs first appear approximately at nine weeks of gestation and proliferate until about 18 weeks of gestation; oligodendroglia start to differentiate until about 27 weeks of gestation (Back et al., 2001; Jakovcevski et al., 2009; Sim et al., 2011)
Early oligodendroglial differentiation, at least in the murine brain, is mediated by activation of transcription factors Znf488 and Znf536, down-regulation of Sox2, up-regulation of Sox8, Sox9, Sox 10, Olig1 and Olig 2 (Kuhlbrodt et al., 1988; Wegner and Stolt, 2005; Yang et al., 2013; Wang et al., 2014). At early stages, human and murine cells also express platelet derived growth factor receptor $\alpha(\mathrm{PDGF} \alpha)$, gangliosides (as revealed by the antibody A2B5) and NG2 (Hart et al., 1989; Noble et al., 1988; Wolswijk and Noble, 1989; Richardson et al., 1988; Roy et al., 1999; Chang et al., 2000; Dawson et al., 2000; Levine et al., 2001; Sim et al., 2006, 2011; Wang et al., 2014). The transition of OPCs to post-mitotic oligodendrocytes is characterized by chromatin condensation with heterochromatin formation (Huang et al, 2015), up-regulation of selected microRNAs and silencing of genes involved in cell proliferation including PDGF, FGF and Wnt, among other factors (Yu et al., 2010, 2013; Zhao et al., 2010; Dugas et al., 2010; Ackerman et al., 2015; Giera et al., 2015; Barca-Mayo and Lu, 2012; Magri et al., 2014; Mitew et al., 2014; Fitzpatrick et al., 2015). Wnt/ $\beta$-catenin pathways play different roles in oligodendrocyte development and myelination in different brain regions and at different stages (Guo et al., 2015). These transcription factors are controlled by epigenetic remodeling of the chromatin by histone acetylation and methylation. Histone deacetylases 1 and 2 (HDAC 1 and 2) actively participate in this process (Marin-Husstege et al., 2002; Shen et al., 2005; Liu et al., 2007a, 2015).

Early stages of oligodendrocyte lineage are identified by the expression of Olig1, Olig2 and Nkx2.2 (Liu et al., 2007b). PDGF-R $\alpha$, NG2, Olig1, Olig 2, Sox 10 and A2B5 are OPC differentiation and pre-oligodendrocyte markers. Loss of PDGF-R $\alpha$ and NG2, and increased expression of surface lipid sulfatide, galactocerebroside and CNP, together with Olig 1 and Olig 2, are characteristic of immature oligodendrocytes (Marinelli et al., 2016).

After oligodendrocyte differentiation, myelination is triggered by myelin regulatory factor (MYRF) which is expressed in post-mitotic oligodendrocytes (Cahoy et al., 2008). This is accompanied by increased expression of MBP, MAG, PLP1, MOG and CNP which have MYRF binding motivs in their promoters (Emery et al., 2009; Koenning et al., 2012; Bujalka et al., 2013; McKenzie et al., 2014; Emery and Lu, 2015). At this time, oligodendrocytes also produce sulfatides and galactocerebrosides as main lipid components of myelin. MBP, MAG, MOG and PLP are mainly found in myelin under physiological conditions in the mature brain; carbonic anhydrase II, CNP and galactocerebroside can be identified in oligodendrocytes in brain tissue sections; surface lipid sulfatide, Olig1, Olig2 and Sox 10 are additional markers expressed in myelinating oligodendrocytes (Bradl and Lassmann, 2010; Marinelli et al., 2016).

The role played by neurons and axons during myelinogenesis has been detailed before. Whether oligodendroglial subtypes depend on the type of axons and the type of neurons is a matter for study (Ludwin, 1979; Tauber et al., 1980; Tomassy et al., 2014; Battefeld et al., 2016; Micheva et al., 2016).

\section{Oligodendroglia and axon integrity}

In addition to studies showing the role of axons in the development of oligodendroglia, several in vitro and in vivo experimental models have demonstrated that oligodendroglia are involved in support of axonal transport and axon integrity (Nave and Trapp, 2008; Lee et al., 2012; Saab et al., 2013; Beirowski, 2013; Morrison et al., 2013; White and Krämer-Albers, 2014; Simons et al., 2016). Axon outgrowth is also sustained in part by growth factors such as GDNF and BDNF produced by oligodendrocytes (Du and Dreyfus, 2002; Wilkins et al., 2003; Dai et al., 2003) 
Oligodendrocyte cell death is produced by diphtheria toxin in mice selectively expressing diphtheria toxin receptor in oligodendoglia or by conditionally targeting diphtheria toxin to PLP-CrER mice (Ghosh et al., 2011; Oluich et al., 2012). In all these settings, oligodendroglial cell death is accompanied by axonal damage with little if any myelin destruction and with the absence of secondary immune reaction (Pohl et al., 2011; Oluich et al., 2012).

Mice with altered expression of PLP, a protein primarily affected in certain forms of Pelizaeus-Merzbacher disease, is manifested by demyelination and axonal damage (Sidman et al., 1964; Griffiths et al., 1981; Schneider et al., 1992; Gotow et al., 1999; Al-Saktawi et al., 2003; Karim et al., 2007; Mayer et al., 2011). However, axonal damage, mainly or exclusively, is found in PLP1 null mice (Griffiths et al., 1998; Edgar et al., 2004), presumably due to altered axonal transport (Edgar et al., 2004, 2010). Axonal mitochondrial dysfunction via altered metabolic coupling occurs in PLP-deficient mice (Yin et al., 2016).

Mice lacking CNP show early axonal damage and disruption of the paranodal architecture, followed by axonal degeneration and myelin damage (Lappe-Siefke et al., 2003; Rasband et al., 2005; Edgar et al., 2009). This may be due to increased myelin compaction interfering with oligodendrocyte metabolic effects on axons (Edgar and Nave, 2009).

Finally, transgenic mice lacking MAG have subtle changes in myelin structure accompanied by reduced axon caliber, reduced neurofilament phosphorylation and progressive axon loss (Fruttiger et al., 1995; Yin et al., 1998; Pan et al., 2005).

In addition to the involvement of particular myelin proteins in the maintenance of axon stability, other data provide strong support for the notion of metabolic interaction between oligodendrocytes and axons. During development, oligodendrocytes import glucose and lactate (Rinholm et al., 2011). However, mature oligodendrocytes can survive only with glycolysis. Conditional Cox10 mutant mice in which oligodendroglia (and Schwann cells) fail to assemble mitochondrial complex IV (cytochrome c oxidase: COX) show peripheral but not central myelin abnormalities. These alterations are accompanied by increased brain lactate concentrations, thus suggesting that enhanced glycolysis in oligodendroglia, aimed at preserving energy supply, may maintain axon integrity in spite of altered mitochondrial metabolism in oligodendrocytes (Funfschilling et al., 2012).

Blood-derived glucose taken up by oligodendrocytes through glial glucose transporter 1 (GLUT1) is metabolized via glycolysis to produce piruvate and lactate which are delivered to the axons through specific solute carriers, the monocarboxylase transporters (Saab et al., 2013). Solute carrier (SLC) protein family 16 includes monocarboxylate transporters (MCT) located in cell membranes (Pierre and Pellerin, 2005). MCT1 is mainly expressed in oligodendrocytes (Rinholm et al., 2011; Lee et al., 2012). Inhibition of MCT1 in organotypic cultures of the spinal cord in glucose-deprived media is toxic to neurons but not to oligodendroglial cells; the effects on neurons are reversed with the addition of lactate into the medium (Lee et al., 2012). in vivo experiments geared at inducing reduction of MCT1 activity result in axonal damage (Lee et al., 2012). Together, these observations suggest that MCT1 serves as intermediate transporter of metabolites necessary to energy metabolism in neurons.

Oligodendrocyte and axon interactions are not only bi-directional; astrocytes also participate as crucial players. Oligodendrocytes are connected with astrocytes through gap junctions composed of connexins (Cx); Cx32 and Cx47 are synthesized by oligodendrocytes, and Cx30 and Cx43 by astrocytes (Orthmann-Murphy et al., 2007). Mice lacking either $\mathrm{Cx} 47$ or $\mathrm{Cx} 32$ are viable but transgenic mice lacking both Cx32 and Cx47 show thin or ab- sent myelin sheaths, vacuolation, enlarged periaxonal collars, oligodendrocyte cell death, and axonal loss (Menichella et al., 2003). Double mutations of Cx30 and Cx47, affecting oligodendroglial and astrocytic components of gap junctions, show severe vacuolization and myelination defects in all white matter tracts of the CNS, accompanied by decreased numbers of oligodendrocytes, severe astrogliosis and microglial activation in white matter tracts (Tress et al., 2012). Cx47 is also expressed in OPCs and its expression increases in co-cultures with astrocytes which induce proliferation of oligodendrocytes via $\mathrm{Cx} 47$-mediated activation of the ERK/Id4 pathway and sphingosine-1-phosphate receptors 3 (Liu et al., 2017a, b; Xu et al., 2017). Cx26 is localized in individual gap junctions between astrocytes and in heterotypic gap junctions between astrocytes and oligodendrocytes (Nagy et al., 2011).

\section{Oligodendrocytes in brain aging}

Human myelination is uniquely expanded and vulnerable to aging (Tse and Herrup, 2017). White matter lucencies with age were discovered by neuroimaging studies (Hachinski et al., 1987; Meyer et al., 1992). Progressive white matter decline in human brain, as revealed by magnetic resonance imaging (MRI), starts at about 45 years of age (Bartzokis et al., 2001, 2003; Sperling et al., 2014) and it is enhanced in Alzheimer's disease (Bartzokis et al., 2003). This is accompanied by white matter hyperlucencies which correspond either to areas of poor perfusion, areas of myelin pallor, or periventricular edema (Barber et al., 1999; Young et al., 2008; Black et al., 2009; Holland et al., 2008; Erten-Lyons et al., 2013; Liu et al., 2017a, b), thus indicating that age-related white matter alterations are multifactorial.

Small blood vessel disease is not uncommon from middle-age onwards and it is likely causative of variegated lesions in the white matter including hypoperfusion, status cribosus, small infarcts or lacunes, and diffuse white matter demyelination (so called Binswanger encephalopathy when clinically manifestesd as cognitive impairment) (Kalaria et al., 2015).

All these changes may be silent depending on the degree and localtion of lesions but they are also causative of cognitive impairment once certain thresholds are reached (Ferrer, 2010)

The time of OPC division is increased in old age and therefore oligodendrocyte repair is delayed (Lasiene et al., 2009; Psachuolia et al., 2009; Zhu et al., 2011). Moreover late oligodendrocyte progenitors are particularly vulnerable to hypoxia (Back et al., 2002). HDCA1 and Olig2 are downregulated in the aging brain (Shen et al., 2008a, b) thus limiting rates of remyelination.

Oligodendroglial nuclei in the aging white matter show signatures of oxidative DNA damage which increase in Alzheimer's disease (Al-Mashhadi et al., 2015). Oxidative damage likely involves RNA, proteins and lipids, as in other cells and regions. Whether specific oligodendroglial proteins are oxidatively damaged in old age deserves study. Likewise, further information is needed to learn about the functional integrity of oligodendrocyte glucose and monocarboxylate transporters in old age.

\section{Oligodendrogliopathy}

The term astrogliopathy refers to alterations of astrocytes occurring in diseases of the nervous system, includes reactive astrogliosis (mainly manifested as an increase in the amount of GFAP and in the number of astrocytes containing GFAP), and stresses the cardinal role of astrocytic dysfunction in the pathogenesis of neurological diseases (Seifert et al., 2006; Pekny and Pekna, 2014; Pekny et al., 2016; Osborn et al., 2016; Verkhratsky et al., 2017a, b). Astrocytopathy refers to decrease in the number of astrocytes, 
atrophy/degeneration and loss of function occurring as a primary cause of a disease or as a factor contributing to the development and progression of a particular disease (Pekny et al., 2016; Ferrer, 2017).

The term oligodendrogliopathy has developed more recently (Wenning et al., 2008; Bleasel et al., 2016) to stress the prominent role of altered oligodendrocytes in the pathogenesis of certain neurological diseases (Fellner and Stefanova, 2013; Tognata and Miller, 2016; Ettle et al., 2016a, b). Oligodendrogliopathy is crucial in demyelinating diseases and most leukodystrophies. Indeed, the term oligodendrogliopathy was initially coined by Lassman et al. in the context of myein-associated glycoprotein deficiency (Lassmann et al., 1997), and astro- and oligodendrogliopathy are early events in CNS demyelination (Zhang et al., 2013; Rone et al., 2016). Yet disturbances of oligodendrocyte function have also emerged as determining factors in apparently distant diseases such as psychiatric disorders including schizophrenia and major depression (Miyata et al., 2015; Birey et al., 2017).

Here, we review oligodendrogliopathy in relevant neurodegenerative diseases with abnormal protein aggregates.

\subsection{Multiple system atrophy}

Multiple system atrophy (MSA) is a sporadic adult-onset degenerative disease manifested clinically by parkinsonism, cerebellar symptoms and autonomic dysfunction, and neuropathologically by
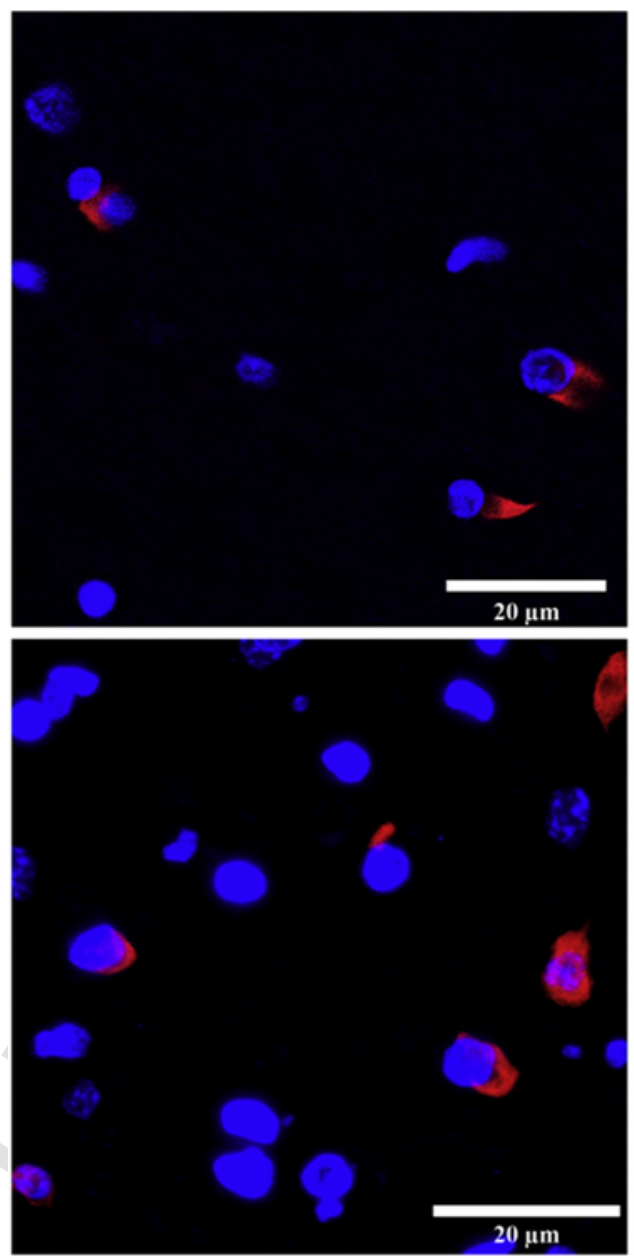

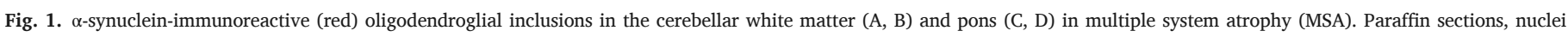
stained with DRAQ5 ${ }^{\mathrm{TM}}$ (blue); A, C, D, bar $=15 \mu \mathrm{m}$; B, bar $=20 \mu \mathrm{m}$. degeneration of the olivopontocerebellar system, substantia nigra and autonomous nervous system, together with the presence of oligodendroglial and neuronal inclusions containing abnormal $\alpha$-synuclein (Holton et al., 2011). MSA is a prototypic oligodendroglioneural synucleinopathy (Jellinger, 2018) (Fig. 1).

Four stages or grades of neuropathology have been proposed in MSA. However, differences in the main forms of clinical presentation-nigro-striatal degeneration and olivopontocerebellar atrophy, as well as individual variations - make practical use of the proposed classification at advanced stages of the disease difficult (Jellinger et al., 2005; Ozawa et al., 2004).

Reduced white matter and myelin staining, together with altered lipid levels, is found in the striatum, cerebellar white matter, fascicles of the pons and medulla oblongata, and, often, white matter of the cerebral hemispheres and internal capsule (Matsuo et al., 1998; Schocke et al., 2002; Shiga et al., 2005; Blain et al., 2006; Paviour et al., 2007; Brooks and Seppi, 2009; Prodoehl et al., 2013; Don et al., 2014). These lesions are accompanied by characteristic oligodendroglial inclusions called Papp-Lantos inclusions which are the hallmark of the disease (Papp et al., 1989).

Early studies showed the presence of ubiquitin and tau in these inclusions (Abe et al., 1992; Murayama et al., 1992; Papp and Lantos, 1994; Papp et al., 1989; Takeda et al., 1997). Subsequent inquiries revealed $\alpha$-synuclein as the main component of oligodendroglial inclusions in MSA (Spillantini et al., 1998; Tu et al., 1998;
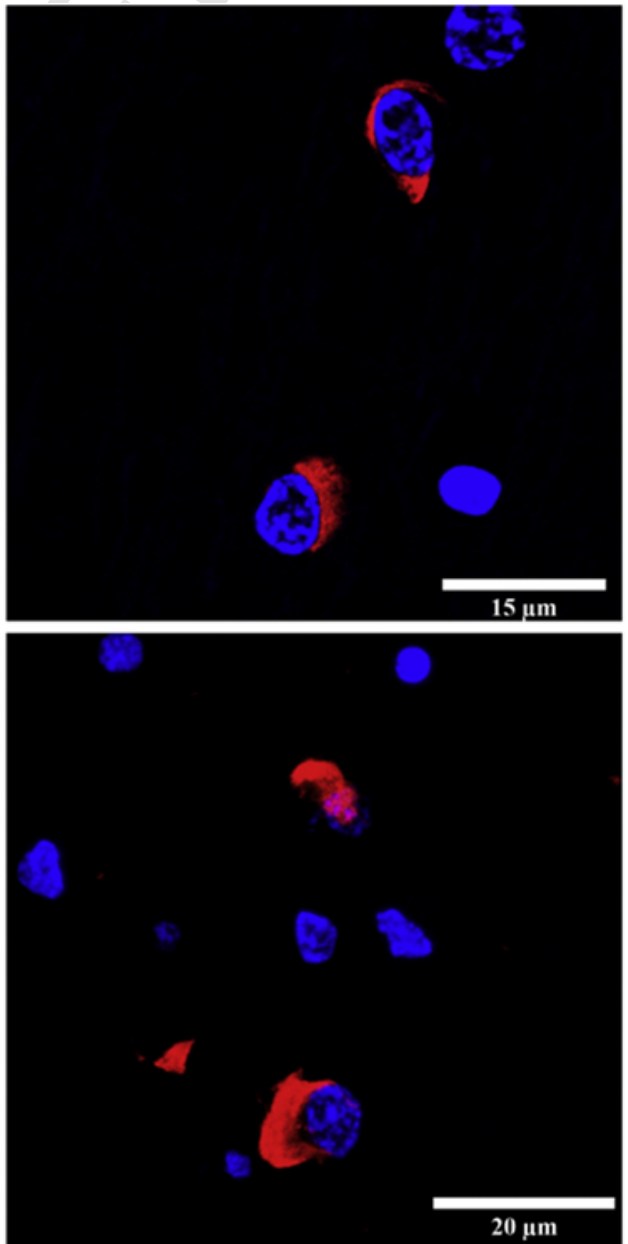
Wakabayashi et al., 1998; Gai et al., 2003; Jellinger and Lantos, 2010).

The distribution of $\alpha$-synuclein deposits correlates with the main pathological lesions, and the number of inclusions increases with disease progresion (Papp and Lantos, 1994; Inoue et al., 1997; Halliday et al., 2011). Abnormal $\alpha$-synuclein deposits are also found less numerously in the cytoplasm and nuclei of neurons (Papp and Lantos, 1992; Wenning and Jellinger, 2005).

The source of $\alpha$-synuclein in MSA oligodendrocytes is controversial. From very little to nearly no $\alpha$-synuclein mRNA is expressed in adult control and MSA oligodendrocytes (Solano et al., 2000; Ozawa et al., 2001; Miller et al., 2005). However, one study reported mRNA $\alpha$-synuclein expression in oligodendrocytes, although it is not clear whether the expression is increased in $\alpha$-synuclein-containing oligodendroglial inclusions in MSA (Asi et al., 2014). Other surveys showed the presence of $\alpha$-synuclein protein in cultured oligodendrocytes (Richter-Landsberg et al., 2000). Moreover, $\alpha$-synuclein has been demonstrated in oligodendroglial cell lineage derived from induced pluripotent stem cells (iPSCs) from human healthy cases and patients with Parkinson's disease and MSA with decreased $\alpha$-synuclein expression during oligodendrocyte maturation; transcripts are also detected in human and rodent oligodendrocytes isolated by fluorescence-activated cell sorting (FACS) (Djelloul et al., 2015).

As an alternate proposal, $\alpha$-synuclein in oligodendrocytes may originate in neurons and then become trapped by oligodendrocytes. Monomeric, oligomeric and fibrillar forms of $\alpha$-synuclein uptake occur in oligodendrocytes in vitro and in vivo; $\alpha$-synuclein can transfer to grafted oligodendroglial cells from host rat brain neurons overexpressing human $\alpha$-synuclein (Reyes et al., 2014). Neuronal to oligodendroglia $\alpha$-synuclein transfer is further supported in transgenic mice expressing A53 T human $\alpha$-synuclein enhanced by docosahexaenoic acid (Kisos et al., 2012). $\alpha$-synuclein uptake in both neurons and oligodendroglia seems to be mediated by endocytosis as dynamin GTPase suppression decreases $\alpha$-synuclein uptake in neurons and oligodendrocytes (Konno et al., 2012). Finally, slow degradation of $\alpha$-synuclein in oligodendroglial cells has been suggested as an accompanying factor in the generation of Papp-Lantos inclusions (Fellner et al., 2011).

$\alpha$-synuclein in MSA is abnormally nitrated, phosphorylated and oxidized, and has anomalous solubility (Dickson et al., 1999; Giasson et al., 2000; Duda et al., 2000; Campbell et al., 2001; Fujiwara et al., 2002; Hasegawa et al., 2002; Pountney et al., 2004; Tong et al., 2010; Ubhi et al., 2011).

In addition to abnormal $\alpha$-synuclein, MSA inclusions contain several proteins including synphilin-1, SUMO-1, ubiquitin, FBXO7, dorfin, PACRG, NUB-1, HtrA2/OMI, XIAP, $\alpha B$-crystallin, proteasome subunits, HSP70, HSP90, PDI, p62, NBR1, LRRK2, clusterin, methallothionein-III, cyclin-dependent kinase 5, mitogen-activated protein kinase, P39, Elk1, tubulin polymerization-promoting protein $\mathrm{p} 25 \alpha$ (TPPP/p25 $\alpha$ ), tau, $\gamma$-tubulin, MAP5, histone deacetylase 6, DARPP32, midkine, Rab5, rabaptin-5, 14-3-3 and AMBRA-1, among others (Abe et al., 1992; Murayama et al., 1992; Takeda et al., 1997; Spillantini et al., 1998; Gai et al., 1999; Nakamura et al., 1998, 2000; Piao et al., 2001; Honjyo et al., 2001; Iwata et al., 2001; Kato et al., 2000; Sasaki et al., 2002; Wakabayashi et al., 2002; Kawamoto et al., 2002; Hishikawa et al., 2003; Kovács et al., 2004; Pountney et al., 2005a, b; Tanji et al., 2007; Song et al., 2007; Taylor et al., 2007; Kovács et al., 2007; Wenning et al., 2008; Kawamoto et al., 2008; Honjo et al., 2008, 2011; Pountney et al., 2011; Chiba et al., 2012; Odagiri et al., 2012; Zhao et al., 2013; Wong et al., 2013; Kawamoto et al., 2014; Miki et al., 2018). Impaired protesome function and autophagy play key roles in the pathogenesis of protein aggregates in oligodendrocytes in MSA (Schwarz et al., 2012).

The meaning of the great number of proteins trapped in oligodendroglial inclusions is not known, but some of these proteins are implicated in particular functions. p25 $\alpha$ is re-localized in oligodendrocytes in MSA before the appearance of oligodendroglial inclusions, and the interaction of p25 $\alpha$ with MBP is altered (Song et al., 2007). Moreover, p25 $\alpha$ induces $\alpha$-synuclein aggregation (Lindersson et al., 2005; Kragh et al., 2009). Therefore, p25 $\alpha$ seems to have a double effect, enhancing $\alpha$-synuclein aggregation and impairing myelination.

Oligodendroglia inclusions also contain tubulin $\beta$-III which co-localizes with $\alpha$-synuclein in abnormal inclusions in certain MSA transgenic mice (Nakayama et al., 2009). Interactions of tubulin $\beta$-III and other cytoskeletal proteins, such as tau, with abnormal $\alpha$-synuclein have deleterious effects on the microtubules (Nakayama et al., 2012; Ota et al., 2014).

Immunoprecipitation studies have also shown abnormal $\alpha$-synuclein interactions with Rab3a in the cerebellum and pons in MSA, thus suggesting alterations in membrane and synaptic vesicle trafficking in MSA (Dalfó and Ferrer, 2005).

The expression of several proteins is increased in the white matter of affected regions in MSA. For example, ABCA8, an ATP-binding cassette lipid transporter, which promotes sphingomyelin production in oligodendrocytes, is increased in white matter in MSA (Bleasel et al., 2013). Transfected human oligodendrocytes with ABCA8 produce an increase in $\alpha$-synuclein and p25 $\alpha$ (Bleasel et al., 2013), thus suggesting that ABCA8 is involved in MSA pathogenesis although not necessarily present in oligodendroglial inclusions. In the same line, the endoplasmic reticulum stress response is activated at early stages of the disease in areas with oligodendroglial inclusions (Makioka et al., 2010).

It has been reported that the volume of the nuclei of oligodendrocytes is reduced in MSA in regions devoid of inclusions (Uyama et al., 2009). Yet it is not clear whether the same applies to the nuclei of oligodendroglia bearing inclusions. Moreover, the number of oligodendrocytes seems to be preserved in the white matter in MSA (Ettle et al., 2016a, b; Nykjaer et al., 2017). On the other hand, the number of OPCs is increased in MSA, and some OPCs contain $\alpha$-synuclein inclusions (Ahmed et al., 2013a; May et al., 2014).

Several animal and cell models have been developed to gain understanding about MSA. Expression of oligodendroglial $\alpha$-synuclein has been generated following intrastriatal injection of chimeric viral vectors expressing $\alpha$-synuclein under the control of MBP; interestingly, phosphorylated and proteinase-resistant $\alpha$-synuclein is detected in the striatum and substantia nigra, indicating, in addition, the capacity for seeding (Bassil et al., 2017). Other viral vector models are currently assessed in rodent and nonhuman primates (Mandel et al., 2017).

Transgenic models reproduce $\alpha$-synuclein overxpression and phosphorylation in oligodendroglia under the control of myelin gene promoters, either MBP, PLP or CNP (Kahle et al., 2002; Yazawa et al., 2005; Shults et al., 2005; Tank et al., 2014; Fernagut et al., 2014; Fellner et al., 2015; Bleasel et al., 2016; Overk et al., 2018). All of them show, albeit with particularities, clinical phenotype and neuropathology reminiscent of MSA (Kuzdas et al., 2013; Boudes et al., 2013; Flabeau et al., 2014). Myelin loss occurs in every model, and reduced numbers of oligodendroglia are reported in some of them (Yazawa et al., 2005; Stemberger et al., 2010; Stefanova et al., 2012). The number of OPCs is increased in transgenic mice generated with MBP promoter (May et al, 2014). Additional evidence shows that $\alpha$-synuclein overexpression impairs the maturation of OPCs and reduces the production of MBP (Ettle et al., 2014), and that $\alpha$-synuclein overexpres- 
sion in oligodendrocytes in primary and stem cell-derived oligodendrocytes impairs myelin formation (Ettle et al., 2016a, b).

Other factors condition $\alpha$-synuclein alterations and oligodendrocyte deterioration in MSA. $\alpha$-synuclein pathology and myelin damage are enhanced following mitochondrial inhibition and oxidative stress in transgenic mice (Stefanova et al., 2005; Ubhi et al., 2009). This is reproduced in vitro when oxidative stress induces $\alpha$-synuclein aggregation in cultured oligodendroglia (Riedel et al., 2011; Puka $\beta$ and Richter-Landsberg, 2014; Pukaß et al., 2015). $\alpha$-synuclein accumulation is also attained following proteasomal inhibition (Stefanova et al., 2012). This is further supported by studies in vitro demonstratring altered autophagy and proteasomal activity in oligodendrocytes following $\alpha$-synuclein expression (Schwarz et al., 2012). The effects of $\alpha$-synuclein uptake and mitochondrial damage have been sustained in astrocytes after uptake of $\alpha$-synuclein monomers (Lindström et al., 2017); no similar studies are available regarding oligodendrocytes. Interestingly, oxidative and proteolytic stress also induces the recruitment of tau in oligodendrocytes overexpressing $\alpha$-synuclein (Riedel et al., 2009).

Finally, transgenic mice expressing oligodendroglial $\alpha$-synuclein under the MBP promoter show reduced GDNF protein expression and preserved GDNF mRNA, suggesting that abnormal $\alpha$-synuclein brings about post-translational effects on GDNF expression. Normalization of GDNF levels ameliorates behavior and neuropathological deficits in these mice (Ubhi et al., 2010, 2012).

Mechanisms of disease progression are not known but in vitro $\alpha$-synuclein uptake studies, $\alpha$-synuclein accumulation in oligodendrocytes in certain murine paradigms, and more importantly, transmission studies of MSA to transgenic mice are in line with the concept of cell-to-cell transmission of abnormal MSA $\alpha$-synuclein. in vitro studies demonstrate $\alpha$-synuclein uptake by oligodendrocytes and formation of intracellular aggregates reminiscent of oligodendroglial inclusions in MSA (Kisos et al., 2012; Konno et al., 2012). $\alpha$-synuclein transmission to oligodendrocytes and precursors, in addition to neurons, occurs in embryonic rat brain tissue grafted to mice producing human $\alpha$-synuclein under a viral vector (Reyes et al., 2014). Redistribution of $\alpha$-synuclein from neurons to oligodendrocytes is observed in double-transgenic mice (Rockenstein et al., 2012). Most clear evidence of $\alpha$-synuclein transmission comes from the observation that MSA homogenates inoculated into the brain of mice produce a neurodegenerative disease characterized by the accumulation of abnormal $\alpha$-synuclein in neurons and oligodendroglia similar to that seen in human MSA (Watts et al., 2013). The same results are obtained after inoculation of homogenates obtained from other series of MSA cases thus replicating first studies; importantly, no similar oligodendroglial inclusions are found after inoculation of homogenates from cases with Lewy body disease, thus suggesting the existence of specific MSA strains (Prusiner et al., 2015). These findings together with propagation of MSA-derived $\alpha$-synuclein in cultured cells (Woerman et al., 2015) suggest that MSA has the properties of a prion-like disease with the capacity to propagate to oligodendroglail cells (Woerman et al., 2017).

Interestingly, $\alpha$-synuclein induces fibrillization of tau, and co-incubation promotes fibrillization of both proteins (Giasson et al., 2003). Double-transgenic mice expressing both $\alpha$-synuclein and tau show synergistic fibrillization of these two proteins (Fillon and Kahle, 2005). Concurrence of $\alpha$-synuclein and tau in abnormal neurites and less commonly in neurons in the Contursi kindred of familial PD rarely co-localizes with almost complete spatial disparity (Duda et al., 2002). Rare tau granular deposits are seen in oligodendrocytes in MSA which do not co-localize with $\alpha$-synuclein deposits thus suggesting that tau aggregation might be another pathway of oligodendroglial degeneration in this disease (Nigashi et al., 2011; Jellinger, 2012). Oxidatively modified $\alpha$-synuclein graded by the proteasome and it plays a pro-aggregative role for tau in oligodendroglial cells exposed to particular settings (Riedel et al., 2009).

\subsection{Lewy body diseases}

Lewy body diseases (LBD) include Parkinson's disease (PD) and Dementia with Lewy bodies (DLB). Both are characterized by distinct premotor symptoms followed by parkinsonism due to the involvement of the autonomic nervous system, selected nuclei of the medulla oblongata and pons, and eventually the substantia nigra pars compacta, respectively. Cognitive deficits may appear with disease progression in PD, whereas dementia is an early symptom in DLB. Involvement of the cerebral cortex, although with differences in PD and DLB, is causative of cognitive impairment and dementia. The term LBD comes from the presence of intraneuronal inclusions named Lewy bodies composed of abnormal $\alpha$-synuclein which is nitrated, phosphorylated, abnormally conformed and aggregated, and with altered solubility; abnormal $\alpha$-synuclein is also accumulated in aberrant neurites (Jellinger, 2011; Ince, 2011; Revesz et al., 2015).

The putative progression of PD has been classified into six stages from the medulla oblongata (and olfactory bulb) to the pons, midbrain, limbic system, diencephalic nuclei and neocortex (Braak et al., 2003, 2004). Involvement of the autonomic nervous system is also considered an early stage of PD pathology. Cases without clinical symptoms or with pre-motor symptoms (without parkinsonism) and with Lewy bodies and neurites in the lower parts of the brain stem are categorized as pre-motor or incidental PD (Dickson et al., 2008; Ferrer et al., 2012). Yet some incidental LBD cases have LBs in the cerebral cortex and these cases have been categorized as putative preclinical stages of DLB (Frigerio et al., 2011).

White matter involvement in PD is limited, whereas white matter involvement in DLB is variable, mainly affecting the posterior lobes, and often linked with associated Alzheimer's disease (AD) pathology (Bohnen and Albin, 2011; Nedelska et al., 2015; Firbank et al., 2016; Joki et al., 2018). Decreased size of oligodendroglial nuclei has been described in LBD independently of the concomitant AD pathology (Gagyi et al., 2012). The reasons and functional consequences are not known.

$\alpha$-synuclein-positive inclusions in astrocytes and oligodendroglia are found in the midbrain in PD; they are composed of filamentous structures about $25-40 \mathrm{~nm}$ in diameter, and their presence correlates with neuronal loss, at least in the substantia nigra (Wakabayashi et al., 2000). Oligodendroglial inclusions containing abnormal $\alpha$-synuclein have also been reported in many nuclei and fiber tracts of the brain stem containing Lewy bodies or Lewy neurites (Seidel et al., 2015).

Oligodendrocytosis occurs in the substantia nigra and striatum following acute and chronic 1-methyl-4-phenyl-1,2,3,6-tetrahydropyridine (MPTP) treatment in mice and macaques, respectively, used as models of PD (Annese et al., 2013). This suggests that oligodendrocytes are vulnerable to this treatment although its implication in LBDs is not known. The meaning of reported auto-antibodies against MAG in parkinsonian patients without correlation with disease severity (Papuć et al., 2016) deserves further study.

There is a bulk of information regarding prion-like propagation of neuronal $\alpha$-synuclein in several in vivo and vitro paradigms of LBDs (Ulusoy et al., 2015; Rey et al., 2016; Shimozawa et al., 2017; Choi et al., 2018; just to include additional references to those signaled in previous paragraphs).

As already mentioned in MSA, oligodendrocytes can take up recombinant $\alpha$-synuclein monomers, oligomers and, to a lesser extent, fibrils, and $\alpha$-synuclein can be transferred to grafted oligoden- 
droglial cells from host rat brain neurons overexpresing $\alpha$-synuclein (Reyes et al., 2014). Curiuosly, no oligodendroglial $\alpha$-synuclein-immunoreactive inclusions are produced after inoculation of brain homogenates from cases with LBD in striking contrast with the inoculation of MSA homogenates, which have the capacity to transfer abnormal $\alpha$-synuclein to oligodendrocytes in addition to neurons, and to generate oligodendroglioneural $\alpha$-synucleinopathy (Watts et al., 2013; Prusiner et al., 2015).

\subsection{Tauopathies}

Tauopathies are adult-age neurodegenerative diseases defined by the accumulation of abnormally phosphorylated tau in neurons and glial cells. Tau proteins are encoded by microtubule associated protein tau gene, MAPT, the transcription of which by splicing produces six isoforms in the brain. Some tauopathies are identified as 4R-tauopathies, and others as 3R-tauopathies depending on the axon 10 splicing. Sporadic tauopathies include Pick's disease (PiD), a 3R tauopathy; and progressive supranuclear palsy (PSP), corticobasal degeneration (CBD) and argyrophilic grain disease (AGD), all of them 4R-tauopathies, each with particular clinical, neuropathological and biochemical traits (Dickson et al., 2011a, b; Muñoz et al., 2011; Tolnay and Braak, 2011; Lowe and Kalaria, 2015; Kovacs, 2015; Kovacs and Tauopathies, 2015; Kovacs et al., 2017). Familial tauopathies are linked to mutations in MAPT and they are usually manifested neuropathologically as frontotemporal lobar degeneration (FTLD) and clinically as dementia (FTD) with parkinsonism; tau deposits are composed of 4R-, 3R- or 4R+3R-tau repeats depending on the site of the mutation (Ghetti et al., 2011a, b).

Alzheimer's disease (AD) has a component of neuronal tauopathy but the presence of $\beta$-amyloid plaques is mandatory, at present, for its categorization. Primary age-related tauopathy (PART) is a recently named sporadic $4 R+3 R$-tauopathy which is characterized by the presence of NFTs in the same localtions and with the same Braak stages but without $\beta$-amyloid plaques (Crary et al., 2014; Jellinger et al., 2015). Whether PART is part of $\mathrm{AD}$ is a matter of academic discussion (Duyckaerts et al., 2015; Giaccone, 2015). Advanced stages of PART may be causative of dementia with only tangles (Jellinger and Bancher, 1998). Aging-related tau astrogliopathy (ARTAG) is another 4R-tauopathy in old age restricted to astrocytes (Kovacs et al., 2016). Globular glial tauopathy will be defined later.

A combination of different tauopathies is not rare in old-aged individuals (Rahimi and Kovacs, 2014; Kovacs et al., 2017).

White matter atrophy, including demyelination and axonal loss, is common in tauopathies (Chin and Goldman, 1996; Dickson et al., 1996). Axonal damage in tauopathies is commonly interpreted as the result of neuronal damage (Kneynsberg et al., 2017). However, glial cells may act as additional pivotal players because of their damage resulting from abnormal tau deposits in astrocytes and oligodendroglia.

Several types of inclusions in oligodendrocytes and oligodendroglial processes are distinguished in tauopathies (Fig. 2). Coiled bodies and threads are found in PiD, PSP, CBD and AGD (Wakabayashi et al., 1994; Feany et al., 1995; Nishimura et al., 1995; Arima et al., 1997; Tolnay et al., 1997; Ikeda et al., 1998; Jellinger, 1998; Komori, 1999; Arai et al., 2001; Oyanagi et al,
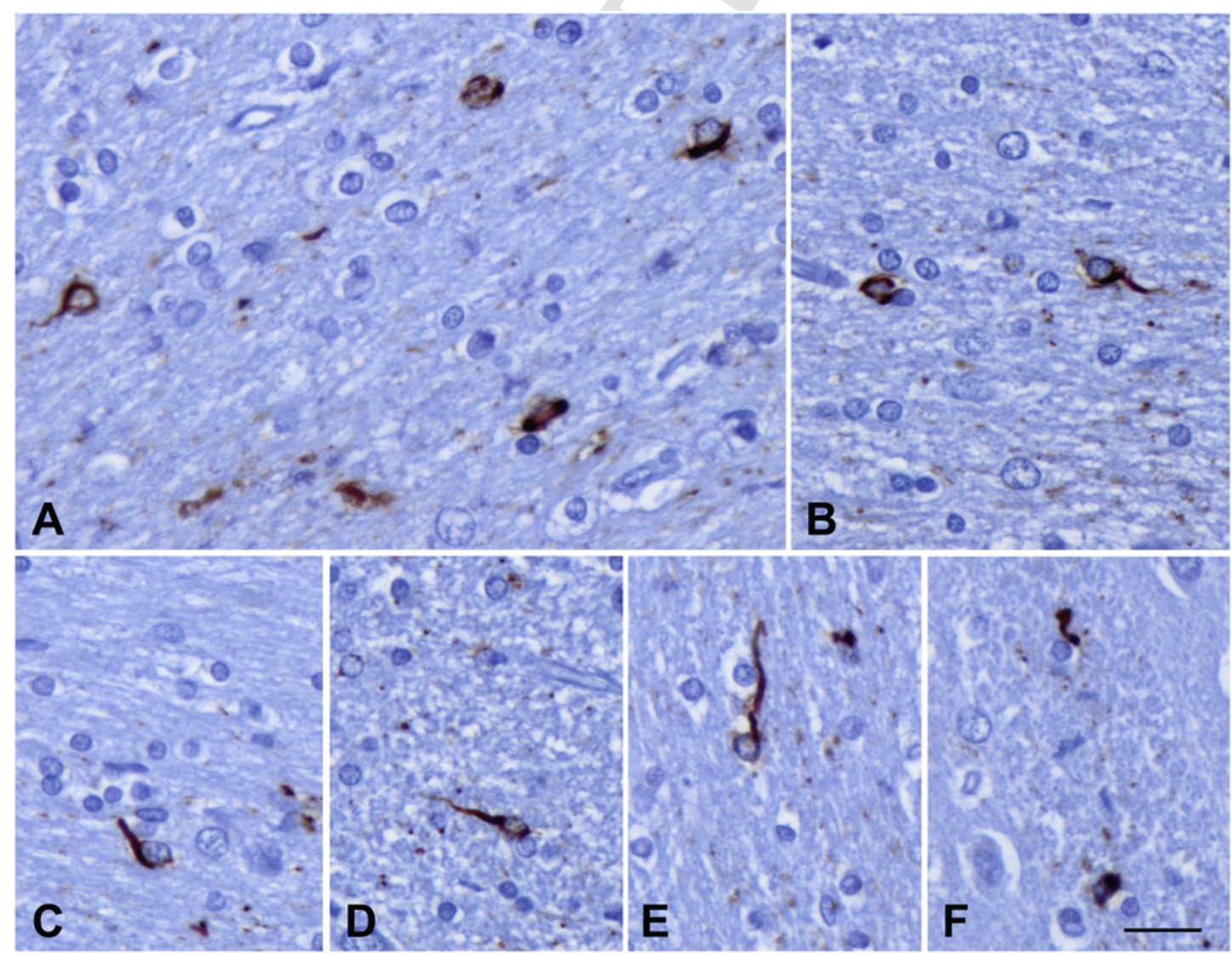

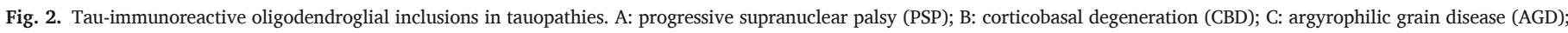

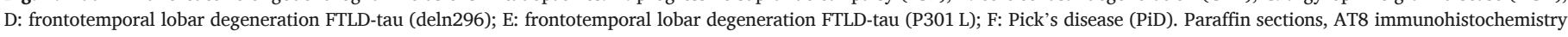
slightlhy counterstained with haematoxylin; bar $=25 \mu \mathrm{m}$. 
2001; Williams, 2006; Ferrer et al., 2008; Grinberg and Heinsen, 2009; Mimuro et al., 2010; Pham et al., 2011; Kovacs et al., 2018; Komori, 2017). Similar inclusions are noted in the majority of cases with FTLD linked to MAPT mutations (FTLD-tau) (Spillantini et al., 1997; Bird et al., 1999; Iseki et al., 2001; Spina et al., 2008; Dickson et al., 2011a, b; Ghetti et al., 2011a, 2011b). Coiled bodies also occur in dementia pugilistica and chronic traumatic encephalopathy (Saing et al., 2012; Ling et al., 2017), inflammatory diseases such as subacute sclerosis panencephalitis (Ikeda et al., 1995a, b), and LBDs (Dugger et al., 2014), among other neurodegenerative disorders (Tacik et al., 2016).

Coiled bodies and interfascicular threads in PSP are composed of abnormal tubules of $13 \mathrm{~nm}-15 \mathrm{~nm}$ in diameter and fuzzy outer contours which are immunolabelled with anti-tau antibodies (Arima et al., 1997). Oligodendroglial inclusions are fine and branching in PSP and thick and comma-like in CBD (Komori, 1999; Arima, 2006; Williams, 2006). Differences in the morphology of abnormal tubules in oligodendroglial inclusions in tauopathies probably reflect differing molecular, including tau, composition between these entities (Arima, 2006). Coiled bodies are stained with antibodies against anti-phosphorylated tau antibodies (Fig. 3), and antibodies against 4R-tau, but 3R-tau-immunoreactive oligodendroglial inclusions are also recognized in PiD (Ferrer et al., 2014).

Tau in coiled bodies is hyperphosphorylated at different sites including Thr181, Ser199, Thr231, Ser262, Ser422, Ser202-Thr205 (antibody AT8), Ser396-Ser404 (antibody PHF1) and Thr212/Ser214 (tau-100), and has altered conformation as revealed by antibodies Alz50 (amino acids 5-15) and MC-1 (amino acids 312-322); however, coiled bodies are not stained with tau-C3 (which recognizes tau truncated at aspartic acid 421) (Ferrer et al., 2014). Oligodendrocytes containing hyperphosphorylated tau inclusions coexpress phosphorylated (active) tau kinases p-38, stress-activated kinase/c-Jun N-terminal kinase (SAPK/ JNK), mitogen-activated protein kinase/extracellular signal-regulated kinase (MAPK/ERK) and glycogen synthase kinase-3 (Ferrer et al., 2002, 2003a, c). PP2 A-like phosphatases probably modulate tau phosphorylation (Goldbaum and Richter-Landsberg, 2002).

In contrast to neurons with tangles in $\mathrm{AD}$ and tauopathies, the sequence encoded by exon 3 of the tau protein is under-expressed in oligodendroglial coiled bodies in CBD but not in PSP (Feany et al., 1995; Nishimura et al., 1997). Ubiquitin, apolipoprotein E, alpha1-antichymotrypsin and heparan sulfate are all absent from glial inclusions (Ikeda et al., 1998).

Globular glial tauopathy (GGT) is a rare form of 4R-tauopathy with predominant involvement of the white matter, and characterized by the presence of globular inclusions in oligodendroglia and distinct tau-positive inclusions in astrocytes, in addition to deposition in neurons (Molina et al., 1998; Bigio et al., 2001; Berry et al., 2001; Ferrer et al., 2003b; Powers et al., 2003; Clark et al., 2015; Piao et al., 2005; Josephs et al., 2006; Kovacs et al., 2008; Giaccone et al., 2008; Fu et al., 2010; Ahmed et al., 2011; Graff-Radford et al, 2016) (Fig. 4). Neuropathological consensus has classified GGT into three types: type I is usually manifested as frontotemporal dementia and the principal involvement corresponds to the frontal and temporal lobes; type II is commonly manifested by motor involvement and parkinsonism, and affects the corticospinal tracts; and type III presents with frontotemporal dementia, parkinsonism and motor neuron disease, which implies a more generalized distribution of the tauopathy (Ahmed et al., 2013b). This schematic classification has some affect on clinical practice (Burrell et al., 2016).

GGT is mostly sporadic but certain taoupathies linked to MAPT mutations show variable amounts of globular inclusions in oligoden- drocytes and bizarre astrocytic inclusions resembling sporadic GGT (Tacik et al., 2015; Zarranz et al., 2005, see also Ferrer et al., 2014; Borrego-Écija et al., 2017). Tau phosphorylation sites and conformational modifications described in coiled bodies also occur in globular inclusions in oligodendrocytes; in addition, globular inclusions contain truncated forms of tau at the carboxy-terminal and are ubiquitinated (Ferrer et al., 2014). Therefore, a major difference between coiled bodies and globular glial inclusions is the stage of pre-tangle in the former and the stage of tangle in the latter. Decreased nuclear TPPP/p25 $\alpha$ parallels microglial activation, myelin loss and association with tau inclusions in GGT (Rohan et al., 2016).

Small globular oligodendroglial inclusions (called small Pick bodies) are seen in the white matter in PiD (Kovacs, 2015). Rare globular inclusions have been reported in a single case of familial AD (Gelpi et al., 2013).

Protein aggregation in glial cells compromises stress responses and protein degradation pathways. $\alpha \mathrm{B}$-crystallin and other small HSPs are expressed in oligodendroglia (and astrocytes) in tauopathies. However, they do not necessarily co-localize with tau inclusions, thus suggesting generalized stress rather than restricted response in glial cells with abnormal protein aggregates (López-González et al., 2014). It may be posited that stress responses are directed to correcting protein misfolding, and that, to a certain extent, they succeed, and aggregates are not formed in many glial cells.

Ubiquitin-immunoreactivity is found in a minority of coiled bodies but it is almost a constant in globular inclusions in GGT (Ferrer et al., 2014). This might indicate variable involvement of the ubiquitin-proteasome system in the development of oligodendroglial inclusions. Additional information comes from cellular models in which proteasomal inhibition in cultured oligodendrocytes leads to protein aggregate formation (Leik et al., 2013). Histone deacetylase HDAC6 is expressed in oligodendrocytes and its inhibition results in microtubule alteration, and acetylation and phosphorylation of tau (Noack et al., 2014). Tau acetylation inhibits its degradation and contributes to tau aggregation (Min et al., 2010; Cohen et al., 2011). Accordingly, HDAC6 inhibition induces tau acetylation, the formation of protein aggregates, the alteration of stress responses and the impairment of autophagy (Leyk et al., 2015).

A few glial cells colocalize with HSP and ubiquitin thus pinpointing the combined reaction of stress responses and impaired function of the ubiquitin-protesome system (Richter-Landsberg and Bauer, 2004). Further insights linking HDAC6, tau acetylation, tau phosphorylation, stress responses, proteasome and autophagy are exemplified in oligodendroglia cell culture paradigms (Richter-Landsberg, 2016).

Whether the constructs in cell cultures occur in all human tauopathies deserves further research. Tau is acetylated in oligodendroglial inclusions in FTLD-tau (Irwin et al., 2013) but apparently not in AGD including grains and coiled bodies (Grinberg et al., 2013). In this way, factors coming into play in individual oligodendrocytes probably have multiple facets in the different tauopathies.

Hyperphosphorylated tau intracytoplasmic filamentous inclusions are commonly seen in transgenic mouse models of tauopathies both in animals overexpressing human tau and those bearing different tau mutations which are causative of familial FTLD-tau.

Tau pathology in glial cells has been generated in transgenic mice overexpressing human tau in neurons and glial cells. In these animals, tau pathology resembling astrocytic plaques and coiled bodies in oligodendrocytes is observed in old mice; these changes 


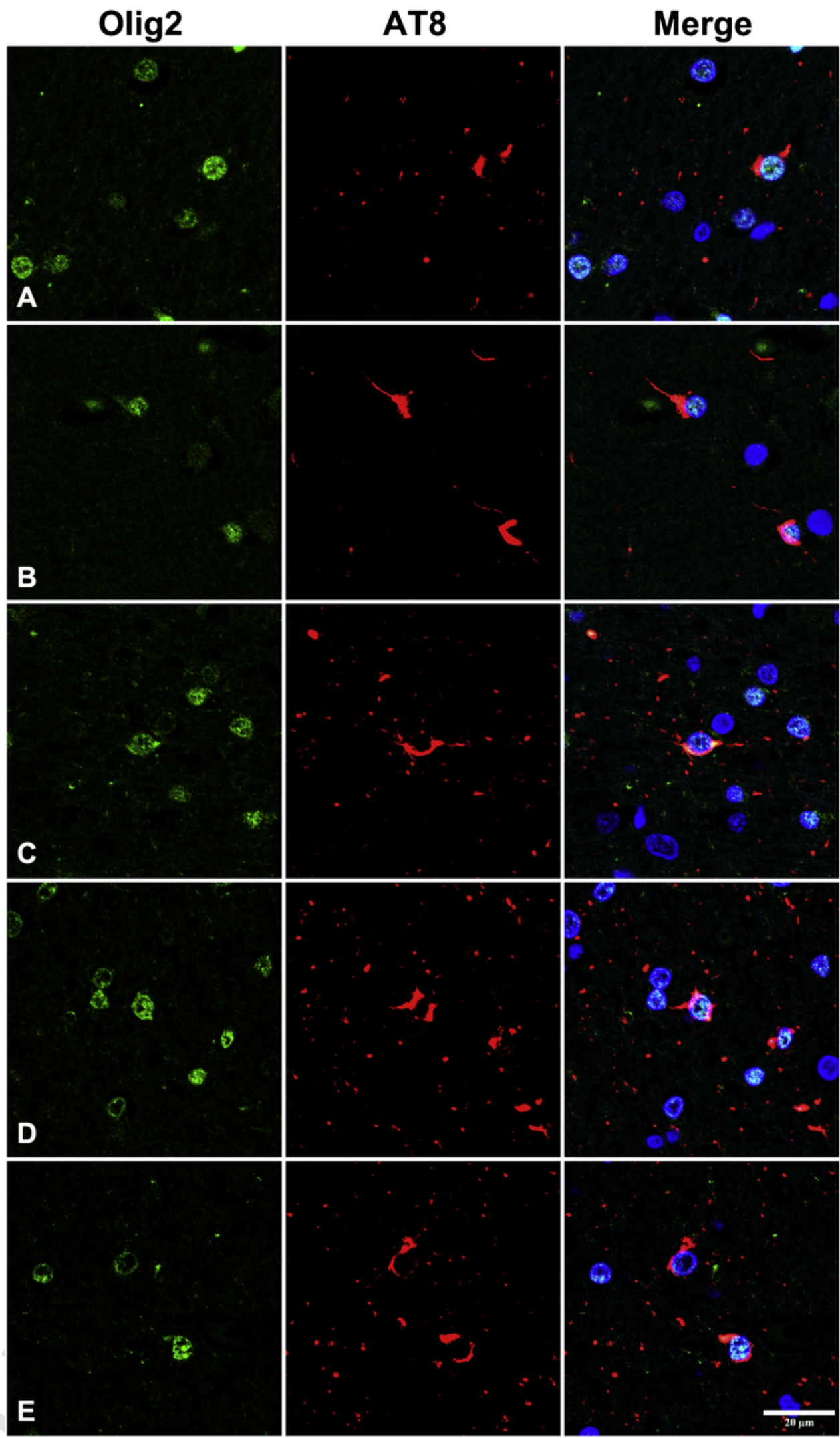

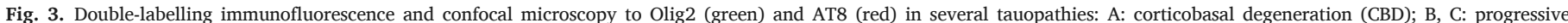
supranuclear palsy (PSP); D, E: argyrophilic grain disease (AGD). Paraffin sections, nuclei stained with DRAQ5 ${ }^{\mathrm{TM}}$ (blue), bar $=20 \mu \mathrm{m}$. 


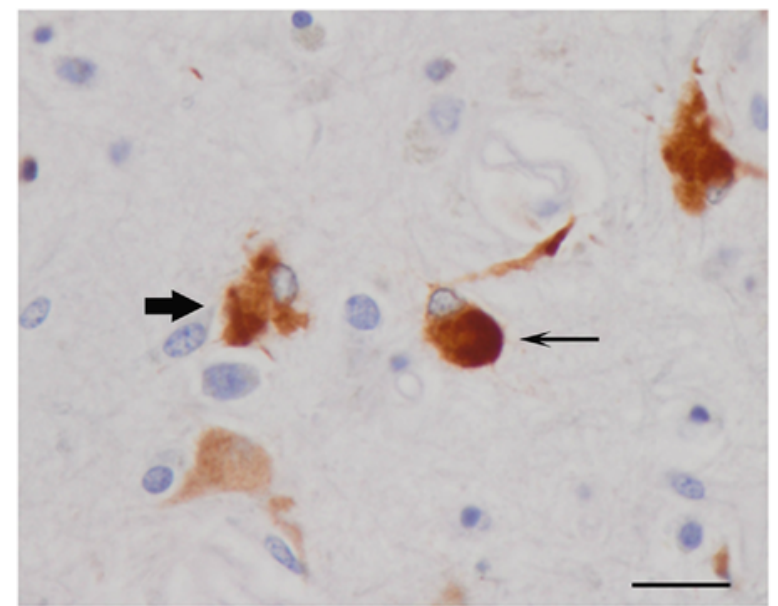

Fig. 4. Tau-immunoreactive oligodendroglial inclusion (thin arrow) in globular glial tauopathy (GGT). An astrocyte with hyper-phosphorylated tau deposits is labelled with a thick arrow. Paraffin sections, AT8 immunohistochemistry slightlhy counterstained with haematoxylin; bar $=25 \mu \mathrm{m}$.

are associated with glial and axonal degeneration (Higuchi et al., 2002).

Transgenic mice expressing G272 V tau accumulate abnormal filaments in oligodendrocytes; these filaments are either straight or have a twisted structure with a periodicity of $75 \mathrm{~nm}$, and they are composed of abnormal tau hyperphosphorylated at different sites. Fibrillar oligodendroglial and neuronal inclusions are also seen in the spinal cord (Götz et al., 2001). Transgenic mice bearing P301 L tau develop cytoplasmic neuronal inclusions, and oligodendroglial and astrocytic filamentous inclusions composed of abnormal hyperphosphorylated tau aggregates (Lin et al., 2003). Oligodendroglial inclusions are also seen in transgenic mice bearing the P301S mutation (Fig. 5). Selective overexpression of mutant tau in oligoden- drocytes using CNP promoter in mice produces filamentous inclusions in oligodendrocytes and progressive impairment of axonal transport followed by myelin and axonal disruption; these changes precede the appearance of thioflavin-S-positive tau inclusions in oligodendrocytes (Higuchi et al., 2005). Interstingly, endogenous mouse tau is deposited in oligodendrocytes in mice expressing transgenic human tau, in a way that makes evident that mouse tau has the capacity to be recruited and aggregated in oligodendrocytes (Ren et al., 2014).

These models reveal that tau accumulation in oligodendroglial cells is accompanied by axon degeneration and demyelination. White matter damage is further demonstrated in the spinal cord of transgenic mice bearing the P301 L tau mutation (Zher et al., 2004; Lin et al., 2005a, b). Lesions are consistent with vacuolar myelopathy and dying-back axonopathy; myelin debris is engulfed by macrophages whereas oligodendocytes in damaged regions have membrane-bound cytoplasmic inclusions (Lin et al., 2005a, 2005b). Other studies stress the occurrence of active caspase-3-immunoreactive, TUNEL-positive oligodendrocytes in affected white matter, arguing that axonal degeneration is accompanied by apoptosis of oligodendrocytes (Zher et al., 2004). Deleterious effects of abnormal tau in oligodendrocytes are further proven in cultured oligodendrocytes in which the expression of human tau and FTDP-tau mutant tau causes cell death (Richter-Landsberg, 2008).

Defective microtubule network and altered myelination in tau transgenic mice is associated with reduced expression of kinesin which modulates intracellular trafficking; abnormal tau may interfere with kinesin-dependent MBP translocation thus favoring altered myelination in these mice (Carson et al., 1997; Higuchi et al., 2002; Richter-Landsberg, 2008).

Curiously, neuronal expression of P301S tau accelerates OPC differentiation and myelin formation following focal white matter demyelination (Ossola et al., 2016). Whether these changes move in favor of regeneration is not known.
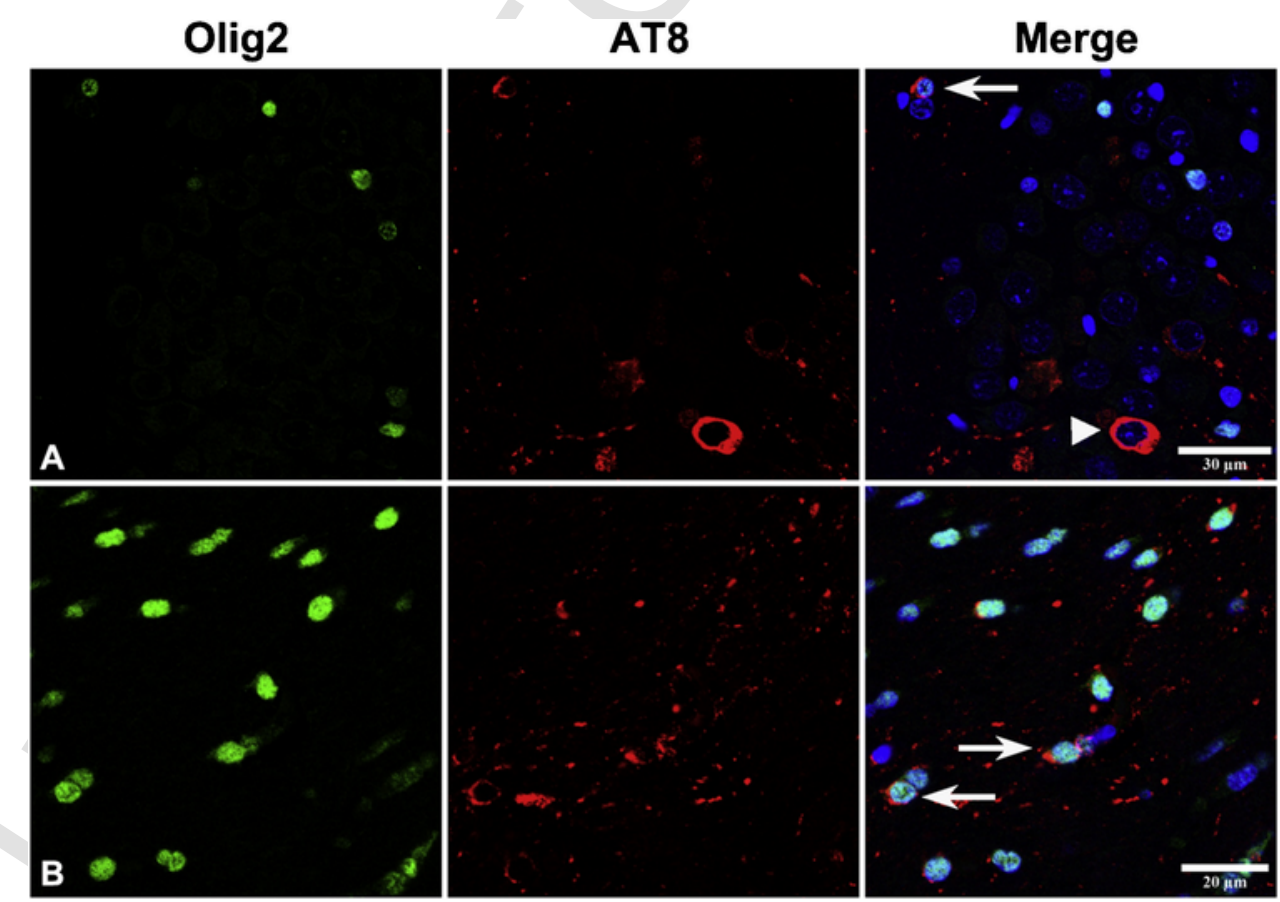

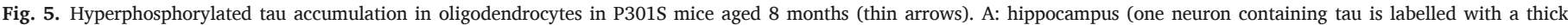

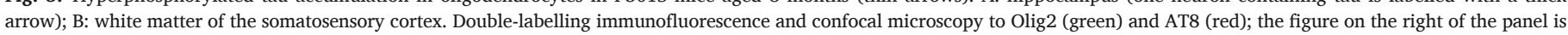
merge of the other two. Paraffin sections, nuclei are visualized with DRAQ5 ${ }^{\mathrm{TM}}$ (blue); A, bar $=30 \mu \mathrm{m}$; B, bar $=20 \mu \mathrm{m}$. 
Tau seeding in vivo has been demonstrated in a number of mouse models after inoculation of human brain homogenates (Goedert et al., 2017). Seeding and spreading of abnormal tau occurs after inoculation of brain homogenates from $\mathrm{AD}$ and other tauopathies into the brain of transgenic mice overexpressing human tau or mutated tau (Boluda et al., 2015; Clavaguera et al., 2009, 2015; Lewis and Dickson, 2016). The use of transgenic mice is based on the assumption that this substrate facilitates tau seeding and propagation. The characteristics of seeding differ depending on the type of tauopathy, implying that several types of tau species have particular properties (Clavaguera et al., 2013a, b; Boluda et al., 2015; Narasimhan et al., 2017). Seeding of human tau from homogenates of $\mathrm{AD}$ and tauopathies with neuronal and glial components is also observed after inoculation into the brain of wild-type mice (Guo et al., 2016; Narasimhan et al., 2017). Tau-immunoreactive oligodendroglial inclusions are observed after inoculation of CBD homogenates but apparently only very rarely or not at all following inoculation of AD homogenates (Boluda et al., 2015). All these experiments have been performed using brain samples with tau pathology only in neurons or in neurons and glial cells. Recent studies have shown that sarkosyl-insoluble fractions of brain homogenates from ARTAG inoculated into the hippocampus of wild-type mice generate intracytoplasmic hyperphosphorylated tau inclusions in astrocytes, oligodendrocytes, fiber tracts and neurons near the site of injection (Ferrer et al., 2018) (Fig. 6). These observations indicate that not only neurons but also astrocytes containing hyperphosphorylated tau have the capability of seeding tau to neurons and glial cells. Moreover, they point to the cardinal role of astrocytopathy in the pathogenesis of neurodegenerative diseases with abnormal protein aggregates, including the participation of oligodendrocyte targets in this process (Ferrer et al., 2018).

\subsection{Alzheimer's disease}

Alzheimer's disease (AD) is the most frequent cause of cognitive decline and dementia in the elderly. Pathologically, AD is classically defined by the combination of senile plaques composed of different $\beta$-amyloid species, and neurons with neurofibrillary tangles (NFTs) containing hyperphosphorylated 3R- and 4R-tau which disturbs microtubule assembly, and results in the formation of paired helical filaments. $\beta$-amyloid deposition also occurs in blood vessels, leading to $\beta$-amyloid angiopathy, whereas abnormal tau is also accumulated in dystrophic neurites surrounding senile plaques and in neuropil threads (Duyckaerts and Dickson, 2011; Lowe and Kalaria, 2015). NFTs progress from the entorhinal and transentorhinal cortex to the hippocampus, limbic system and cerebral cortex. NFTs also in- volve in parallel the olfactory bulb, selected nuclei of the brain stem, nuclei of the basal forebrain, amygdala and diencephalon. NFT progression follows a sterotyped pattern which allows the categorization of severity into stages (Braak and Braak, 1991, 1999). $\beta$-amyloid deposition and distribution of senile plaques also extends with disease progression but the pattern differs from that of NFTs, at least in sporadic AD (Thal et al., 2002). In addition to these basic alterations, $A D$ exhibits a compendium of biological alterations which modify many molecular pathways and variegated functions (Ferrer, 2012; Braak and Del Tredici, 2015).

Reduced size of the white matter, white matter hyperlucencies and myelin pallor are common abnormalities in AD (Barber et al., 1999; Bartzokis et al., 2003; Gouw et al., 2008; Holland et al., 2008; Radanovic et al., 2013; Amlien and Fjell, 2014; Firbank et al., 2016; Joki et al., 2018). Changes in white matter are parallel but do not correlate with $\beta$-amyloid deposition (Roseborough et al., 2017), and, importantly, they are recognized at early stages of the disease (Hoy et al., 2017). The size of the nuclei of oligodendrocytes is reduced in AD (Gagi et al., 2012). In addition, several oligodendroglial nuclei in the white matter show DNA oxidative damage, while other oligodendrocytes exhibit increased expression of p53 as a marker of stress, and a senescent phenotype (Al-Mashhadi et al., 2015; Wharton et al., 2015; Tse and Herrup, 2017).

White matter radiological and neuropathological changes are accompanied by early and progressive reduction in the levels of cholesterol and myelin proteins MBP, PLP and CNP (Vlkolinsky et al., 2001; Roher et al., 2002), and decreased Olig2- and NG2-glia-immunoreactive cells (Behrendt et al., 2013; Nielsen et al., 2013). The mechanisms of oligodendroglial damage are not known, and several factors including inflammation, oxidative stress, apoptosis and tau deposition in neuronal processes have been suggested (Cai and Xiao, 2016). in vitro studies show the toxic effect of $\beta$-amyloid species on OPCs and oligodendrocytes (Xu et al., 2001; Takao et al., 2004; Desai et al., 2010). Activated microglia induces death of OPCs and limits their function in remaining cells (Pang et al, 2010). Curiously, Bridging interactor 1(BIN1), the second most significant susceptibility locus in late-onset $\mathrm{AD}$, is mainly expressed in mature oligodendrocytes and in white matter tracts (De Rossi et al., 2016). Increased BIN1 expression and BIN1 interaction with tau have been reported (Holler et al., 2014; Sottejeau et al., 2015); BIN1 also interacts with actin (Dräger et al., 2017), together pointing to possible BIN1-linked cytoskeletal alterations in oligodendocytes in AD.

Oligodendroglial cell death and myelin loss occur at early stages in 3xTg- $\mathrm{AD}$ mice harbouring the human precursor amyloid protein Swedish mutation, a presenilin knock-in mutation and P301 L tau. Exposure to $A \beta_{1-42}$ increases caspase- 3 expression and induces apo-
Olig2
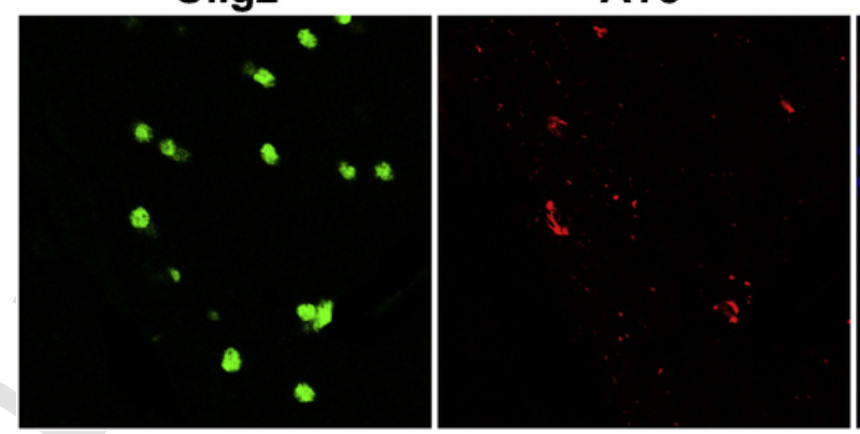

Merge

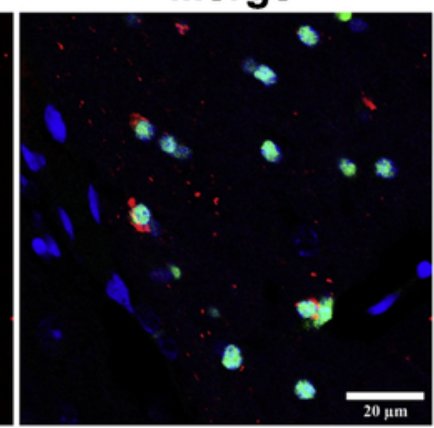

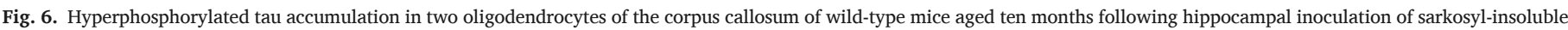

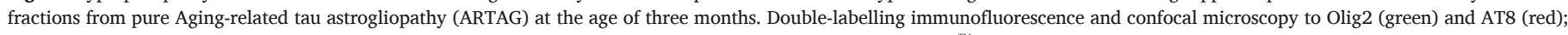
the figure on the right of the panel is merge of the other two. Paraffin sections, nuclei are visualized with DRAQ $5^{\mathrm{TM}}(\mathrm{blue})$; bar $=20 \mu \mathrm{m}$. 
tosis of oligodendrocyte precursors in vitro that is reversed following viral vector-derived intracellular transport of an antibody against $A \beta_{1-42}$ (Desai et al., 2009, 2010).

These data must be interpreted with caution regarding white matter changes in $\mathrm{AD}$ and their relation with altered oligodendrocytes. Vascular pathology, mostly affecting small blood vessels, is practically constant in $\mathrm{AD}$. In addition to $\beta$-amyloid angiopathy, atrophy, edema and increased pynocitosis in endothelial cells, atrophy of the muscle cells, thickening and disruption of the basal membrane and increased expression of collagen IV, heparan sulfate, proteoglycans and laminin are detected in capillaries and arterioles. Moreover, aquaporin- 4 expression is altered in perivascular astrocytes (Kalaria et al., 1996; Ferrer, 2010). These changes are consistent with chronic hypoperfusion (Kalback et al., 2004).

Tau-immunoreactive inclusions in oligodendrocytes are not characteristic of $\mathrm{AD}$, although coiled bodies can be found in $\mathrm{AD}$ combined with other tauopathies such as AGD. However, age-related increase in $\beta$-amyloid plaques and $\beta$-amyloid angiopathy, tau-positive astrocytes and oligodendrocytes (coiled bodies), and neuritic clusters occurs in housed gorillas (Perez et al., 2013). Curiously, tauopathy but not $\beta$-amyloidopathy develops in wild mountain gorillas of similar age (Perez et al., 2016). Intraneuronal and intraoligodendroglial tau accumulation occurs in the temporal cortex in non-human primate cynomolgus monkey before the age of 20 months with poor correlation to the levels of insoluble $\beta$-amyloid; AD-related pathology increases at more advanced ages (Oikawa et al., 2010). Tau-immunoreactive oligodendroglial (and neuronal and astrocytic) inclusions composed of straight filaments of $10-14 \mathrm{~nm}$ are also found in the brains of aged baboons (Schultz et al., 2000). Available data are consistent with the idea that brain aging in non-human primates is predominantly manifested as a tauopathy with involvement of neurons and glial cells.

\subsection{Amyotrophic lateral sclerosis and Frontotemporal lobar degeneration- TDP (ALS/FTLD-TDP)}

\subsubsection{Amyotrophic lateral sclerosis (ALS)}

ALS is a neurodegenerative disease involving the cortical motorneurons, the motorneurons of the spinal cord and selected nuclei of the brain stem, producing spasticity, muscle wasting, difficult swallowing and final respiratory insufficiency. In addition to the motor system, other regions can be affected; the frontal and temporal cortex is damaged in some cases leading to cognitive impairment and dementia of frontotemporal lobe type. Indeed, variable overlap exists between ALS and FTLD (Hortobágyi and Cairns, 2015; Ince et al., 2015).

ALS can be classified as sporadic (sALS) or genetic (gALS), often affecting several members of a family (fALS). The principal gene defects causing adult fALS are mutations in SOD1 (superoxide dismutase 1), VAMP (vesicle associated membrane protein B and C), CHMP2B (charged multivesicular body protein $2 \mathrm{~B}$ ), ANG (angiogenin), TARDBP (transactive response (TAR) DNA binding protein of $43 \mathrm{kD}$ : TDP-43), FUS (fused-in-sarcoma), OPTN (optineurin), ATXN2 (ataxin 2), UBQLN (ubiquilin 2), C9Orf72 (chromosome 9 open reading frame 72) and SQTM1 (sequestosome 1 p62) (Hortobágyi and Cairns, 2015). Of these, SOD1, CHMP2B, ANG, TARDBP, VCP, UBQLN, C9Orf72, FUS and SQTM1 are also causative of FTLD (Hortobágyi and Cairns, 2015; Ince et al., 2015). The majority of patients suffering from ALS are sporadic with no known mutations; however, hexapeptide repeat expansions in C9Orf72 are recognized in a number of apparently non-genetic ALS.

Loss of large motorneurons (Betz cells) in the motor cortex, degeneration of the pyramidal tracts, loss of motorneurons in selected nuclei of the brain stem and anterior horn of the spinal cord, and myelin pallor of the corresponding optic nerves and anterior roots of the spinal cord are the principal neuropathological characteristics of ALS. Curiously, oculomotor nuclei in the brain stem and Onuf's nuclei in the lower spinal cord are spared in classical forms. Additonal involvement of the Clarke's column, posterior spinocerebellar tracts and posterior tracts occurs in cases bearing SOD1 mutations. As indicated before, other regions of the brain, mainly the frontal and temporal cortex, may be affected in some cases (Hortobágyi and Cairns, 2015; Ince et al., 2015).

In addition to neuron loss, astrogliosis and microgliosis are accompanying reactions in the affected regions. Proximal axonal balloonings filled with neurofilaments are rather common in rapidly progressing cases. Remanining motorneurons show variable alterations including disruption of the Golgi complex and intracytoplasmic inclusions which have the morphology of skein-like inclusions, round inclusions and small granular deposits, all of them containing abnormal TDP-43 (Ince et al., 2015; Hortobágyi and Cairns, 2015). Bunina bodies composed of cystatin $\mathrm{C}$ and transferrin are also concurrently observed. fALS due to mutations in fused-sarcoma (FUS) do not contain these types of TDP-43 inclusions but rather round basophilic neuronal inclusions composed of FUS, ubiquitin and p62 (Mackenzie and Neumann, 2017). Therefore fALS-FUS cannot be considered within the spectrum of TDP-43 proteinopathgies.

Staging of TDP-43 pathology in ALS has been proposed in line with similar categorization stages in AD and PD (Brettschneider et al., 2013). In stage 1, abnormal TDP-43 inclusions are restricted to motorneurons of the primary motor cortex, motorneurons of the anterior horn of the spinal cord and certain motor nuclei of the brain stem. In stage 2, abnormal TDP-43 extends to neurons of the reticular formation of the brain stem and deep nuclei of the cerebellum. In stage 3, TDP-43- immunoreactive inclusions are also noted in the prefrontal cortex and basal ganglia. In stage 4, the hippocampal formation and the anteromedial areas of the temporal cortex show TDP-43-immunoreactive inclusions.

In a refinement of this staging proposal, posterior assessment identifies oligodendroglial TDP-43-immunoreactive inclusions as an early pathological event in the spinal cord in ALS, and occasional involvement of the oculomotor nucleus and sometimes the Onuf's nucleus, at advanced stages of the disease, categorized as stage 5 (Brettschneider et al., 2014b)

\subsubsection{Frontotemporal lobar degeneration-TDP}

Frontotemporal lobar degeneration-TDP defines a subgroup of non-tau FTLD cases with ubiquitin-immunoreactive inclusions whose main component is abnormal TDP-43. About 50\% are familial and mainly linked to mutations in granulin (GRN), TARDBP, valosin (VAL) and C9Orf72. Clinically, FTLD-TDP is manifested as behavioural variant, progressive non-fluent aphasia or semantic dementia. Pathologically, the frontal and temporal lobes are atrophic, while the cerebral cortex in these regions shows neuron loss and spongiosis in the upper cortical layers, and astrocytic gliosis; the white matter shows variable reduction and myelin pallor. The hallmarks of FTLD-TDP are nuclear TDP-43 mislocalization, neuronal intracytoplasmic and intranuclear inclusions, and aberrant neurites containing abnormal TDP-43. The majority of tau-negative, TDP-43-negative FTLD cases with intracytoplasmic inclusions contain FUS, and they are considered FUS-proteinopathies (Neumann et al., 2009; Urwin et al., 2010).

Four FTLD-TDP neuropathological types have been proposed depending on the amount and distribution of the types of inclusions which roughly match with genetic variants (Mackenzie et al., 2009; Mackenzie and Neumann, 2011; Bigio, 2011a; Cruts et al., 2013; Ash et al, 2013; Hortobágyi and Cairns, 2015). In addition to 
the cerebral neocortex and hippocampus, other brain regions are affected, particularly the amygdala, striatum, thalamus, several nuclei of the brain stem and motorneurons of the spinal cord. Characteristic TDP-43-negative, p62- and ubiquitin-positive inclusions are noted in the granular layer of the cerebellum in FTLD-TDP linked to C9Orf72 hexanucleotide repeat expansions (Simón-Sánchez et al., 2012). Further molecular properties point to ALS/FTLD-TDP linked to C9Orf72 repeat expansions as a particular type within TDP-43-proteinopathies (Bigio, 2011b, 2012).

Rather than a stage categorization, as applied in other neurodegenerative diseases, sequential distribution of TDP-43 pathology has been proposed in FTLD-TDP (Brettschneider et al., 2014a). Pattern I (lowest burden of pathology) is characterized by TDP-43 inclusions in the orbital gyri, gyrus rectus and amygdala; pattern II affects the middle frontal and anterior cingulated gyrus, anteromedial temporal lobe areas, superior and medial temporal gyri, striatum, and red nucleus; stage III involves the motor cortex, bulbar somatosensor neurons and the anterior horn of the spinal cord; finally, pattern IV exhibits, in addition, involvement of the visual cortex (Brettschneider et al., 2014a).

\subsubsection{Common protein inclusions: common dysfunctions?}

As mentioned above, neuronal intracytoplasmic TDP-43-immunoreactive inclusions are neuropathological hallmarks of the majority of cases with ALS and, by definition, of all cases of FTLD-TDP (Arai et al., 2006; Neumann et al., 2006). The presence of TDP-43 inclusions in human and transgenic mice bearing SOD1 mutations is controversial (Cai et al., 2005; MacKenzie et al., 2007; Tan et al., 2007; Turner et al., 2008; Shan et al., 2009; Maekawa et al., 2009; Okamoto et al., 2011).
TDP-43 in ALS/FTLD-TDP is abnormally phosphorylated (P-TDP43), has abnormal solubility, presents truncated, pathogenic forms (Winton et al., 2008; Zhang et al., 2009) and has characteristics of amyloid (Bigio et al., 2013). This abnormal TDP-43 together with normal TDP-43 translocates from the nucleus to the cytoplasm giving rise to intracytoplasmic neuronal inclusions and aberrant neurites which are linked to toxic effects on neurons (Hasegawa et al., 2008; Nishimura et al., 2010; Barmada et al., 2010; Yang et al., 2010). Yet the effects of abnormal TDP-43 are more complex, encompassing gain and loss of function (Halliday et al., 2012). Altered proteasomal function and autophagy play a role in the process of protein aggregation and deposition in affected cells (Urushitani et al., 2010; Wang et al., 2010; van Eersel et al., 2011; Barmada et al., 2014). Direct evidence of this involvement is the immunoreactivity to ubiquitin and p62 of typical inclusions in ALS/ FTLD-TDP.

In addition to neuronal and neuritic TDP-43-positive inclusions, oligodendroglial TDP-43-immunoreactive inclusions are found in the anterior horn of the spinal cord in ALS (Brettschneider et al., 2013; Rohan et al., 2014; Hortobágyi and Cairns, 2015) (Fig. 7). P-TDP-43-immunoreactive oligodendroglial inclusions in ALS are also encountered in the motor, sensory and premotor cortex, but not in the corpus callosum, cingulum or lateral tracts of the spinal cord (Fatima et al., 2015).

TDP-43 oligodendroglial pathology in the deep layers of the cerebral cortex and white matter is a characteristic feature in FTLD-TDP (Neumann et al., 2007) (Fig. 8). It is more marked in frontal and temporal lobes but the brainstem and spinal cord are also affected (Neumann et al., 2007).

Cerebral and cerebellar white matter damage when compared with controls is observed in ALS cases bearing C9Orf72 repeat ex-

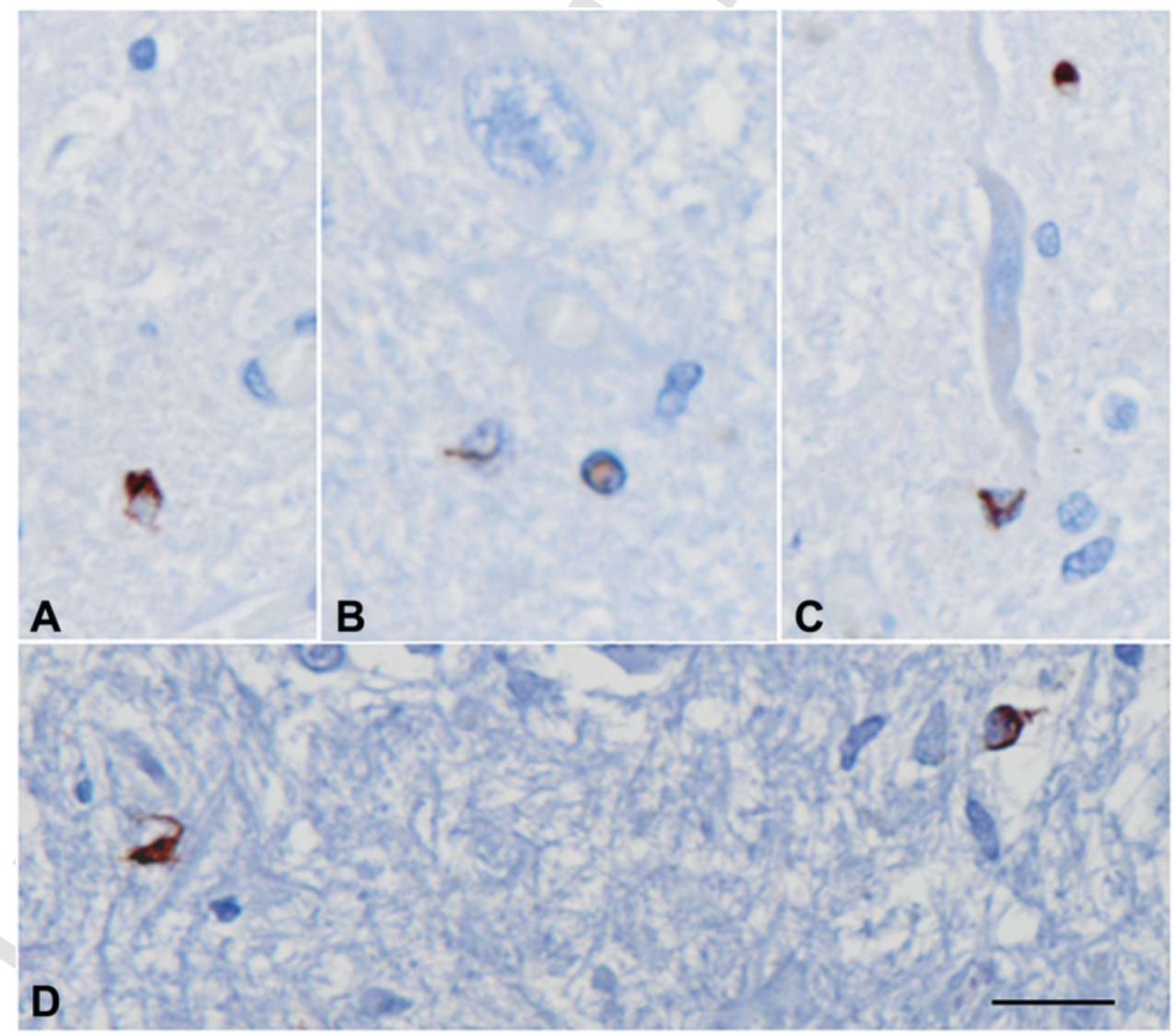

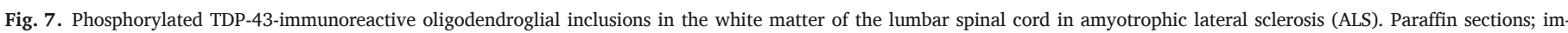
munohistochemistry with anti-phosphorylated TDP-43 antibody slightly counterstained with hematoxylin; bar $=25 \mu \mathrm{m}$. 


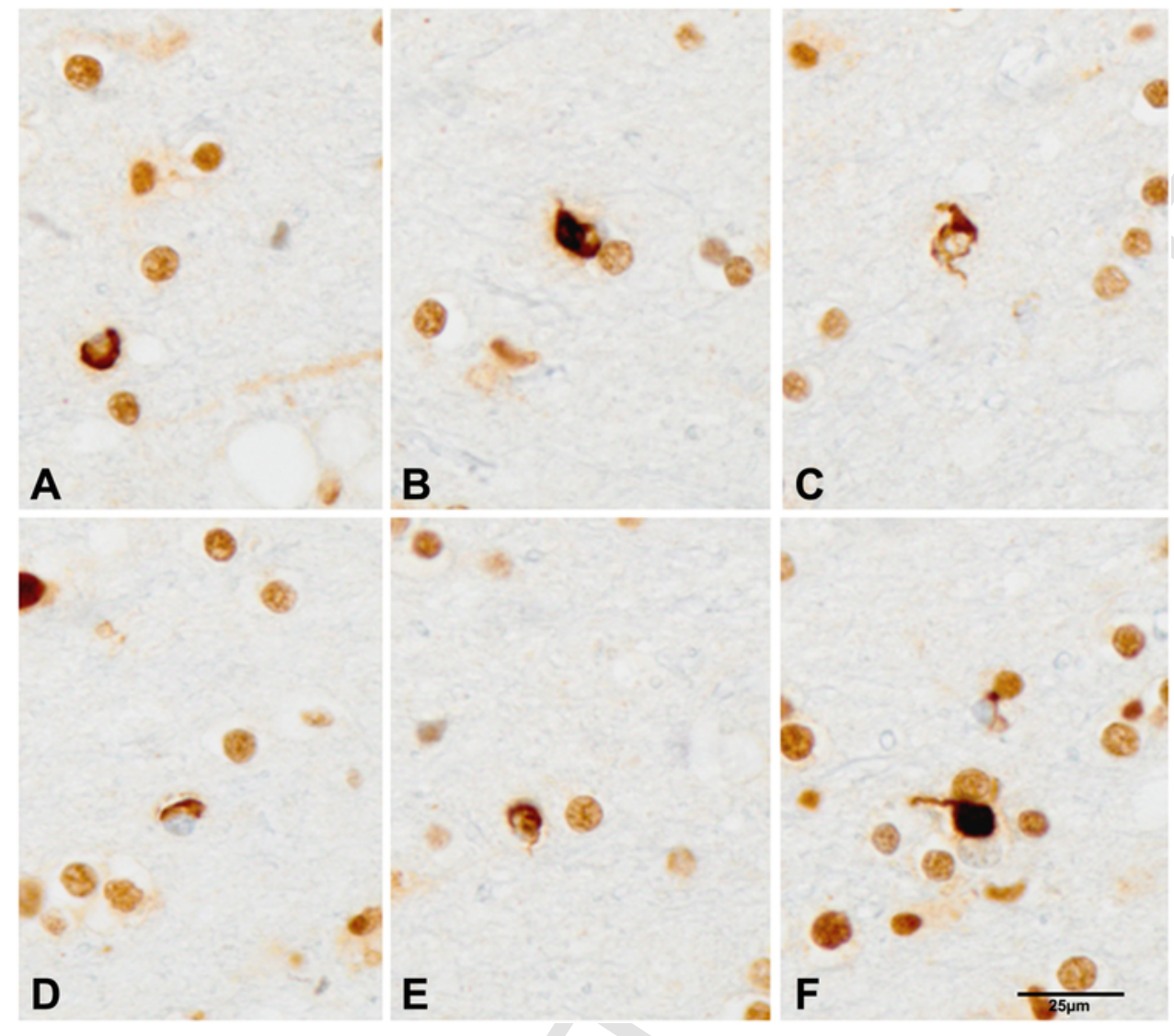

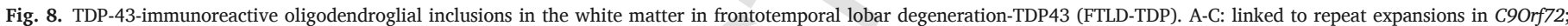
D-F: sporadic cases with not known mutations. Paraffin sections; immunohistochemistry with anti-TDP-43 antibody, slightly counterstained with hematoxylin; bar $=25 \mu$ m.

pansions (Bede et al., 2013; Agosta et al., 2017). White matter involvement is common in FTLD-TDP, and it is more marked in FTLD-TDP in patients bearing GRN mutations when compared with patients bearing C9Orf72 repeat expansions (Ameur et al., 2016; Papma et al., 2017; Sudre et al., 2017).

Oligodendroglial cells have been implicated in the pathogenesis of ALS in a cascade of effects which includes ROS production and damage, recruitment of alterations derived from activated microglia and astrocytes, effects of toxic substances produced by damaged neurons and abnormal responses of NG2-glia (Ince et al., 2011; Nonneman et al., 2014). However, most studies of this are based on SOD1 transgenic mice, which are used as a model for a minority of cases with fALS responding to unique pathogenic mechanisms not shared by other forms of familial and sporadic ALS. Oligodendroglial SOD1 toxicity in transgenic mice can barely be translated to sALS (Ferraiuolo et al,, 2016). In the mouse model of SOD1 mutation, altered oligodendrocytes appear in the grey matter before disease onset and they increase with disease progression; abnormal oligodendrocytes have reduced MBP and MCT1 expression, thus resulting in altered myelin formation and impaired support to axons (Lee et al., 2012; Philips et al., 2013; Morrison et al., 2013).

MCT1 protein levels in motor cortex and MCT1 mRNA expression in the spinal cord are also reduced in sALS (Lee et al., 2012): This is important information, revealing altered oligodendroglial function in oligodendrocytes in common forms of ALS. Moreover OPCs increase in number in motor cortex, but OPC differentiation is impaired and myelination diminished, in transgenic mice and in human ALS (Kang et al., 2013).

Levels of oligodendrocytic connexin 32 and connexin 47 are reduced in the ventral horn of the spinal horn in SOD1-transgenic mice, implying that oligo-astroglial interactions are disturbed in fALS (Cui et al., 2014).

Prion-like spreading has been postulated in ALS (Polymenidou and Cleveland, 2011; Kanouchi et al., 2012; Grad et al., 2015). The description of TDP-43 stages in ALS progression points to the likelihood of abnormal TDP-43 spreading (Brettschneider et al., 2013). in vitro studies suggest the possibility of oligodendroglia involvement in the spreading of TDP-43 pathology and subsequent neuronal degeneration in ALS. In favor of this hypothesis is the observation of TDP-43 aggregates in TDP-43-transfected neurons, astrocytes and oligodendrocytes under conditions of proteasome inhibition; aggregates from dying cells are incorporated into neighbouring cells thus facilitating spreading of TDP-43 aggregates in vitro (Ishii et al., 2017). However, TDP-43 oligodendroglial inclusions are not found in deep corticospinal and other white matter tracts from the motor cortex, and as a consequence the propagation of pathology between neurons may not involve oligodendrocytes (Fatima et al., 2015).

FTLD-TDP linked to GRN mutations has a unique combination of neuronal and glial inclusions. In addition to neuronal and glial TDP-43-immunoreactive aggregates, other abnormal proteins are consistently recognized in the cerebral cortex including 3R- and 4R-tau neuronal pre-tangles and tau-immunoreactive astrocytes and oligodendrocytes, together with $\alpha$-synuclein-positive oligodendroglial cells (Hosokawa et al., 2017).

TDP-43 neuronal and oligodendroglial inclusions are also found in the brains of $\mathrm{AD}$ and DLB but not in PD and tauopathies. TDP-43-immunoreactive neuronal inclusions predominate in the hippocampus and amygdala where they rarely co-localize with neurofibrillary tangles or $\alpha$-synuclein inclusions. No co-localization of TDP-43, 
$\alpha$-synuclein and tau is seen in oligodendroglial cells (Higashi et al., 2007).

\subsection{Creutzfeldt-Jakob's disease (CJD) and other prion diseases}

Prion diseases or prionopathies are a group of transmissible encephalopathies linked to the prion protein $\left(\mathrm{PrP}^{\mathrm{C}}\right)$ which is converted into an abnormally conformed protein named prion $\left(\mathrm{PrP}^{\mathrm{SC}}\right)$. $\operatorname{PrP}^{\mathrm{SC}}$ is pathogenic and aggregates in brain and other tissues. Human prion diseases are sporadic, iatrogenic or genetic Creutzfeld-Jakob's disease (CJD), Gerstmann-Straüsler-Scheinker (GSS) disease, and fatal familial insomnia (FFI) due to mutations in PRNP gene. Animal prion diseases are typical and atypical scrapie in sheep and goat, chronic wasting disease in deer, elk, moose and reindeer, and bovine spongiform encephlalopathy in cattle (Prusiner, 2004; Head et al., 2015).

Characteristic neuropathological lesions are neuron loss, spongiform change (vacuolization of the neuropil due to extreme swelling of neuronal processes), neuronal vacuolization and deposition of $\operatorname{PrP}^{S C}$ in the neuropil forming synaptic-like inclusions, plaque-like, linear and perineuronal deposits, and neuronal aggregates in some cases. This is accompanied by marked astrogliosis and reactive microgliosis (Gambetti et al., 2011; Budka et al., 2011; Parchi et al., 2011; Ghetti et al., 2011a, b; Head et al., 2015).

$\operatorname{PrP}^{\mathrm{C}}$ is normally expressed not only in neurons but also in astrocytes and oligodendrocytes. PrP mRNA expression is similar in glial cells and neurons and doubles during post-natal development in hamsters and rats (Moser et al., 1995). Functions of $\operatorname{PrP}^{\mathrm{C}}$ during development include modulation of the differentiation of human stem cells into neurons, astrocytes and oligodendrocytes; silencing PrP surpresses differentiation of OPCs into neurons, astrocytes and oligodendroglia (Leey and Baskakov, 2014). This observation is in line with previous studies showing that $\operatorname{PrP}^{\mathrm{C}}$ during development and adulthood controls OPC proliferation and oligodendroglial differentiation; $\mathrm{PrP}^{\mathrm{C}}$ knock-out mice show increased OPC proliferation, decreased oligodendroglial differentiation and increased numbers of OPCs in adulthood without changes in myelination (Bribián et al., 2012). The effect of PrP upon stem/progenitor cell signaling is through modulation of Notch (Martin-Lannere et al., 2017).

Little is known about the molecular pathology of oligodendrocytes in prion diseases. Yet recent studies have shown preserved expression of OLIG1, OLIG2, SOX10, NG2 and genes involved in myelination but GALC (coding for galactosylceramidase), SLC2 A1 (solute carrier family 2 member 1: glucose transporter member 1: GLUT1) and MCT1 (monocarboxylic acid transporter 1) mRNA expression levels significantly reduced in the frontal cortex in CJD MM1 and CJD VV2 (Andrés-Benito et al., 2018).
Prion diseases are the paradigm of transmissible neurodegenerative disease in which the infectious agent is not a nucleic acid but a protein. Prion protein $\left(\operatorname{PrP}^{\mathrm{C}}\right)$, encoded by $P R N P$, is normal in the brain where it has a number of physiological functions (Wulf et al., 2017). $\operatorname{PrP}^{\mathrm{SC}}$ has the same amino acid sequence as $\mathrm{PRP}^{\mathrm{C}}$ (excepting in mutated forms due to mutations in $P R N P$ ) but with abnormal conformation which confers unique properties to the pathogenic protein, mainly resistance to several physical and chemical agents, toxic effects on neurons, and, importantly, the capacity to transmit the same abnormal conformation to $\mathrm{PRP}^{\mathrm{C}}$ under physical contact between $\mathrm{PrP}^{\mathrm{SC}}$ and $\mathrm{PrP}^{\mathrm{C}}$ (Prusiner, 1982; Prusiner et al., 1998; Prusiner, 2004; Collinge and Clarke, 2007; Aguzzi et al., 2008; Aguzzi and Falsig, 2012; Collinge, 2016). Recent studies have shown that human astrocytes have the capacity to take up and degrade normal and protease-resistant prion protein (Choi et al., 2014) and that they can transfer $\operatorname{PrP}^{S C}$ to neurons via nanotubules (Victoria et al., 2016) thereby contributing to prion disease progression.

Oligodendrocytes are apparently resistant to $\mathrm{PrPSC}$ infectivity (Prinz et al., 2004). However, axon and myelin damage in human, experimental scrapie and bovine spongiform encephalopathy is well documented by optical and ultrastructural examination (Liberski et al., 1992). Abnormal interactions between oligodendroglia and astrocytes are observed in experimental CJD and scrapie (Liberski et al., 1997), as is engulfment of oligodendrocytes by hypertrophic astrocytes in the white matter in CJD (Shintaku and Yutani, 2004). Moreover, PRPSC is localized as arrays adjacent to myelin fibers in the cerebrum and cerebellum in CJD (El Hachimi et al., 1998). This is borne out by the observation of $\mathrm{PrP}$ in the inner mesaxon and paranodal cytoplasm of oligodendroglia in atypical (but not in classical) scrapie, thus supporting the idea that certain prion strains may interfere in trafficking between axons and oligodendroglia (Jeffrey et al., 2017). Altered astrocyte/oligodendrocyte interactions are probably important in the pathogenesis of CJD and other glial prionopathies. The lack of information on this matter invites further inquiry. Rarely, PrPRes can be seen in the nucleus and perinuclear region in oligodendrocytes in CJD (Fernandez-Vega et al., 2018) (Fig. 9).

\section{Final comments}

There is extensive information about the structure and function of oligodendrocytes, oligodendroglial precursors, diversity of precursors and adult oligodendroglial cells, signaling pathways modulating maturation and development of myelinating cells, interactions of oligodendrocytes and neurons and astrocytes, and participation of oligodendrocytes in energy metabolism, as well as mainte-
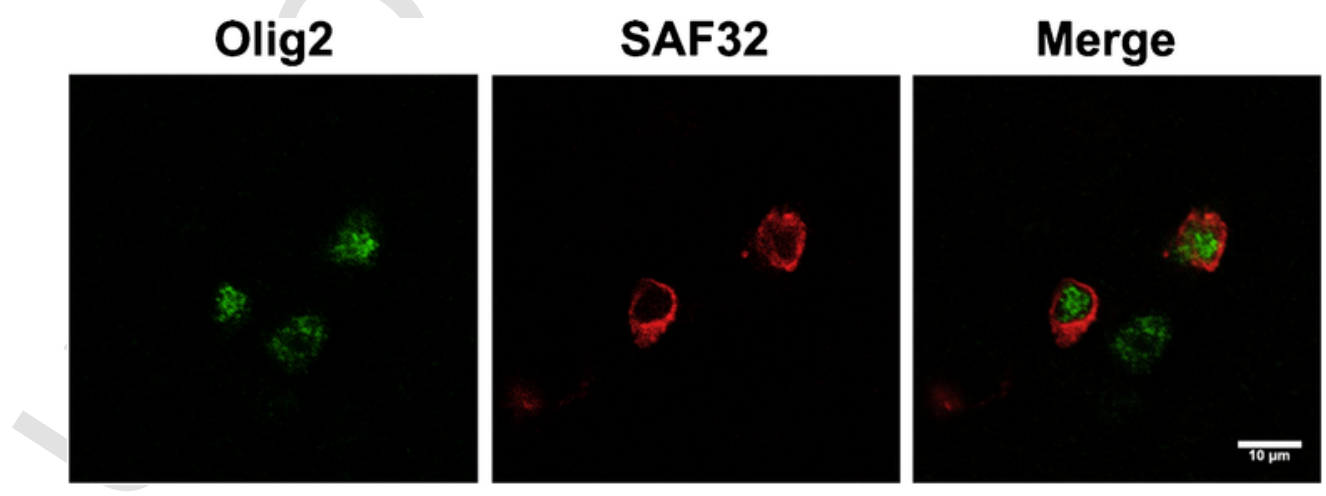

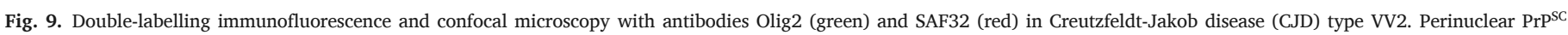
deposition is found in two oligodendrocytes in the subcortical white matter. Paraffin sections, nuclei stained with DRAQ $5^{\mathrm{TM}}(\mathrm{blue})$, bar $=10 \mu \mathrm{m}$. 
nance of axon integrity and the normal functioning of the central nervous system. Oligodendrocytes can be damaged following ischemia, trauma, and inflammation of the central nervous system. The term oligodendrogliopathy refers to the role of altered oligodendrocytes in the pathogenesis of aging and certain neurological diseases. Oligodendrogliopathy has been recognized in neurodegenerative diseases with abnormal protein aggregates in which abnormal proteins (i.e. $\alpha$-synuclein, tau, TDP-43 and PrP) accumulate in the brain, including multiple system atrophy, Lewy body diseases (such as Parkinson's disease and Dementia with Lewy bodies), sporadic and genetic tauopathies, Alzheimer's disease, amyotrophic lateral sclerosis, frontotemporal lobar degeneration linked to TDP43-proteinopathy, and Creutzfeldt-Jakob's disease. In most of these disorders, abnormal protein aggregates accumulate in oligodendrocytes (in addition to neurons and astrocytes). Such deposits are not mere bystanders but rather are associated with functional alterations in oligodendrocytes which impair myelination and energy transfer to neurons and axons, and which disrupt the oligodendrocyte/astrocyte syncytium that maintains homeostasis in the central nervous system. Moreover, functional alterations in oligodendrocytes are also detected in the absence of oligodendroglial inclusions in certain diseases. These aspects are emerging as cardinal factors in the pathogenesis of neurodegenerative diseases with abnormal protein aggregates. Despite recent advances, work is still needed to identify oligodendroglial signaling pathways altered in neurodegenerative diseases with abnormal protein aggregates, the regeneration capacities of oligodendrocyte precursors, and the factors that can contribute to the restoration of oligodendroglial function in these disorders.

\section{Conflict of interests}

No relevant data.

\section{Uncited references}

Armstrong et al. (2010), Belachew et al. (2003), Cai et al. (2015), Crawford et al. (2014), Davidson et al. (1998), Mobius et al. (2008), Nagaishi et al. (2011), Tawk et al. (2011), Vigano and Dimou (2016) and Zehr et al. (2004).

\section{Acknowledgements}

Part of this work was supported by the Ministry of Economy and Competitiveness, Institute of Health Carlos III (co-funded by European Regional Development Fund, ERDF, a way to build Europe) FIS PI17/ 00809, and co-finanzed by ERDF under the program Interreg Poctefa: RedPrion 148/16. I wish to thank Margarita Carmona, Benjamín Torrejón-Escribano and Daniela Diaz-Lucena for technical assistance, and T. Yohannan for editorial help.

\section{References}

Abe, H., Yagishita, S., Amano, N., Iwabuchi, K., Hasegawa, K., Kowa, K., 1992. Argyrophilic glial intracytoplasmic inclusions in multiple system atrophy: immunocytochemical and ultrastructural study. Acta Neuropathol. 84, 273-277.

Abney, E.R., Bartlett, P.P., Raff, M.C., 1981. Astrocytes, ependymal cells, and oligodendrocytes develop on schedule in dissociated cell cultures of embryonic rat brain. Dev. Biol. 83, 301-310.

Ackerman, S.D., Garcia, C., Piao, X., Gutmann, D.H., Monk, K.R., 2015. The adhesion GPCR Gpr56 regulates oligodendrocyte development via interactions with Go12/13 and RhoA. Nat. Commun. 6 (6122).

Aggarwal, S., Yurlova, L., Simons, M., 2011. Central nervous system myelin: structure, synthesis and assembly. Trends Cell Biol. 21, 585-593.

Aggarwal, S., Yurlova, L., Snaidero, N., Reetz, C., Frey, S., Zimmermann, J., Pahler, G., Janshoff, A., Friedrichs, J., Muller, D.J., Goebel, C., Simons, M., 2011. A size barrier limits protein diffusion at the cell sur- face to generate lipid-rich myelin-membrane sheets. Dev. Cell 21, 445-456.

Aggarwal, S., Snaidero, N., Pahler, G., Frey, S., Sanchez, P., Zweckstetter, M., Janshoff, A., Schneider, A., Weil, M.T., Schaap, I.A., Görlich, D., Simons, M., 2013. Myelin membrane assembly is driven by a phase transition of myelin basic proteins into a cohesive protein meshwork. PLoS Biol. 11, e1001577.

Agosta, F., Ferraro, P.M., Riva, N., Spinelli, E.G., Domi, T., Carrera, P., Copetti, M., Falzone, Y., Ferrari, M., Lunetta, C., Comi, G., Falini, A., Quattrini, A., Filippi, M., 2017. Structural and functional brain signatures of C9orf72 in motor neuron disease. Neurobiol. Aging 57, 206-219.

Agresti, C., Meomartini, M.E., Amadio, S., Ambrosini, E., Volonté, C., Aloisi, F., Visentin, S., 2005. Metabotropic P2 receptor activation regulates oligodendrocyte progenitor migration and development. Glia 50, 132-144.

Aguzzi, A, Falsig, J., 2012. Prion propagation, toxicity and degradation. Nat. Neurosci. 15 936-939.

Aguzzi, A., Sigurdson, C., Heikenwaelder, M., 2008. Molecular mechanisms of prion pathogenesis. Annu. Rev. Pathol. 3, 11-40.

Ahmed, Z., Doherty, K.M., Silveira-Moriyama, L., Bandopadhyay, R., Lashley, T., Mamais, A., Hondhamuni, G., Wray, S., Newcombe, J., O'Sullivan, S.S., Wroe, S., de Silva, R., Holton, J.L., Lees, A.J., Revesz, T., 2011. Globular glial tauopathies (GGT) presenting with motor neuron disease or frontotemporal dementia: an emerging group of 4-repeat tauopathies. Acta Neuropathol. 122, 415-428.

Ahmed, Z., Asi, Y.T., Lees, A.J., Revesz, T., Holton, J.L., 2013. Identification and quantification of oligodendrocyte precursor cells in multiple system atrophy, progressive supranuclear palsy and Parkinson's disease. Brain Pathol. 23, 263-273.

Ahmed, Z., Bigio, E.H., Budka, H., Dickson, D.W., Ferrer, I., Ghetti, B., Giaccone, G., Hatanpaa, K.J., Holton, J.L., Josephs, K.A., Powers, J., Spina, S., Takahashi, H., White 3rd, C.L., Revesz, T., Kovacs, G.G., 2013. Globular glial tauopathies (GGT): consensus recommendations. Acta Neuropathol. 126, 537-544.

Ainger, K., Avossa, D., Morgan, F., Hill, S.J., Barry, C., Barbarese, E., Carson, J.H., 1993. Transport and localization of exogenous myelin basic protein mRNA microinjected into oligodendrocytes. J. Cell Biol. 1993 (123), 431-441.

Ainger, K., Avossa, D., Diana, A.S., Barry, C., Barbarese, E., Carson, J.H., 1997. Transport and localization elements in myelin basic protein mRNA. J. Cell Biol. 1997 (138), 1077-1087.

Al-Mashhadi, S., Simpson, J.E., Heath, P.R., Dickman, M., Forster, G., Matthews, F.E., Brayne, C., Ince, P.G., Wharton, S.B., 2015. Medical Research Council Cognitive, F. Ageing S. Oxidative glial cell damage associated with white matter lesions in the aging human brain. Brain Pathol. 25, 565-574.

Almazan, G., Honegger, P., DuPasquier, P., Matthieu, J.M., 1996. Dexamethasone stimulates the biochemical differentiation of fetal forebrain cells in re-aggregating cultures. Dev. Neurosci. 8, 14-23.

Al-Saktawi, K., Leterrier, J.F., Ohsawa, Y., Watanabe, T., Isahara, K., Shibata, R., Ikenaka, K., Uchiyama, Y., et al., 2003. Genetic background determines phenotypic severity of the Plp rumpshaker mutation. J. Neurosci. Res. 72, 12-24.

Ameur, F., Colliot, O., Caroppo, P., Ströer, S., Dormont, D., Brice, A., Azuar, C., Dubois, B., Le Ber, I., Bertrand, A., 2016. White matter lesions in FTLD: distinct phenotypes characterize GRN and C9ORF72 mutations. Neurol. Genet. 2, e47.

Amlien, I.K., Fjell, A.M., 2014. Diffusion tensor imaging of white matter degeneration in Alzheimer's disease and mild cognitive impairment. Neuroscience 276, 206-215.

Andrés-Benito, P., Domínguez-González, M., Ferrer, I., 2018. Altered gene transcription linked to astrocytes and oligodendrocytes in frontal cortex in Creutzfeldt-Jakob disease. Prion https://doi.org/10.1080/19336896.2018.1500076, Accepted for publication.

Annese, V., Barcia, C., Ros-Bernal, F., Gómez, A., Ros, C.M., De Pablos, V., Fernández-Villalba, E., De Stefano, M.E., Herrero, M.T., 2013. Evidence of oligodendrogliosis in 1-methyl-4-phenyl-1,2,3,6-tetrahydropyridine (MPTP)-induced Parkinsonism. Neuropathol. Appl. Neurobiol. 39, 132-143.

Arai, T., Ikeda, K., Akiyama, H., Shikamoto, Y., Tsuchiya, K., Yagishita, S., Beach, T., Rogers, J., Schwab, C., McGeer, P.L., 2001. Distinct isoforms of tau aggregated in neurons and glial cells in brains of patients with Pick's disease, corticobasal degeneration and progressive supranuclear palsy. Acta Neuropathol. 101, 167-173.

Arai, T., Hasegawa, M., Akiyama, H., Ikeda, K., Nonaka, T., Mori, H., Mann, D., Tsuchiya, K., Yoshida, M., Hashizume, Y., Oda, T., 2006. TDP-43 is a component of ubiquitin positive tau-negative inclusions in frontotemporal lobar degeneration and amyotrophic lateral sclerosis. Biochem. Biophys. Res. Commun. 351, 602-611.

Arancibia-Carcamo, L, Attwell, D., 2014. The node of Ranvier in CNS pathology. Acta Neuropathol. 128, 161-175.

Arima, K., 2006. Ultrastructural characteristics of tau filaments in tauopathies: immuno-electron microscopic demonstration of tau filaments in tauopathies. Neuropathology 26, 475-483.

Arima, K., Nakamura, M., Sunohara, N., Ogawa, M., Anno, M., Izumiyama, Y., Hirai, S., Ikeda, K., 1997. Ultrastructural characterization of the tau-immunoreactive tubules in the oligodendroglial perikarya and their inner loop processes in progressive supranuclear palsy. Acta Neuropathol. 93, 558-566. 
Armstrong, R.A., Ellis, W., Hamilton, R.L., Mackenzie, I.R., Hedreen, J., Gearing, M., Montine, T., Vonsattel, J.P., Head, E., Lieberman, A.P., Cairns, N.J., 2010. Neuropathological heterogeneity in frontotemporal lobar degeneration with TDP-43 proteinopathy: a quantitative stud of 94 cases using principal component analysis. J. Neural Transm. $117,227-230$.

Ash, P.E., Bienick, K.F., Gendron, T.F., Caulfield, T., Lin, W.L., Dejesus-Hernandez, M., van Blitterswijk, M.M., Jansen-West, K., Paul 3rd, J.W., Rademakers, R., Boylan, K.B., Dickson, D.W., Petrucelli, L., 2013. Unconventional translation C9ORF72 GGGCC expansion generates insoluble polypeptides specific to c9FTD/ALS. Neuron 77, 639-646.

Asi, Y.T., Simpson, J.E., Heath, P.R., Wharton, S.B., Lees, A.J., Revesz, T., Houlden, H., Holton, J.L., 2014. $\alpha$-synuclein mRNA expression in oligodendrocytes in MSA. Glia 62, 964-970.

Aston, C., Jiang, L., Sokolov, B.P., 2005. Transcriptional profiling reveals evidence for signaling and oligodendroglial abnormalities in the temporal cortex from patients with major depressive disorder. Mol. Psychiatry 10, 309-322.

Babbs, C.F., Shi, R., 2013. Subtle paranodal injury slows impulse conduction in a mathematical model of myelinated axons. PLoS One 8, e67767.

Back, S.A., Luo, N.L., Borenstein, N.S., Levine, J.M., Volpe, J.J., Kinney, H.C., 2001. Late oligodendrocyte progenitors coincide with the developmental window of vulnerability for human perinatal white matter injury. J. Neurosci. 21, 1302-1312.

Back, S.A., Han, B.H., Luo, N.L., Chricton, C.A., Xanthoudakis, S., Tam, J., Arvin, K.L., Holtzman, D.M., 2002. Selective vulnerability of late oligodendrocyte progenitors to hypoxia-ischemia. J. Neurosci. 22, 455-463.

Bakhti, M., Aggarwal, S., Simons, M., 2013. Myelin architecture: zippering membranes tightly together. Cell. Mol. Life Sci. 71, 1265-1277.

Bakhti, M., Snaidero, N., Schneider, D., Aggarwal, S., Möbius, W., Janshoff, A., Eckhardt, M., Nave, K.-A., Simons, M., 2013. Loss of electrostatic cell-surface repulsion mediates myelin membrane adhesion and compaction in the central nervous system. Proc. Natl. Acad. Sci. 110, 3143-3148.

Bakiri, Y., Karadottir, R., Cossell, L., Attwell, D., 2011. Morphological and electrical properties of oligodendrocytes in the white matter of the corpus callosum and cerebellum. J. Physiol. 589, 559-573.

Bankston, A.N., Mandler, M.D., Feng, Y., 2013. Oligodendroglia and neurotrophic factors in neurodegeneration. Neurosci. Bull. 29, 216-228.

Barber, R., Scheltens, P., Gholkar, A., Ballard, C., McKeith, I., Ince, P., Perry, R., O’Brien, J., 1999. White matter lesions on magnetic resonance imaging in dementia with Lewy bodies, Alzheimer's disease, vascular dementia, and normal aging. J. Neurol. Neurosurg. Psychiat. 67, 66-72.

Barca-Mayo, O., Lu, Q.R., 2012. Fine-tuning oligodendrocyte development by microRNAs. Front. Neurosci. 6 (13).

Barmada, S.J., Skibinski, G., Korb, E., Rao, E.J., Wu, J.Y., Finkbeiner, S., 2010. Cytoplasmic mislocalization of TDP-43 is toxic to neurons and enhanced by a mutation associated with familial amyotrophic lateral sclerosis. J. Neurosci. 30, 639-649.

Barmada, S.J., Serio, A., Arjun, A., Bilican, B., Daub, A., Ando, D.M., Tsvetkov, A., Pleiss, M., Li, X., Peisach, D., Shaw, C., Chandran, S., Finkbeiner, S., 2014. Autophagy induction enhances TDP43 turnover and survival in neuronal ALS models. Nat. Chem. Biol. 10, 677-685.

Baron, W, Hoekstra, D., 2010. On the biogenesis of myelin membranes: sorting, trafficking and cell polarity. FEBS Lett. 584, 1760-1770.

Barres, B.A., Raff, M.C., 1993. Proliferation of oligodendrocyte precursor cells depends on electrical activity in axons. Nature 361, 258-260.

Barres, B.A., Raff, M.C., 1999. Axonal control of oligodendrocyte development. J. Cell Biol. 147, 1123-1128.

Barres, B.A., Hart, I.K., Coles, H.S., Burne, J.F., Voyvodic, J.T., Richardson, W.D., Raff, M.C., 1992. Cell death and control of cell survival in the oligodendrocyte lineage. Cell $70,31-46$.

Barry, J., Gu, Y., Jukkola, P., O’Neill, B., Gu, H., Mohler, P.J., Rajamani, K.T., Gu, C., 2014. Ankyrin-G directly binds to kinesin-1 to transport voltage-gated Na channels into axons. Dev. Cell 28, 117-131.

Bartzokis, G., Beckson, M., Lu, P.H., Nuechterlein, K.H., Edwards, N., Mintz, J., 2001. Age-related changes in frontal and temporal lobe volumes in men: a magnetic resonance imaging study. Arch. Gen. Psychiatry 58, 461-465.

Bartzokis, G., Cummings, J.L., Sultzer, D., Henderson, V.W., Nuechterlein, K.H., Mintz, J., 2003. White matter structural integrity in healthy aging adults and patients with Alzheimer disease: a magnetic resonance imaging study. Arch. Neurol. 60, 393-398.

Bassil, F., Guerin, P.A., Dutheil, N., Li, Q., Klugmann, M., Meissner, W.G., Bezard, E., Fernagut, P.O., 2017. Viral-mediated oligodendroglial alpha-synuclein expression models multiple system atrophy. Mov. Disord. 32, 1230-1239.

Battefeld, A., Tran, B.T., Gavrilis, J., Cooper, E.C., Kole, M.H., 2014. Heteromeric kv7.2/ 7.3 channels differentially regulate action potential initiation and conduction in neocortical myelinated axons. J. Neurosci. 34, 3719-3732.

Battefeld, A., Klooster, J., Kole, M.H., 2016. Myelinating satellite oligodendrocytes are integrated in a glial syncytium constraining neuronal high-frequency activity. Nat. Commun. 7, 11298.

Bauer, N.G., Richter-Landsberg, C., Ffrench-Constant, C., 2009. Role of the oligodendroglial cytoskeleton in differentiation and myelination. Glia 57, 1691-1705.
Baumann, N, Pham-Dinh, D., 2001. Biology of oligodendrocyte and myelin in the mammalian central nervous system. Physiol. Rev. 81, 871-927.

Bede, P., Bokde, A.L., Byrne, S., Elamin, M., McLaughlin, R.L., Kenna, K., Fagan, A.J., Pender, N., Bradley, D.G., Hardiman, O., 2013. Multiparametric MRI study of ALS stratified for the C9orf72 genotype. Neurology 81, 361-369.

Bedner, P., Steinhauser, C., Theis, M., 2012. Functional redundancy and compensation among members of gap junction protein families?. Biochim. Biophys. Acta 1818, 1971-1984.

Behrendt, G., Baer, K., Buffo, A., Curtis, M.A., Faull, R.L., Rees, M.I., Gotz, M., Dimou, L., 2013. Dynamic changes in myelin aberrations and oligodendrocyte generation in chronic amyloidosis in mice and men. Glia 61, 273-286.

Beirowski, B., 2013. Concepts for regulation of axon integrity by enwrapping glia. Front. Cell. Neurosci. 7, 256

Belachew, S., Chittajallu, R., Aguirre, A.A., Yuan, X., Kirby, M., Anderson, S., Gallo, V., 2003. Postnatal NG2 proteoglycan-expressing progenitor cells are intrinsically multipotent and generate functional neurons. J. Cell Biol. 161, 169-186.

Bergles, D.E., Roberts, J.D., Somogyi, P., Jahr, C.E., 2000. Glutamatergic synapses on oligodendrocyte precursor cells in the hippocampus. Nature 405, 187-191.

Berry, R.W., Quinn, B., Johnson, N., Cochran, E.J., Ghoshal, N., Binder, L.I., 2001. Pathological glial tau accumulations in neurodegenerative disease: review and case report. Neurochem. Int. 39, 469-479.

Bigio, E.H., 2011. TDP-43 variants of frontotemporal lobar degeneration. J. Mol. Neurosci. $45,390-401$.

Bigio, E.H., 2011. C9ORF72, the new gene on the block, causes C9FTD/ALS: new insights provided by neuropathology. Acta Neuropathol. 122, 653-655.

Bigio, E.H., 2012. Motor neuron disease: the C9orf72 hexanucleotide repeat expansion in FTD and ALS. Nat. Rev. Neurol. 8, 249-250.

Bigio, E.H., Lipton, A.M., Yen, S.H., Hutton, M.L., Baker, M., Nacharaju, P., White 3rd, C.L., Davies, P., Lin, W., Dickson, D.W., 2001. Frontal lobe dementia with novel tauopathy: sporadic multiple system tauopathy with dementia. J. Neuropathol. Exp. Neurol. 60, 328-341.

Bigio, E.H., Wu, J.Y., Deng, H.X., Bit-Ivan, E.N., Mao, Q., Ganti, R., Peterson, M., Siddique, N., Geula, C., Siddique, T., Mesulam, M., 2013. Inclusions in frontotemporal lobar degeneration with TDP-43 proteinopathy (FTLD-TDP) and amyotrophic lateral sclerosis (ALS), but not FTLD with FUS proteinopathy (FTLD-FUS), have properties of amyloid. Acta Neuropathol. 125, 463-465.

Bird, T.D., Nochlin, D., Poorkaj, P., Cherrier, M., Kaye, J., Payami, H., Peskind, E., Lampe, T.H., Nemens, E., Boyer, P.J., Schellenberg, G.D., 1999. A clinical pathological comparison of three families with frontotemporal dementia and identical mutations in the tau gene (P301L). Brain 122, 741-756.

Birey, F., Kokkosis, A.G., Aguirre, A., 2017. Oligodendroglial-lineage in brain plasticity, homeostasis and psychiatric disorders. Curr. Opin. Neurobiol. 47, 93-103.

Black, S., Gao, F., Bilbao, J., 2009. Understanding white matter disease: imaging-pathological correlations in vascular cognitive impairment. Stroke 40, S48-52.

Blain, C.R., Barker, G.J., Jarosz, J.M., Coyle, N.A., Landau, S., Brown, R.G., Chaudhuri, K.R., Simmons, A., Jones, D.K., Williams, S.C., Leigh, P.N., 2006. Measuring brain stem and cerebellar damage in parkinsonian syndromes using diffusion tensor MRI. Neurology 67, 2199-2205.

Bleasel, J.M., Hsiao, J.H., Halliday, G.M., Kim, W.S., 2013. Increased expression of ABCA8 in multiple system atrophy brain is associated with changes in pathogenic proteins. J. Park. Dis. 3, 331-339.

Bleasel, J.M., Halliday, G.M., Kim, W.S., 2016. Animal modeling an oligodendrogliopathymultiple system atrophy. Acta Neuropathol. Comm. 4, 12.

Boda, E., Vigano, F., Rosa, P., Fumagalli, M., Labat-Gest, V., Tempia, F., Abbracchio, M.P., Dimou, L., Buffo, A., 2011. The GPR17 receptor in NG2 expressing cells: focus on in vivo cell maturation and participation in acute trauma and chronic damage. Glia 59, 1958-1973.

Bohnen, N.I., Albin, R.L., 2011. White matter lesions in Parkinson disease. Nat. Rev. Neurol. 7, 229-236.

Boluda, S., Iba, M., Zhang, B., Raible, K.M., Lee, V.M., Trojanowski, J.Q., 2015. Differential induction and spread of tau pathology in young PS19 tau transgenic mice following intracerebral injections of pathological tau from Alzheimer's disease or corticobasal degeneration brains. Acta Neuropathol. 129, 221-237.

Bonfanti, E., Gelosa, P., Fumagalli, M., Dimou, L., Vigano, F., Tremoli, E., Cimino, M. Sironi, L., Abbracchio, M.P., 2017. The role of oligodendrocyte precursor cells expressing the GPR17 receptor in brain remodeling after stroke. Cell Death Dis. 8, e2871.

Bongarzone, E.R., Howard, S.G., Schonmann, V., Campagnoni, A.T., 1998. Identification of the dopamine D3 receptor in oligodendrocyte precursors: potential role in regulating differentiation and myelin formation. J. Neurosci. 18, 5344-5353.

Borrego-Écija, S., Morgado, J., Palencia-Madrid, L., Grau-Rivera, O., Reñé, R., Hernández, I., Almenar, C., Balasa, M., Antonell, A., Molinuevo, J.L., Lladó, A., Martínez de Pancorbo, M., Gelpi, E, Sánchez-Valle, R., 2017. Frontotemporal Dementia Caused by the P301L Mutation in the MAPT Gene: Clinicopathological Features of 13 Cases from the Same Geographical Origin in Barcelona, Spain. Dement. Geriatr. Cogn. Disord. 44, 213-221. 
Boudes, M., Uvin, P., Pinto, S., Voets, T., Fowler, C.J., Wenning, G.K., De Ridder, D., Stefanova, N., 2013. Bladder dysfunction in a transgenic mouse model of multiple system atrophy. Mov. Disord. 28, 347-355.

Boullerne, A.I., 2016. The history of myelin. Exp. Neurol. 283, 431-445.

Braak, H., Braak, E., 1991. Neuropathological staging of Alzheimer-related changes. Acta Neuropathol. 82, 239-259.

Braak, H, Del Tredici, K., 2015. The preclinical phase of the pathological process underlying sporadic Alzheimer's disease. Brain 138, 2814-2833.

Braak, H., Del Tredici, K., Rüb, U., de Vos, R.A.I., Jansen Steur, E.N.H., Braak, E., 2003. Staging of brain pathology related to sporadic Parkinson's disease. Neurobiol. Aging 24, 197-211.

Braak, H., Ghebremedhin, E., Rüb, U., Bratzke, H., del Tredici, K., 2004. Stages in the development of Parkinson's disease-related pathology. Cell Tissue Res. 318, 121-134.

Braak, H., Braak, E., 1999. Temporal sequence of Alzheimer's disease-related pathology. In: Peters, A., Morrison, J.H., (eds) Cerebral cortex vol. 14, Neurodegenerative and age-related changes in structure and function of cerebral cortex. Kluwer Academic/ Plenum Publishers, New York, Boston, Dordrecht, London, Moscow, pp 475-512.

Bradl, M, Lassmann, H., 2010. Oligodendrocytes: biology and pathology. Acta Neuropathol. 119, 37-53.

Brasko, C., Hawkins, V., De La Rocha, I.C., Butt, A.M., 2017. Expression of Kir4.1 and Kir5.1 inwardly rectifying potassium channels in oligodendrocytes, the myelinating cells of the CNS. Brain Struct. Funct. 222, 41-59.

Brettschneider, J., Del Tredici, K., Toledo, J.B., Robinson, J.L., Irwin, D.J., Grossman, M., Suh, E., Van Deerlin, V.M., Wood, E.M., Baek, Y., Kwong, L., Lee, E.B., Elman, L., McCluskey, L., Fang, L., Feldengut, S., Ludolph, A.C., Lee, V.M., Braak, H., Trojanowski, J.Q., 2013. Stages of p-TDP-43 pathology in amyotrophic lateral sclerosis. Ann. Neurol. 74, 20-38.

Brettschneider, J., Del Tredici, K., Irwin, D.J., Grossman, M., Robinson, J.L., Toledo, J.B., Fang, L., Van Deerlin, V.M., Ludolph, A.C., Lee, V.M., Braak, H., Trojanowski, J.Q., 2014. Sequential distribution of pTDP-43 pathology in behavioral variant frontotemporal dementia (bvFTD). Acta Neuropathol. 127, 423-439.

Brettschneider, J., Arai, K., Del Tredici, K., Toledo, J.B., Robinson, J.L., Lee, E.B., Kuwabara, S., Shibuya, K., Irwin, D.J., Fang, L., Van Deerlin, V.M., Elman, L., McCluskey, L., Ludolph, A.C., Lee, V.M., Braak, H., Trojanowski, J.Q., 2014. TDP-43 pathology and neuronal loss in amyotrophic lateral sclerosis spinal cord. Acta Neuropathol. 128, 423-437.

Bribián, A., Fontana, X., Llorens, F., Gavín, R., Reina, M., García-Verdugo, J.M., Torres, J.M., de Castro, F., del Río, J.A., 2012. Role of the cellular prion protein in oligodendrocyte precursor cell proliferation and differentiation in the developing and adult mouse CNS. PLoS One 7, e33872.

Brinkmann, B.G., Agarwal, A., Sereda, M.W., Garratt, A.N., Muller, T., Wende, H., Stassart, R.M., Nawaz, S., Humml, C., Velanac, V., Radyushkin, K., Goebbels, S., Fischer, T.M., Franklin, R.J., Lai, C., Ehrenreich, H., Birchmeier, C., Schwab, M.H., Nave, K.A., 2008. Neuregulin-1/ErbB signaling serves distinct functions in myelination of the peripheral and central nervous system. Neuron 59, 581-595

Brooks, D.J., Seppi, K., 2009. Neuroimaging Working Group on MSA. Proposed neuroimaging criteria for the diagnosis of multiple system atrophy. Mov. Disord. 24, 949-964.

Brown, A.M., Wender, R., Ransom, B.R., 2001. Metabolic substrates other than glucose support axón function in central white matter. J. Neurosci. Res. 66, 839-843.

Budde, H., Schmitt, S., Fitzner, D., Opitz, L., Salinas-Riester, G., Simons, M., 2010. Control of oligodendroglial cell number by the miR-17-92 cluster. Development 137, 2127-2132.

Budka, H., Head, M.W., Ironside, J.W., Gambetti, P., Parchi, P., Tagliavini, F., 2011. Sporadic Creutzfeldt-Jakob disease. In: Dickson, DW, Weller, RO (Eds.), Neurodegeneration: the Molecular Pathology of Dementia and Movement Disorders, second edition Willey-Blackwell, Chichester, West Sussex, pp. 322-335.

Bujalka, H., Koenning, M., Jackson, S., Perreau, V.M., Pope, B., Hay, C.M., Mitew, S., Hill, A.F., Lu, Q.R., Wegner, M., Srinivasan, R., Svaren, J., Willingham, M., Barres, B.A., Emery, B., 2013. MYRF is a membrane-associated transcription factor that autoproteolytically cleaves to directly activate myelin genes. PLoS Biol. 11, e1001625.

Bunge, R.P., 1968. Glial cells and the central myelin sheath. Physiol. Rev. 48, 197-251.

Burrell, J.R., Forrest, S., Bak, T.H., Hodges, J.R., Halliday, G.M., Kril, J.J., 2016. Expanding the phenotypic associations of globular glial tau subtypes. Alzheimers Dement. 4, $6-13$.

Butt, A.M., 2006. Neurotransmitter-mediated calcium signaling in oligodendrocyte physiology and pathology. Glia 54, 666-675.

Buttigieg, J., Eftekharpour, E., Karimi-Abdolrezaee, S., Fehlings, M.G., 2011. Molecular and electrophysiological evidence for the expression of BK channels in oligodendroglial precursor cells. Eur. J. Neurosci. 34, 538-547.

Cahoy, J.D., Emery, B., Kaushal, A., Foo, L.C., Zamanian, J.L., Christopherson, K.S., Xing, Y., Lubischer, J.L., Krieg, P.A., Krupenko, S.A., Thompson, W.J., Barres, B.A., 2008. A transcriptome database for astrocytes, neurons, and oligodendrocytes: a new resource for understanding brain development and function. J. Neurosci. 28, 264-278.

Cai, Z, Xiao, M., 2016. Oligodendrocytes and Alzheimer's disease. Int. J. Neurosci. 126, 97-104.
Cai, J., Qi, Y., Hu, X., Tan, M., Liu, Z., Zhang, J., Li, Q., Sander, M., Qiu, M., 2005. Generation of oligodendrocyte precursor cells from mouse dorsal spinal cord independent of Nkx6 regulation and Shh signaling. Neuron 45, 41-53.

Cai, M., Lee, K.W., Choi, S.M., Yang, E.J., 2015. TDP-43 modification in the hSOD1(G93A) amyotrophic lateral sclerosis mouse model. Neurol. Res. 37, 253-262.

Calza, L., Fernandez, M., Giuliani, A., Aloe, L., Giardino, L., 2002. Thyroid hormone activates oligodendrocyte precursors and increases a myelin-forming protein and NGF content in the spinal cord during experimental allergic encephalomyelitis. Proc. Natl. Acad. Sci. U. S. A. 99, 3258-3263.

Campbell, B.C., McLean, C.A., Culvenor, J.G., Gai, W.P., Blumbergs, P.C., Jakala, P., Beyreuther, K., Masters, C.L., Li, Q.X., 2001. The solubility of $\alpha$-synuclein in multiple system atrophy differs from that of dementia with Lewy bodies and Parkinson's disease. J. Neurochem. 76, 87-96.

Carson, J.H., Worboys, K., Ainger, K., Barbarese, E., 1997. Translocation of myelin basic protein mRNA in oligodendrocytes requires microtubules and kinesin. Cell Motil. Cytoskeleton 38, 318-328.

Cerghet, M., Skoff, R.P., Swamydas, M., Bessert, D., 2009. Sexual dimorphism in the white matter of rodents. J. Neurol. Sci. 286, 76-80.

Chang, A., Nishiyama, A., Peterson, J., Prineas, J., Trapp, B.D., 2000. NG2-positive oligodendrocyte progenitor cells in adult human brain and multiple sclerosis lesions. J. Neurosci. 20, 6404-6412.

Chapman, H., Waclaw, R.R., Pei, Z., Nakafuku, M., Campbell, K., 2013. The homeobox gene Gsx2 controls the timing of oligodendroglial fate specification in mouse lateral ganglionic eminence progenitors. Development 140, 2289-2298.

Charles, P., Hernandez, M.P., Stankoff, B., Aigrot, M.S., Colin, C., Rougon, G., Zalc, B., Lubetzki, C., 2000. Negative regulation of central nervous system myelination by polysialylated-neural cell adhesion molecule. Proc. Natl. Acad. Sci. U. S. A. 2000 (97), 7585-7590.

Chen, C., Westenbroek, R.E., Xu, X., Edwards, C.A., Sorenson, D.R., Chen, Y., McEwen, D.P., O'Malley, H.A., Bharucha, V., Meadows, L.S., Knudsen, G.A., Vilaythong, A. Noebels, J.L., Saunders, T.L., Scheuer, T., Shrager, P., Catterall, W.A., Isom, L.L., 2004. Mice lacking sodium channel beta1 subunits display defects in neuronal excitability, sodium channel expression, and nodal architecture. J. Neurosci. 24, 4030-4042.

Chen, Y., Aulia, S., Tang, B.L., 2006. Myelin-associated glycoprotein-mediated signaling in central nervous system pathophysiology. Mol. Neurobiol. 34, 81-91.

Chen, Y., Wu, H., Wang, S., Koito, H., Li, J., Ye, F., Hoang, J., Escobar, S.S., Gow, A., Arnett, H.A., Trapp, B.D., Karandikar, N.J., Hsieh, J., Lu, Q.R., 2009. The oligodendrocyte-specific $\mathrm{G}$ protein-coupled receptor GPR17 is a cell-intrinsic timer of myelination. Nat. Neurosci. 12, 1398-1406.

Chiba, Y., Takei, S., Kawamura, N., Kawaguchi, Y., Sasaki, K., Hasegawa-Ishii, S., Furukawa, A., Hosokawa, M., Shimada, A., 2012. Immunohistochemical localization of aggresomal proteins in glial cytoplasmic inclusions in multiple system atrophy. Neuropathol. Appl. Neurobiol. 38, 559-571.

Chin, S.S., Goldman, J.E., 1996. Glial inclusions in CNS degenerative diseases. J. Neuropathol. Exp. Neurol. 55, 499-508.

Choi, Y.P., Head, M.W., Ironside, J.W., Priola, S.A., 2014. Uptake and degradation of protease-sensitive and -resistant forms of abnormal human prion protein aggregates by human astrocytes. Am. J. Pathol. 184, 3299-3307.

Choi, Y.R., Cha, S.H., Kang, S.J., Kim, J.B., Jou, I., Park, S.M., 2018. Prion-like propagation of $\alpha$-synuclein is regulated by the Fc $\gamma$ RIIB-SHP- $1 / 2$ signaling pathway in neurons. Cell Rep. 22, 136-148.

Chong, S.Y., Rosenberg, S.S., Fancy, S.P., Zhao, C., Shen, Y.A., Hahn, A.T., McGee, A.W., Xu, X., Zheng, B., Zhang, L.I., Rowitch, D.H., Franklin, R.J., Lu, Q.R., Chan, J.R., 2012. Neurite outgrowth inhibitor Nogo-A establishes spatial segregation and extent of oligodendrocyte myelination. Proc. Natl. Acad. Sci. U. S. A. 109, 1299-1304.

Chrast, R., Saher, G., Nave, K.A., Verheijen, M.H., 2011. Lipid metabolism in myelinating glial cells: lessons from human inherited disorders and mouse models. J. Lipid Res. $52,419-434$

Clark, C.N., Lashley, T., Mahoney, C.J., Warren, J.D., Revesz, T., Rohrer, J.D., 2015. Temporal Variant Frontotemporal dementia is associated with globular glial tauopathy. Cogn. Behav. Neurol. 28, 92-97.

Clarke, L.E., Young, K.M., Hamilton, N.B., Li, H., Richardson, W.D., Attwell, D., 2012. Properties and fate of oligodendrocyte progenitor cells in the corpus callosum, motor cortex, and piriform cortex of the mouse. J. Neurosci. 32, 8173-8185.

Clavaguera, F., Bolmont, T., Crowther, R.A., Abramowski, D., Frank, S., Probst, A., Fraser, G., Stalder, A.K., Beibel, M., Staufenbiel, M., Jucker, M., Goedert, M., Tolnay, M., 2009. Transmission and spreading of tauopathy in transgenic mouse brain. Nat. Cell Biol. 11, 909-913.

Clavaguera, F., Akatsu, H., Fraser, G., Crowther, R.A., Frank, S., Hench, J., Probst, A., Winkler, D.T., Reichwald, J., Staufenbiel, M., Ghetti, B., Goedert, M., Tolnay, M., 2013. Brain homogenates from human tauopathies induce tau inclusions in mouse brain. Proc. Natl. Acad. Sci. U. S. A. 110, 9535-9540.

Clavaguera, F., Lavenir, I., Falcon, B., Frank, S., Goedert, M., Tolnay, M., 2013. "Prion-like" templated misfolding in tauopathies. Brain Pathol. 23, 342-349. 
Clavaguera, F., Hench, J., Goedert, M., Tolnay, M., 2015. Invited review: prion-like transmission and spreading of tau pathology. Neuropathol. Appl. Neurobiol. 41, 47-58.

Cohen, T.J., Guo, J.L., Hurtado, D.E., Kwong, L.K., Mills, I.P., Trojanowski, J.Q., Lee, V.M., 2011. The acetylation of tau inhibits its function and promotes pathological tau aggregation. Nat. Commun. 2, 252.

Collinge, J., 2016. Mammalian prions and their wider relevance in neurodegenerative diseases. Nature 539, 217-226.

Collinge, J., Clarke, A.R., 2007. A general model of prion strains and their pathogenicity. Science 318, 930-936.

Crary, J.F., Trojanowski, J.Q., Schneider, J.A., Abisambra, J.F., Abner, E.L., Alafuzoff, I., Arnold, S.E., Attems, J., Beach, T.G., Bigio, E.H., Cairns, N.J., Dickson, D.W., Gearing, M., Grinberg, L.T., Hof, P.R., Hyman, B.T., Jellinger, K., Jicha, G.A., Kovacs, G.G., Knopman, D.S., Kofler, J., Kukull, W.A., Mackenzie, I.R., Masliah, E., McKee, A., Montine, T.J., Murray, M.E., Neltner, J.H., Santa-Maria, I., Seeley, W.W., Serrano-Pozo, A., Shelanski, M.L., Stein, T., Takao, M., Thal, D.R., Toledo, J.B., Troncoso, J.C., Vonsattel, J.P., White 3rd, C.L., Wisniewski, T., Woltjer, R.L., Yamada, M., Nelson, P.T., 2014. Primary age-related tauopathy (PART): a common pathology associated with human aging. Acta Neuropathol. 128, 755-766.

Crawford, A.H., Stockley, J.H., Tripathi, R.B., Richardson, W.D., Franklin, R.J., 2014. Oligodendrocyte progenitors: adult stem cells of the central nervous system?. Exp. Neurol. 260, 50-55.

Crawford, A.H., Tripathi, R.B., Richardson, W.D., Franklin, R.J., 2016. Developmental origin of oligodendrocyte lineage cells determines response to demyelination and susceptibility to age-associated functional decline. Cell Rep. 15, 761-773.

Cruts, M., Gijselinck, I., Van Langenhove, T., van der Zee, J., Van Broeckhoven, C., 2013. Current insights into the C9orf72 repeat expansion diseases of the FTLD/ALS spectrum. Trends Neurosci. 36, 450-459.

Cui, Y., Masaki, K., Yamasaki, R., Imamura, S., Suzuki, S.O., Hayashi, S., Sato, S., Nagara, Y., Kawamura, M.F., Kira, J., 2014. Extensive dysregulation of oligodendrocytic and astrocytic connexins are associated with disease progression in an amyotrophic lateral sclerosis mouse model. J. Neuroinflam. 11, 42.

Dai, X., Lercher, L.D., Clinton, P.M., Du, Y., Livingston, D.L., Vieira, C., Yang, L., Shen, M.M., Dreyfus, C.F., 2003. The trophic role of oligodendrocytes in the basal forebrain. J. Neurosci. Off. J. Soc. Neurosci. 23, 5846-5853.

Dalfó, E, Ferrer, I., 2005. $\alpha$-synuclein binding to rab3a in multiple system atrophy. Neurosci. Lett. 380, 170-175.

Darmanis, S., Sloan, S.A., Zhang, Y., Enge, M., Caneda, C., Shuer, L.M., Gephart, M.G.H., Barres, B.A., Quake, S.R., 2015. A survey of human brain transcriptome diversity at the single cell level. PNAS 112, 7285-7290.

David, S., Miller, R.H., Patel, R., Raff, M.C., 1984. Effects of neonatal transection on glial cell development in the rat optic nerve: evidence that the oligodendrocyte-type 2 astrocyte cell lineage depends on axons for its survival. J. Neurocytol. 13, 961-974.

Davidson, W.S., Jonas, A., Clayton, D.F., George, J.M., 1998. Stabilization of $\alpha$-synuclein secondary structure upon binding to synthetic membranes. J. Biol. Chem. 273, 9443-9449.

Dawson, M.R., Levine, J.M., Reynolds, R., 2000. NG2-expressing cells in the central nervous system: are they oligodendroglial progenitors?. J. Neurosci. Res. 61, 471-479.

Dawson, M.R., Polito, A., Levine, J.M., Reynolds, R., 2003. NG2-expressing glial progenitor cells: an abundant and widespread population of cycling cells in the adult rat CNS. Mol. Cell. Neurosci. 24, 476-488.

De Angelis, F., Bernardo, A., Magnaghi, V., Minghetti, L., Tata, A.M., 2012. Muscarinic receptor subtypes as potential targets to modulate oligodendrocyte progenitor survival, proliferation, and differentiation. Dev. Neurobiol. 72, 713-728.

De Monasterio-Schrader, P, Jahn, O., Tenzer, S., Wichert, S.P., Patzig, J., Werner, H.B., 2012. Systematic approaches to central nervous system myelin. Cell. Mol. Life Sci. 69, 2879-2894.

De Rossi, P., Buggia-Prévot, V., Clayton, B.L., Vasquez, J.B., van Sanford, C., Andrew, R.J., Lesnick, R., Botté, A., Deyts, C., Salem, S., Rao, E., Rice, R.C., Parent, A., Kar, S., Popko, B., Pytel, P., Estus, S., Thinakaran, G., 2016. Predominant expression of Alzheimer's disease-associated BIN1 in mature oligodendrocytes and localization to white matter tracts. Mol. Neurodegener. 11, 59.

Del Río-Hortega, P, 1921. La glía de escasa radiaciones (oligodendroglia). Trab. Lab. Histol. Patol. 1-15, 1-43.

Demerens, C., Stankoff, B., Logak, M., Anglade, P., Allinquant, B., Couraud, F., Zalc, B., Lubetzki, C., 1996. Induction of myelination in the central nervous system by electrical activity. Proc. Natl. Acad. Sci. U. S. A. 93, 9887-9892.

Desai, M.K., Sudol, K.L., Janelsins, M.C., Mastrangelo, M.A., Frazer, M.E., Bowers, W.J., 2009. Triple-transgenic Alzheimer's disease mice exhibit region-specific abnormalities in brain myelination patterns prior to appearance of amyloid and tau pathology. Glia $57,54-65$.

Desai, M.K., Mastrangelo, M.A., Ryan, D.A., Sudol, K.L., Narrow, W.C., Bowers, W.J., 2010. Early oligodendrocyte/myelin pathology in Alzheimer's disease mice constitutes a novel therapeutic target. Am. J. Pathol. 177, 1422-1435.

Devaux, J., Alcaraz, G., Grinspan, J., Bennett, V., Joho, R., Crest, M., Scherer, S.S., 2003. Kv3.1b is a novel component of CNS nodes. J. Neurosci. 23, 4509-4518.
Devaux, J.J., Kleopa, K.A., Cooper, E.C., Scherer, S.S., 2004. KCNQ2 is a nodal K+ channel. J. Neurosci. 24, 1236-1244.

Dickson, D.W., Feany, M.B., Yen, S.H., Mattiace, L.A., Davies, P., 1996. Cytoskeletal pathology in non-Alzheimer degenerative dementia: new lesions in diffuse Lewy body disease, Pick's disease, and corticobasal degeneration. J. Neural Transm. Suppl. 47, $31-46$.

Dickson, D.W., Liu, W., Hardy, J., Farrer, M., Mehta, N., Uitti, R., Mark, M., Zimmerman, T., Golbe, L., Sage, J., Sima, A., D’Amato, C., Albin, R., Gilman, S., Yen, S.H., 1999. Widespread alterations of $\alpha$-synuclein in multiple system atrophy. Am. J. Pathol. 155, 1241-1251.

Dickson, D.W., Fujishiro, H., DelleDonne, A., Menke, J., Ahmed, Z., Klos, K.J., Josephs, K.A., Frigerio, R., Burnett, M., Parisi, J.E., Ahlskog, J.E., 2008. Evidence that incidental Lewy body disease is pre-symptomatic Parkinson's disease. Acta Neuropathol. 115, 437-444.

Dickson, D.W., Hauw, J.J., Agid, Y., Litvan, I., 2011. Progressive supranuclear palsy and corticobasal degeneration. In: Dickson, DW, Weller, RO (Eds.), Neurodegeneration: the Molecular Pathology of Dementia and Movement Disorders, second edition, Willey-Blackwell, Chichester, West Sussex, pp. 135-155.

Dickson, D.W., Kouri, N., Murray, M.E., Josephs, K.A., 2011. Neuropathology of frontotemporal lobar degeneration-tau (FTLD-tau). J. Mol. Neurosci. 45, 384-389.

Dimou, L, Gallo, V., 2015. NG2-glia and their functions in the central nervous system. Glia $63,1429-1451$

Dimou, L, Gotz, M., 2014. Glial cells as progenitors and stem cells: new roles in the healthy and diseased brain. Physiol. Rev. 94, 709-737.

Dimou, L., Simon, C., Kirchhoff, F., Takebayashi, H., Gotz, M., 2008. Progeny of Olig2-expressing progenitors in the gray and white matter of the adult mouse cerebral cortex. J. Neurosci. 28, 10434-10442.

Djelloul, M., Holmqvist, S., Boza-Serrano, A., Azevedo, C., Yeung, M.S., Goldwurm, S., Frisén, J., Deierborg, T., Roybon, L., 2015. $\alpha$-synuclein expression in the oligodendrocyte lineage: an in vitro and in vivo study using rodent and human models. Stem Cell Rep. 5, 174-184.

Don, A.S., Hsiao, J.H., Bleasel, J.M., Couttas, T.A., Halliday, G.M., Kim, W., 2014. Altered lipid levels provide evidence for myelin dysfunction in multiple system atrophy. Acta Neuropathol. Commun. 2, 150.

Dräger, N.M., Nachman, E., Winterhoff, M., Brühmann, S., Shah, P., Katsinelos, T., Boulant, S., Teleman, A.A., Faix, J., Jahn, T.R., 2017. Bin1 directly remodels actin dynamics through its BAR domain. EMBO Rep. 18, 2051-2066.

Du, Y., Dreyfus, C.F., 2002. Oligodendrocytes as providers of growth factors. J. Neurosci. Res. 68, 647-654

Duda, J.E., Giasson, B.I., Gur, T.L., Montine, T.J., Robertson, D., Biaggioni, I., Hurtig, H.I., Stern, M.B., Gollomp, S.M., Grossman, M., Lee, V.M., Trojanowski, J.Q., 2000. Immunohistochemical and biochemical studies demonstrate a distinct profile of alpha-synuclein permutations in multiple system atrophy. J. Neuropathol. Exp. Neurol. 59, 830-841.

Duda, J.E., Giasson, B.I., Mabon, M.E., Miller, D.C., Golbe, L.I., Lee, V.M., Trojanowski, J.Q., 2002. Concurrence of $\alpha$-synuclein and tau brain pathology in the Contursi kindred. Acta Neuropathol. 104, 7-11.

Duflocq, A., Le Bras, B., Bullier, E., Couraud, F., Davenne, M., 2008. Nav1.1 is predominantly expressed in nodes of Ranvier and axon initial segments. Mol. Cell. Neurosci. 39, 180-192.

Dugas, J.C., Cuellar, T.L., Scholze, A., Ason, B., Ibrahim, A., Emery, B., Zamanian, J.L., Foo, L.C., McManus, M.T., Barres, B.A., 2010. Dicer1 and miR-219 are required for normal oligodendrocyte differentiation and myelination. Neuron 65, 597-611.

Dugger, B.N., Adler, C.H., Shill, H.A., Caviness, J., Jacobson, S., Driver-Dunckley, E., Beach, T.G., Arizona Parkinson's Disease Consortium, 2014. Concomitant pathologies among a spectrum of parkinsonian disorders. Parkinsonism Relat. Disord. 20, $525-529$.

Duyckaerts, C, Dickson, D., 2011. Neuropathology of Alzheimer's disease. In: Dickson, DW, Weller, RO (Eds.), Neurodegeneration: the Molecular Pathology of Dementia and Movement Disorders, second edition Willey-Blackwell, Chichester, West Sussex, pp. 62-91

Duyckaerts, C., Braak, H., Brion, J.P., Buée, L., Del Tredici, K., Goedert, M., Halliday, G., Neumann, M., Spillantini, M.G., Tolnay, M., Uchihara, T., 2015. PART is part of Alzheimer disease. Acta Neuropathol. 129, 749-756.

Dzamba, D., Honsa, P., Anderova, M., 2013. NMDA receptors in glial cells: pending questions. Curr. Neuropharmacol. 11, 250-262.

Edgar, J.M., Nave, K.-A., 2009. The role of CNS glia in preserving axon function. Curr Opin. Neurobiol. 19, 498-504.

Edgar, J.M., McLaughlin, M., Yool, D., Zhang, S.C., Fowler, J.H., Montague, P., Barrie, J.A., McCulloch, M.C., Duncan, I.D., Garbern, J., Nave, K.A., Griffiths, I.R., 2004. Oligodendroglial modulation of fast axonal transport in a mouse model of hereditary spastic paraplegia. J. Cell Biol. 166, 121-131.

Edgar, J.M., McLaughlin, M., Werner, H.B., McCulloch, M.C., Barrie, J.A., Brown, A., Faichney, A.B., Snaidero, N., Nave, K.A., Griffiths, I.R., 2009. Early ultrastructural defects of axons and axon-glia junctions in mice lacking expression of Cnp1. Glia 57, 1815-1824.

Edgar, J.M., McCulloch, M.C., Montague, P., Brown, A.M., Thilermann, S., Pratola, L., Gruenefelder, F.I., Griffiths, I.R., Nave, K.A., 2010. Demyelination and axonal preservation in a transgenic mouse model of Pelizaeus-Merzbacher disease. EMBO Mol. Med. $2,42-50$.

El Hachimi, K.H., Chaunu, M.P., Brown, P., Foncin, J.F., 1998. Modifications of oligodendroglial cells in spongiform encephalopathies. Exp. Neurol. 154, 23-30. 
Emery, B., 2010. Regulation of oligodendrocyte differentiation and myelination. Science 330, 779-782.

Emery, B., Lu, Q.R., 2015. Transcriptional and epigenetic regulation of oligodendrocyte development and myelination in the CNS. Cold Spring Harb. Perspect. Biol. 7, a020461.

Emery, B., Agalliu, D., Cahoy, J.D., Watkins, T.A., Dugas, J.C., Mulinyawe, S.B., Ibrahim, A., Ligon, K.L., Rowitch, D.H., Barres, B.A., 2009. Myelin gene regulatory factor is a critical transcriptional regulator required for CNS myelination. Cell 138, 172-185.

Erten-Lyons, D., Woltjer, R., Kaye, J., Mattek, N., Dodge, H.H., Green, S., Tran, H., Howieson, D.B., Wild, K., Silbert, L.C., 2013. Neuropathologic basis of white matter hyperintensity accumulation with advanced age. Neurology 81, 977-983.

Eschenroeder, A.C., Vestal-Laborde, A.A., Sanchez, E.S., Robinson, S.E., Sato-Bigbee, C., 2012. Oligodendrocyte responses to buprenorphine uncover novel and opposing roles of m-opioid- and nociceptin/orphanin FQ receptors in cell development: implications for drug addiction treatment during pregnancy. Glia 60, 125-136.

Ettle, B., Reiprich, S., Deusser, J., Schlachetzki, J.C., XiangW, Prots, I., Masliah, E., Winner, B., Wegner, M., Winkler, J., 2014. Intracellular $\alpha$-synuclein affects early maturation of primary oligodendrocyte progenitor cells. Mol. Cell. Neurosci. 62, 68-78.

Ettle, B., Kerman, B.E., Valera, E., Gillmann, C., Schlachetzki, J.C., Reiprich, S., Büttner, C., Ekici, A.B., Reis, A., Wegner, M., Bäuerle, T., Riemenschneider, M.J., Masliah, E., Gage, F.H., Winkler, J., 2016. $\alpha$-synuclein-induced myelination deficit defines a novel interventional target for multiple system atrophy. Acta Neuropathol. 132, 59-75.

Ettle, B., Schlachetzki, J.C.M., Winkler, J., 2016. Oligodendroglia and myelin in neurodegenerative diseases: more than just bystanders?. Mol. Neurobiol. 53, 3046-3062.

Eugenin-von Bernhardi, J, Dimou, L., 2016. NG2-glia, more than progenitor cells. In: In: von Bernardi, R. (Ed.), Glial Cells in Health and Disease of the CNS. Advances in Experimental Medicine and Biology, vol. 949, Springer International Publishing, Switzerland, pp. 27-45.

Fan, L.W., Bhatt, A., Tien, L.T., Zheng, B., Simpson, K.L., Lin, R.C., Cai, Z., Kumar, P., Pang, Y., 2015. Exposure to serotonin adversely affects oligodendrocyte development and myelination in vitro. J. Neurochem. 133, 532-543.

Fancy, S.P., Baranzini, S.E., Zhao, C., Yuk, D.I., Irvine, K.A., Kaing, S., Sanai, N., Franklin, R.J., Rowitch, D.H., 2009. Dysregulation of the Wnt pathway inhibits timely myelination and remyelination in the mammalian CNS. Genes Dev. 23, 1571-1585.

Fang, Y., Huang, X., Wan, Y., Tian, H., Tian, Y., Wang, W., Zhu, S., Xie, M., 2017. Deficiency of TREK-1 potassium channel exacerbates secondary injury following spinal cord injury in mice. J. Neurochem. 141, 236-246.

Farsetti, A., Mitsuhashi, T., Desvergne, B., Robbins, J., Nikodem, V.M., 1991. Molecular basis of thyroid hormone regulation of myelin basic protein gene expression in rodent brain. J. Biol. Chem. 266, 23226-23232.

Fatima, M., Tan, R., Halliday, G.M., Kril, J.J., 2015. Spread of pathology in amyotrophic lateral sclerosis: assessment of phosphorylated TDP-43along axonal pathways. Acta Neuropathol. Commun. 3, 47 .

Feany, M.B., Ksiezak-Reding, H., Liu, W.K., Vincent, I., Yen, S.H., Dickson, D.W., 1995. Epitope expression and hyperphosphorylation of tau protein in corticobasal degeneration: differentiation from progressive supranuclear palsy. Acta Neuropathol. 90, 37-43.

Fellner, L, Stefanova, N., 2013. The role of glia in $\alpha$-synucleinopathies. Mol. Neurobiol. 47, 575-586.

Fellner, L., Jellinger, K.A., Wenning, G.K., Stefanova, N., 2011. Glial dysfunction in the pathogenesis of $\alpha$-synucleinopathies: emerging concepts. Acta Neuropathol. 121, $675-693$.

Fellner, L., Wenning, G.K., Stefanova, N., 2015. Models of multiple system atrophy. Curr. Top. Neurosci. 22, 369-393.

Fernagut, P.O., Meissner, W.G., Biran, M., Fantin, M., Bassil, F., Franconi, J.M., Tison, F., 2014. Age-related motor dysfunction and neuropathology in a transgenic mouse model of multiple system atrophy. Synapse 68, 98-106.

Fernandez-Vega, I., Diaz-Lucena, D., Azkune, I., Geijo, M., Juste, R.A., Llorens, F., Etxenausia, I.V., Santos-Juanes, J., Zarranz Imirizaldu, J.J., Ferrer, I., 2018. Sporadic Creutzfeldt-Jakob disease with glial PrPRes nuclear and perinuclear immunoreactivity. Neuropathology https://doi.org/10.111/neup.12505, Accepted for publication.

Ferraiuolo, L., Meyer, K., Sherwood, T.W., Vick, J., Likhite, S., Frakes, A., Miranda, C.J., Braun, L., Heath, P.R., Pineda, R., Beattie, C.E., Shaw, P.J., Askwith, C.C., McTigue, D., Kaspar, B.K., 2016. Oligodendrocytes contribute to motor neuron death in ALS via SOD1-dependent mechanism. Proc. Natl. Acad. Sci. U. S. A. 113, E6496-E6505.

Ferrer, I., 2010. Cognitive impairment of vascular origin: neuropathology of cognitive impairment of vascular origin. J. Neurol. Sci. 299, 139-149.

Ferrer, I., 2012. Defining Alzheimer as a common age-related neurodegenerative process not inevitably leading to dementia. Prog. Neurobiol. 97, 38-51.

Ferrer, I., 2017. Diversity of astroglial responses across human neurodegenerative disorders and brain aging. Brain Pathol. 27, 645-674.

Ferrer, I., Barrachina, M., Puig, B., 2002. Glycogen synthase kinase-3 is associated with neuronal and glial hyperphosphorylated tau deposits in Alzheimer's disease, Pick's disease, progressive supranuclear palsy and corticobasal degeneration. Acta Neuropathol. 104, 583-591.
Ferrer, I., Barrachina, M., Tolnay, M., Rey, M.J., Vidal, N., Carmona, M., Blanco, R., Puig, B., 2003. Phosphorylated protein kinases associated with neuronal and glial tau deposits in argyrophilic grain disease. Brain Pathol. 13, 62-78.

Ferrer, I., Hernandez, I., Boada, M., Llorente, A., Rey, M.J., Cardozo, A., Ezquerra, M., Puig, B., 2003. Primary progressive aphasia as the initial manifestation of corticobasal degeneration and unusual tauopathies. Acta Neuropathol. 106, 419-135.

Ferrer, I., Pastor, P., Rey, M.J., Muñoz, E., Puig, B., Pastor, E., Oliva, R., Tolosa, E., 2003. Tau phosphorylation and kinase activation in familial tauopathy linked to deln296 mutation. Neuropathol. Appl. Neurobiol. 29, 23-34.

Ferrer, I., Santpere, G., van Leeuwen, F.W., 2008. Argyrophilic grain disease. Brain 146, 1640-1651.

Ferrer, I., López-Gonzalez, I., Carmona, M., Dalfó, E., Pujol, A., Martínez, A., 2012. Neurochemistry and the non-motor aspects of PD. Neurobiol. Dis. 46, 508-526.

Ferrer, I., López-González, I., Carmona, M., Arregui, L., Dalfó, E., Torrejón-Escribano, B., Diehl, R., Kovacs, G.G., 2014. Glial and neuronal tau pathology in tauopathies: characterization of disease-specific phenotypes and tau pathology progression. J. Neuropathol. Exp. Neurol. 73, 81-97.

Ferrer, I., Aguiló García, M., López González, I., Diaz Lucena, D., Roig Villalonga, A., Carmona, M., Llorens, F., Garcia-Esparcia, P., Martinez-Maldonado, A, Frau Mendez, M., Torrejón Escribano, B., Bech Serra, J.J., Sabido, E., de la Torre Gómez, C., del Rio, J.A., 2018. Aging-related tau astrogliopathy (ARTAG): not only tau phosphorylation in astrocytes. Brain Pathol. https://doi.org/10.1111/bpa.12593, (Epub ahead of print).

Ffrench-Constant, C, Colognato, H., Franklin, R.J., 2004. Neuroscience. The mysteries of myelin unwrapped. Science 304, 688-689.

Fillon, G., Kahle, P.J., 2005. Synuclei transgenic mice: relevance to multiple system atrophy. Mov. Dis. 20 (Suppl. 12), S564-66.

Firbank, M.J., Watson, R., Mak, E., Aribisala, B., Barber, R., Colloby, S.J., He, J., Blamire, A.M., O'Brien, J.T., 2016. Longitudinal diffusion tensor imaging in dementia with Lewy bodies and Alzheimer's disease. Parkinsonism Relat. Disord. 24, 76-80.

Fitzner, D., Schneider, A., Kippert, A., Mobius, W., Willig, K.I., Hell, S.W., Bunt, G., Gaus, K., Simons, M., 2006. Myelin basic protein-dependent plasma membrane reorganization in the formation of myelin. EMBO J. 25 (2006), 5037-5048.

Fitzpatrick, J.M., Anderson, R.C., McDermott, K.W., 2015. MicroRNA: key regulators of oligodendrocyte development and pathobiology. Int. J. Biochem. Cell Biol. 65, 134-138.

Flabeau, O., Meissner, W.G., Ozier, A., Berger, P., Tison, F., Fernagut, P.O., 2014. Breathing variability and brainstem serotonergic loss in a genetic model of multiple system atrophy. Mov. Disord. 29, 388-395.

Fogarty, M., Richardson, W.D., Kessaris, N., 2005. A subset of oligodendrocytes generated from radial glia in the dorsal spinal cord. Development 132, 1951-1959.

Frigerio, R., Fiujishiro, H., Ahn, T.B., Josephs, K.A., Maraganone, D.M., DellDonne, A., Parisi, J.E., Klos, K.J., Boeve, B.F., Dickson, D.W., Ahlskog, J.E., 2011. Incidental Lewy body disease: do some cases represent a preclinical stage of dementia with Lewy bodies?. Neurobiol. Aging 32, 857-863.

Fruttiger, M.D., Montag, D., Schachner, M., Martini, R., 1995. Crucial role for the myelin-associated glycoprotein in the maintenance of axon-myelin integrity. Eur. J. Neurosci. 7, 511-515.

Fu, Y.J., Nishihira, Y., Kuroda, S., Toyoshima, Y., Ishihara, T., Shinozaki, M., Miyashita, A., Piao, Y.S., Tan, C.F., Tani, T., Koike, R., Iwanaga, K., Tsujihata, M., Onodera, O., Kuwano, R., Nishizawa, M., Kakita, A., Ikeuchi, T., Takahashi, H., 2010. Sporadic four-repeat tauopathy with frontotemporal lobar degeneration, Parkinsonism, and motor neuron disease: a distinct clinicopathological and biochemical disease entity. Acta Neuropathol. 120, 21-32.

Fujiwara, H., Hasegawa, M., Dohmae, N., Kawashima, A., Masliah, E., Goldberg, M.S., Shen, J., Takio, K., Iwatsubo, T., 2002. $\alpha$-synuclein is phosphorylated in synucleinopathy lesions. Nat. Cell Biol. 4, 160-164.

Fumagalli, M., Daniele, S., Lecca, D., Lee, P.R., Parravicini, C., Fields, R.D., Rosa, P., Antonucci, F., Verderio, C., Trincavelli, M.L., Bramanti, P., Martini, C., Abbracchio, M.P., 2011. Phenotypic changes, signaling pathway, and functional correlates of GPR17-expressing neural precursor cells during oligodendrocyte differentiation. J. Biol. Chem. 286, 10593-10604.

Funfschilling, U., Supplie, L.M., Mahad, D., Boretius, S., Saab, A.S., Edgar, J., Brinkmann, B.G., Kassmann, C.M., Tzvetanova, I.D., Möbius, W., Diaz, F., Meijer, D., Suter, U., Hamprecht, B., Sereda, M.W., Moraes, C.T., Frahm, J., Goebbels, S., Nave, K.A., 2012 Glycolytic oligodendrocytes maintain myelin and long-term axonal integrity. Nature 485, 517-521.

Gagyi, E., Kormos, B., Castellanos, K.J., Valyi-Nagy, K., Korneff, D., LoPresti, P., Woltjer, R., Valyi-Nagy, T., 2012. Decreased oligodendrocyte nuclear diameter in Alzeimer's disease and Lewy body dementia. Brain Pathol. 22, 803-810.

Gai, W., Power, J., Blumbergs, P., Culvenor, J., Jensen, P., 1999. $\alpha$-synuclein immunoisolation of glial inclusions from multiple system atrophy brain tissue reveals multiprotein components. J. Neurochem. 73, 2093-2100.

Gai, W.P., Pountney, D.L., Power, J.H., Li, Q.X., Culvenor, J.G., McLean, C.A., Jensen, P.H., Blumbergs, P.C., 2003. $\alpha$-synuclein fibrils constitute 
the central core of oligodendroglial inclusion filaments in multiple system atrophy. Exp. Neurol. 181, 68-78.

Gambetti, P., Cali, I., Notari, S., Kong, Q., Zou, W.Q., Surewicz, W.K., 2011. Molecular biology and pathology of prion strains in sporadic human prion diseases. Acta Neuropathol. 121, 79-90.

Garcia-Fresco, G.P., Sousa, A.D., Pillai, S.S., Moy, J.N., Crawley, L., Tessarollo, J.L., Dupree, J.L., Bhat, M.A., 2006. Disruption of axoglial junctions causes cytoskeletal disorganization and degeneration of Purkinje neurons axons. Proc. Natl. Acad. Sci. U. S. A. $103,5137-5142$.

Gelpi, E., Cullel, F., Navarro-Otano, J., Lladó, A., 2013. Globular glial-like inclusions in a patient with advanced Alzheimer's disease. Acta Neuropathol. 126, 155-157.

Ghetti, B., Tagliavini, F., Kovacs, G.G., Piccardo, P., 2011. Gerstmann-straüssler-scheinker. In: Dickson, DW, Weller, RO (Eds.), Neurodegeneration: the Molecular Pathology of Dementia and Movement Disorders, second edition, Willey-Blackwell, Chichester, West Sussex, pp. 364-377.

Ghetti, B., Wszolek, Z.K., Boeve, B.F., Spina, S., Goedert, M., 2011. Frontotemporal dementia and parkinsonism linked to chromosome 17. In: Dickson, DW, Weller, RO (Eds.), Neurodegeneration: the Molecular Pathology of Dementia and Movement Disorders, second edition, Willey-Blackwell, Chichester, West Sussex, pp. 110-134.

Ghiani, C.A., Eisen, A.M., Yuan, X., DePinho, R.A., McBain, C.J., Gallo, V., 1999. Neurotransmitter receptor activation triggersp 27 (Kip1) and p21(CIP1) accumulation and G1 cell cycle arrest in oligodendrocyte progenitors. Development 12, 1077-1090.

Ghosh, A., Manrique-Hoyos, N., Voigt, A., Schulz, J.B., Kreutzfeldt, M., Merkler, D., Simons, M., 2011. Targeted ablation of oligodendrocytes triggers axonal damage. PLoS One 6, e22735.

Giaccone, G., 2015. The existence of primary age-related tauopathy suggests that not all the cases with early Braak stages of neurofibrillary pathology are Alzheimer's disease. J. Alzheimers Dis. 48, 919-921.

Giaccone, G., Marcon, G., Mangieri, M., Morbin, M., Rossi, G., Fetoni, V., Patriarca, C., Catania, M., Di Fede, G., Tagliavini, F., Merlin, M., 2008. Atypical tauopathy with massive involvement of the white matter. Neuropathol. Appl. Neurobiol. 34, 468-472.

Giasson, B.I., Duda, J.E., Murray, I.V., Chen, Q., Souza, J.M., Hurtig, H.I., Ischiropoulos, H., Trojanowski, J.Q., Lee, V.M., 2000. Oxidative damage linked to neurodegeneration by selective alpha-synuclein nitration in synucleinopathy lesions. Science 290, 985-989.

Giasson, B.I., Forman, M.S., Higuchi, H., Ll, Golbe, Graves, C.L., Kotzbauer, P.T., Trojanowski, J.Q., Lee, V.M., 2003. Initiation and synergistic fibrillization of tau and $\alpha$-synuclein. Science 300, 636-640.

Gibson, E.M., Purger, D., Mount, C.W., Goldstein, A.K., Lin, G.L., Wood, L.S., Inema, I., Miller, S.E., Bieri, G., Zuchero, J.B., Barres, B.A., Woo, P.J., Vogel, H., Monje, M., 2014. Neuronal activity promotes oligodendrogenesis and adaptive myelination in the mammalian brain. Science 344, 1252304.

Giera, S., Deng, Y., Luo, R., Ackerman, S.D., Mogha, A., Monk, K.R., Ying, Y., Jeong, S.-J., Makinodan, M., Bialas, A.R., Chang, B.S., Stevens, B., Corfas, G., Piao, X., 2015. The adhesion G protein-coupled receptor GPR56 is a cell-autonomous regulator of oligodendrocyte development. Nat. Commun. 6 (6121).

Goedert, M., Eisenberg, D.S., Crowther, R.A., 2017. Propagation of tau aggregates and neurodegeneration. Annu. Rev. Neurosci. 40, 189-210.

Gotow, T., Leterrier, J.F., Ohsawa, Y., Watanabe, T., Isahara, K., Shibata, R., Ikenaka, K., Uchiyama, Y., 1999. Abnormal expression of neurofilament proteins in dysmyelinating axons located in the central nervous system of jimpy mutant mice. Eur. J. Neurosci. 11, 3893-3903.

Götz, J., Tolnay, M., Barmettler, R., Chen, F., Probst, A., Nitsch, R.M., 2001. Oligodendroglial tau filament formation in transgenic mice expressing G272V tau. Eur. J. Neurosci. 13, 2131-2140.

Gouw, A.A., Seewann, A., Vrenken, H., van der Flier, W.M., Rozemuller, J.M., Barkhof, F., Scheltens, P., Geurts, J.J., 2008. Heterogeneity of white matter hyperintensities in Alzheimer's disease: post-mortem quantitative MRI and neuropathology. Brain 131, 3286-3298.

Gow, A., Southwood, C.M., Li, J.S., Pariali, M., Riordan, G.P., Brodie, S.E., Danias, J., Bronstein, J.M., Kachar, B., Lazzarini, R.A., 1999. CNS myelin and sertoli cell tight junction strands are absent in Osp/claudin-11 null mice. Cell 99, 649-659.

Grad, L.I., Fernando, S.M., Cashman, N.R., 2015. From molecule to molecule and cell to cell: prion-like mechanisms in amyotrophic lateral sclerosis. Neurobiol. Dis. 77, $257-265$

Graff-Radford, J., Josephs, K.A., Parisi, J.E., Dickson, D.W., Giannini, C., Boeve, B.F., 2016. Globular glial tauopathy presenting as semantic variant PPA. JAMA Neurol. 73, $123-125$.

Gravel, M., Peterson, J., Yong, V.W., Kottis, V., Trapp, B., Braun, P.E., 1996. Overexpression of 20,30-cyclic nucleotide 30-phosphodiesterase in transgenic mice alters oligodendrocyte development and produces aberrant myelination. Mol. Cell. Neurosci. 7, 453-466.

Gregg, C., Shikar, V., Larsen, P., Mak, G., Chojnacki, A., Yong, V.W., Weiss, S., 2007. White matter plasticity and enhanced remyelination in the maternal CNS. J. Neurosci. 27, 1812-1823.

Griffiths, I.R., Duncan, I.D., McCulloch, M., Harvey, M.J., 1981. Shaking pups: a disorder of central myelination in the Spaniel dog. Part 1. Clinical, genetic and light-microscopical observations. J. Neurol. Sci. 50, 423-433.

Griffiths, I., Klugmann, M., Anderson, T., Yool, D., Thomson, C., Schwab, M.H., Schneider, A., Zimmermann, F., McCulloch, M., Nadon, N., Nave,
K.A., 1998. Axonal swellings and degeneration in mice lacking the major proteolipid of myelin. Science 280, 1610-1613.

Griggs, R.B., Yermakov, L.M., Susuki, K., 2017. Formation and disruption of functional domains in myelinated CNS axons. Neurosci. Res. 116, 77-87.

Grinberg, L.T., Heinsen, H., 2009. Argyrophilic grain disease: an update about a frequent cause of dementia. Dement. Neuropsychol. 3, 2-7.

Grinberg, L.T., Wang, X., Wang, C., Sohn, P.D., Theofilas, P., Sidhu, M., Arevalo, J.B., Heinsen, H., Huang, E.J., Rosen, H., Miller, B.L., Gan, L., Seeley, W.W., 2013. Argyrophilic grain disease differs from other tauopathies by lacking tau acetylation. Acta Neuropathol. 125, 581-593.

Guo, F., Maeda, Y., Ma, J., Xu, J., Horiuchi, M., Miers, L., Vaccarino, F., Pleasure, D., 2010. Pyramidal neurons are generated from oligodendroglial progenitor cells in adult piriform cortex. J. Neurosci. 30, 12036-12049.

Guo, F., Lang, J., Sohn, J., Hammond, E., Chang, M., Pleasure, D., 2015. Canonical Wnt signaling in the oligodendroglial lineage - puzzles remain. Glia 63, 1671-1693.

Guo, J.L., Narasimhan, S., Changolkar, L., He, Z., Stieber, A., Zhang, B., Gathagan, R.J., Iba, M., McBride, J.D., Trojanowski, J.Q., Lee, V.M.Y., 2016. Unique pathological tau conformers from Alzheimer's brains transmit tau pathology in nontransgenic mice. J. Exp. Med. 213, 2635-2654.

Gyllensten, L, Malmfors, T., 2009. Myelination of the optic nerve, its dependence on visual function: a quantitative investigation in mice. J. Embryol. Exp. Morphol. 11, 255-256.

Habib, N., Li, Y., Heidenreich, M., Swiech, L., Avraham-Davidi, I., Trombetta, J.J., Hession, C., Zhang, F., Regev, A., 2016. Div-seq: single-nucleus RNA-seq reveals dynamics of rare adult newborn neurons. Science 353, 925-928.

Habib, N., Avraham-Davidi, I., Basu, A., Burks, T., Shekhar, K., Hofree, M., Choudhury, S.R., Aguet, F., Gelfand, E., Ardlie, K., Ardlie, K., Wetz, D.A., Rozenblatt-Rosen, O. Zhang, F, Regev, A., 2017. Massively parallel single-nucleus RNA-seq with dronc-seq. Nat. Methods 14, 955-958.

Hachinski, V.C., Potter, P., Merskey, H., 1987. Leuko-araiosis. Arch. Neurol. 44, 21-23.

Halliday, G.M., Holton, J.L., Revesz, T., Dickson, D.W., 2011. Neuropathology underlying clinical variability in patients with synucleinopathies. Acta Neuropathol. 122, 187-204.

Halliday, G., Bigio, E.H., Cairns, N.J., Neumann, M., Mackenzie, I.R., Mann, D.M., 2012. Mechanisms of disease in frontotemporal lobar degeneration: gain of function versus loss of function effects. Acta Neuropathol. 124, 373-382.

Harauz, G., Ladizhansky, V., Boggs, J.M., 2009. Structural polymorphism and multifunctionality of myelin basic protein. Biochemistry 48, 8094-8104.

Harris, J.J., Attwell, D., 2012. The energetics of CNS white matter. J. Neurosci. 32, 356-371.

Hart, I.K., Richardson, W.D., Heldin, C.H., Westermark, B., Raff, M.C., 1989. PDGF receptors on cells of the oligodendrocyte-type-2 astrocyte (O-2A) cell lineage. Development 105, 595-603.

Hartline, D.K., 2008. What is myelin?. Neuron Glia Biol. 4, 153-163.

Hartline, D.K., Colman, D.R., 2007. Rapid conduction and the evolution of giant axons and myelinated fibers. Curr. Biol. 17, R29-R35.

Hasegawa, M., Fujiwara, H., Nonaka, T., Wakabayashi, K., Takahashi, H., VM-Y, Lee, Trojanowski, J.Q., Mann, D., Iwatsubo, T., 2002. Phosphorylated $\alpha$-synuclein is ubiquitinated in $\alpha$-synucleinopathy lesions. J. Biol. Chem. 277, 49071-49076.

Hasegawa, M., Arai, T., Nonaka, T., Kametani, F., Yoshida, M., Hashizume, Y., Beach, T.G., Buratti, E., Baralle, F., Morita, M., Nakano, I., Oda, T., Tsuchiya, K., Akiyama, H., 2008. Phosphorylated TDP-43 in frontotemporal lobar degeneration and amyotrophic lateral sclerosis. Ann. Neurol. 64, 60-70.

Hawkins, V, Butt, A., 2013. TASK-1 channels in oligodendrocytes: a role in ischemia mediated disruption. Neurobiol. Dis. 55, 87-94.

Head, M.W., Ironside, J.W., Ghetti, B., Jeffrey, M., Piccardo, P., Will, R., 2015. Prion diseases. In: Love, S, Budka, H, Ironside, J, Perry, A (Eds.), Greenfield'S Neuropathology, ninth edition CRC Press, Boca Raton, Florida, pp. 1016-1086.

Higashi, S., Iseki, E., Yamamoto, R., Minegishi, M., Hino, H., Fujisawa, K., Togo, T., Katsuse, O., Uchikado, H., Furukawa, Y., Kosaka, K., Arai, H., 2007. Concurrence of TDP-43, tau and $\alpha$-synuclein pathology in brains of Alzheimer's disease and dementia with Lewy bodies. Brain Res. 1184, 284-294.

Higuchi, M., Ishihara, T., Zhang, B., Hong, M., Andreadis, A., Trojanowski, J., Lee, V.M., 2002. Transgenic mouse model of tauopathies with glial pathology and nervous system degeneration. Neuron 35, 433-446.

Higuchi, M., Zhang, B., Forman, M.S., Yoshiyama, Y., Trojanowski, J.Q., Lee, V.M., 2005. Axonal degeneration induced by targeted expression of mutant human tau in oligodendrocytes of transgenic mice that model glial tauopathies. J. Neurosci. 25, 9434-9343.

Hildebrand, C., 1971. Ultrastructural and light-microscopic studies of the developing feline spinal cord white matter. I. The nodes of Ranvier. Acta Physiol. Scand. (Suppl. 364), 81-109.

Hildebrand, C., 1971. Ultrastructural and light-microscopic studies of the nodal region in large myelinated fibres of the adult feline spinal cord white matter. Acta Physiol. Scand. (Suppl. 364), 43-79.

Hildebrand, C., Remahl, S., Persson, H., Bjartmar, C., 1993. Myelinated nerve fibres in the CNS. Prog. Neurobiol. 40, 319-384. 
Hill, R.A., Patel, K.D., Medved, J., Reiss, A.M., Nishiyama, A., 2013. NG2 cells in white matter but not gray matter proliferate in response to PDGF. J. Neurosci. 33, 14558-14566.

Hill, R.A., Patel, K.D., Goncalves, C.M., Grutzendler, J., Nishiyama, A., 2014. Modulation of oligodendrocyte generation during a critical temporal window after NG2 cell division. Nat. Neurosci. 17, 1518-1527.

Hines, J.H., Ravanelli, A.M., Schwindt, R., Scott, E.K., Appel, B., 2015. Neuronal activity biases axon selection for myelination in vivo. Nat. Neurosci. 18, 683-689.

Hirrlinger, J., Nave, K.A., 2014. Adapting brain metabolism to myelination and long-range signal transduction. Glia 62, 1749-1761.

Hishikawa, N., Niwa, J., Doyu, M., Ito, T., Ishigaki, S., Hashizume, Y., Sobue, G., 2003. Dorfin localizes to the ubiquitylated inclusions in Parkinson's disease, dementia with Lewy bodies, multiple system atrophy, and amyotrophic lateral sclerosis. Am. J. Pathol. 163, 609-619.

Hochgerner, H., Lönnerberg, P., Hodge, R., Mikes, J., Heskol, A., Hubschle, H., Lin, P., Picelli, S., Manno, G.L., Ratz, M., Dunne, J., Husain, S., Lein, E., Srinivasan, M., Zeisel, A., Linnarsson, S., 2017. Strt-seq-2i: dual-index 50 single cell and nucleus rna-seq on an addressable microwell array. Sci. Rep. 7, 126268.

Holland, C.M., Smith, E.E., Csapo, I., Gurol, M.E., Brylka, D.A., Killiany, R.J., Blacker, D., Albert, M.S., Guttmann, C.R., Greenberg, S.M., 2008. Spatial distribution of white-matter hyperintensities in Alzheimer disease, cerebral amyloid angiopathy, and healthy aging. Stroke 39, 1127-1133.

Holler, C.J., Davis, P.R., Beckett, T.L., Platt, T.L., Webb, R.L., Head, E., Murphy, M.P., 2014. Bridging integrator 1 (BIN1) protein expression increases in the Alzheimer's disease brain and correlates with neurofibrillary tangle pathology. J. Alzheimers Dis. 42, $1221-1227$

Holton, J.L., Lees, A.J., Revesz, T., 2011. Multiple system atrophy. In: Dickson, DW, Weller, RO (Eds.), Neurodegeneration: the Molecular Pathology of Dementia and Movement Disorders, second edition Willey-Blackwell, Chichester, West Sussex, pp. 242-252.

Honjo, Y., Shirakashi, Y., Kawamoto, Y., Akiguchi, I., 2008. Anti-DARPP32 antibody-immunopositive inclusions in the brain of patients with multiple system atrophy. Clin. Neuropathol. 27, 309-316.

Honjo, Y., Ito, H., Horibe, T., Takahashi, R., Kawakami, K., 2011. Protein disulfide isomerase immunopositive glial cytoplasmic inclusions in patients with multiple system atrophy. Int. J. Neurosci. 121, 543-550.

Honjyo, Y., Kawamoto, Y., Nakamura, S., Nakano, S., Akiguchi, I., 2001. P39 immunoreactivity in glial cytoplasmic inclusions in brains with multiple system atrophy. Acta Neuropathol. 101, 190-194.

Horner, P.J., Power, A.E., Kempermann, G., Kuhn, H.G., Palmer, T.D., Winkler, J., Thal, L.J., Gage, F.H., 2000. Proliferation and differentiation of progenitor cells throughout the intact adult rat spinal cord. J. Neurosci. 20, 2218-2228.

Hortobágyi, T., Cairns, N.J., 2015. Amyotrophic lateral sclerosis and frontotemporal lobar degeneration. In: Kovacs, GG (Ed.), Neuropathology of Neurodegenerative Diseases: a Practical Guide. Cambridge University Press, Cambridge, pp. 209-248.

Hosokawa, M., Kondo, H., Serrano, G.E., Beach, T.G., Robinson, A.C., Mann, D.M., Akiyama, H., Hasegawa, M., Arai, T., 2017. Accumulation of multiple neurodegenerative disease-related proteins in familial frontotemporal lobar degeneration associated with granulin mutation. Sci. Rep. 7, 1513.

Hoy, A.R., Ly, M., Carlsson, C.M., Okonkwo, O.C., Zetterberg, H., Blennow, K., Sager, M.A., Asthana, S., Johnson, S.C., Alexander, A.L., Bendlin, B.B., 2017. Microstructural white matter alterations in preclinical Alzheimer's disease detected using free water elimination diffusion tensor imaging. PLoS One 12, e0173982.

Huang, N., Niu, J., Feng, Y., Xiao, L., 2015. Oligodendroglial development: new roles for chromatin accessibility. Neuroscientist 21, 579-588.

Hughes, E.G., Kang, S.H., Fukaya, M., Bergles, D.E., 2013. Oligodendrocyte progenitors balance growth with self-repulsion to achieve homeostasis in the adult brain. Nat. Neurosci. 16, 668-676

Ikeda, K., Akiyama, H., Kondo, H., Arai, T., Arai, N., Yagishita, S., 1995. Numerous glial fibrillary tangles in oligodendroglia in cases of subacute sclerosing panencephalitis with neurofibrillary tangles. Neurosci. Lett. 194, 133-135.

Ikeda, K., Akiyama, H., Kondo, H., Haga, C., 1995. A study of dementia with argyrophilic grains. Possible cytoskeletal abnormality in dendrospinal portion of neurons and oligodendroglia. Acta Neuropathol. 89, 409-414.

Ikeda, K., Akiyama, H., Arai, T., Nishimura, T., 1998. Glial tau pathology in neurodegenerative diseases: their nature and comparison with neuronal tangles. Neurobiol. Aging 19 (Suppl. 1), S85-9.

Ince, P.G., 2011. Dementia with lewy bodies and and pakinson's disease with dementia. In: Dickson, DW, Weller, RO (Eds.), Neurodegeneration: the Molecular Pathology of Dementia and Movement Disorders, second edition Willey-Blackwell, Chichester, West Sussex, pp. 224-237.

Ince, P.G., Highley, J.R., Kirby, J., Wharton, S.B., Takahashi, H., Strong, M.J., Shaw, P.J., 2011. Molecular pathology and genetic advances in amyotrophic lateral sclerosis: an emerging molecular pathway and the significance of glial pathology. Acta Neuropathol. 122, 657-671.

Ince, P.G., Highley, J.R., Wharton, S.B., 2015. Motor neuron disorders. In: Love, S, Budka, H, Ironside, J, Perry, A (Eds.), Greenfield'S Neuropathology, ninth edition CRC Press, Boca Raton, Florida, pp. 817-857.

Inoue, M., Yagishita, S., Ryo, M., Hasegawa, K., Amano, N., Matsushita, M., 1997. The distribution and dynamic density of oligodendroglial cyto- plasmic inclusions (GCIs) in multiple system atrophy: a correlation between the density of GCIs and the degree of involvement of striatonigral and olivopontocerebellar systems. Acta Neuropathol. 93, 585-591.

Irwin, D.J., Cohen, T.J., Grossman, M., Arnold, S.E., McCarty-Wood, E., Van Deerlin, V.M., Lee, V.M., Trojanowski, J.Q., 2013. Acetylated tau neuropathology in sporadic and hereditary tauopathies. Am. J. Pathol. 183, 344-351.

Iseki, E., Matsumura, T., Marui, W., Hino, H., Odawara, T., Sugiyama, N., Suzuki, K., Sawada, H., Arai, T., Kosaka, K., 2001. Familial frontotemporal dementia and parkinsonism with a novel $\mathrm{N} 296 \mathrm{H}$ mutation in exon 10 of the tau gene and a widespread tau accumulation in the glial cells. Acta Neuropathol. 102, 285-292.

Ishibashi, T., Dakin, K.A., Stevens, B., Lee, P.R., Kozlov, S.V., Stewart, C.L., Fields, R.D., 2006. Astrocytes promote myelination in response to electrical impulses. Neuron 49, 823-832.

Ishii, T., Kawakami, E., Endo, K., Misawa, H., Watabe, K., 2017. Formation and spreading of TDP-43 aggregates in cultured neuronal and glial cells demonstrated by time-lapse imaging. PLoS One 12, e0179375.

Iwata, A., Miura, S., Kanazawa, I., Sawada, M., Nukina, N., 2001. $\alpha$-synuclein forms a complex with transcription factor Elk-1. J. Neurochem. 77, 239-252.

Jahn, O., Tenzer, S., Werner, H.B., 2009. Myelin proteomics: molecular anatomy of an insulating sheath. Mol. Neurobiol. 40, 55-72.

Jakovcevski, I., Filipovic, R., Mo, Z., Rakic, S., Zecevic, N., 2009. Oligodendrocyte development and the onset of myelination in the human fetal brain. Front. Neuroanat. 3, 5 .

Jarjour, A.A., Manitt, C., Moore, S.W., Thompson, K.M., Yuh, S.J., Kennedy, T.E., 2003. Netrin-1 is a chemorepellent for oligodendrocyte precursor cells in the embryonic spinal cord. J. Neurosci. 23, 3735-3744.

Jeffrey, M., González, L., Simmons, M.M., Hunter, N., Martin, S., McGovern, G., 2017. Altered trafficking of abnormal prion protein in atypical scrapie: prion protein accumulation in oligodendroglial inner mesaxons. Neuropathol. Appl. Neurobiol. 43, 215-226.

Jellinger, K.A., 1998. Dementia with grains (argyrophilic grain disease). Brain Pathol. 8, 377-386.

Jellinger, K., 2011. Parkinson's disease. In: Dickson, DW, Weller, RO (Eds.), Neurodegeneration: the Molecular Pathology of Dementia and Movement Disorders, second edition Willey-Blackwell, Chichester, West Sussex, pp. 194-223.

Jellinger, K., 2012. Unusual tau in MSA. Neuropathology 32, 110-111.

Jellinger, K.A., 2018. Multiple system atrophy: an oligodendroglioneural synucleinopathy. J. Alzheimers Dis. 62, 1141-1179.

Jellinger, K.A., Bancher, C., 1998. Senile dementia with tangles (tangle predominant form of senile dementia). Brain Pathol. 8, 367-376.

Jellinger, K.A., Lantos, P.L., 2010. Papp-Lantos inclusions and the pathogenesis of multiple system atrophy: an update. Acta Neuropathol. 119, 657-667.

Jellinger, K.A., Seppi, K., Wenning, G.K., 2005. Grading of neuropathology in multiple system atrophy: proposal for a novel scale. Mov. Disord. 20 (Suppl. 12), S29-36.

Jellinger, K.A., Alafuzoff, I., Attems, J., Beach, T.G., Cairns, N.J., Crary, J.F., Dickson, D.W., Hof, P.R., Hyman, B.T., Jack Jr, C.R., Jicha, G.A., Knopman, D.S., Kovacs, G.G. Mackenzie, I.R., Masliah, E., Montine, T.J., Nelson, P.T., Schmitt, F., Schneider, J.A., Serrano-Pozo, A., Thal, D.R., Toledo, J.B., Trojanowski, J.Q., Troncoso, J.C., Vonsattel, J.P., Wisniewski, T., 2015. PART, a distinct tauopathy, different from classical sporadic Alzheimer disease. Acta Neuropathol. 129, 757-762.

Joki, H., Higashiyama, Y., Nakae, Y., Kugimoto, C., Doi, H., Kimura, K., Kishida, H., Ueda, N., Nakano, T., Takahashi, T., Koyano, S., Takeuchi, H., Tanaka, F., 2018. White matter hyperintensities on MRI in dementia with Lewy bodies, Parkinson's disease with dementia, and Alzheimer's disease. J. Neurol. Sci. 385, 99-104.

Josephs, K.A., Katsuse, O., Beccano-Kelly, D.A., Lin, W.L., Uitti, R.J., Fujino, Y., Boeve, B.F., Hutton, M.L., Baker, M.C., Dickson, D.W., 2006. Atypical progressive supranuclear palsy with corticospinal tract degeneration. J. Neuropathol. Exp. Neurol. 65, 396-405.

Kahle, P.J., NeumannM, Ozmen L., Muller, V., Jacobsen, H., Spooren, W., Fuss, B., Mallon, B., Macklin, W.B., Fujiwara, H., Hasegawa, M., Iwatsubo, T., Kretzschmar, H.A., Haass, C., 2002. Hyperphosphorylation and insolubility of $\alpha$-synuclein in transgenic mouse oligodendrocytes. EMBO Rep. 3, 583-588.

Kahlson, M.A., Colodner, K.J., 2016. Glial tau pathology in tauopathies: functional consequences. J. Exp. Neurosci. 9, 43-50.

Kalaria, R.N., Premkumar, D.R., Pax, A.B., Cohen, D.L., Lieberburg, I., 1996. Produc tion and increased detection of amyloid beta protein and amyloidogenic fragments in brain microvessels, meningeal vessels and choroids plexus in Alzheimer's disease. Mol. Brain Res. 35, 58-68.

Kalaria, R., Ferrer, I., Love, S., 2015. Vascular disease, hypoxia and related conditions. In: Love, S, Budka, H, Ironside, J, Perry, A (Eds.), Greenfield's Neuropathology, ninth edition CRC Press, Boca Raton, Florida, pp. 59-209.

Kalback, W., Esh, C., Castano, E.M., Rahman, A., Kojohn, T., Luehrs, D.C., Sue, L., Cisneros, R., Gerber, F., Richardson, C., Bohrmann, B., Walker, D.G., Beach, T.G., Roher, A.E., 2004. Atherosclerosis, vascular amyloidosis and brain hypoperfusion in the pathogenesis of sporadic Alzheimer's disease. Neurol. Res. 26, 525-539.

Kang, S.H., Fukaya, M., Yang, J.K., Rothstein, J.D., Bergles, D.E., 2010. NG2 + CNS glial progenitors remain committed to the oligodendrocyte 
lineage in postnatal life and following neurodegeneration. Neuron 68, 668-681.

Kang, S.H., Li, Y., Fukaya, M., Lorenzini, I., Cleveland, D.W., Ostrow, L.W., Rothstein, J.D., Bergles, D.E., 2013. Degeneration and impaired regeneration of gray matter oligodendrocytes in amyotrophic lateral sclerosis. Nat. Neurosci. 16, 571-579.

Kanouchi, T., Ohkubo, T., Yokota, T., 2012. Can regional spreading of amyotrophic lateral sclerosis motor symptoms be explained by prion-like propagation?. J. Neurol. Neurosurg. Psychiatry 83, 739-745.

Káradóttir, R., Cavelier, P., Bergersen, L.H., Attwell, D., 2005. NMDA receptors are expressed in oligodendrocytes and activated in ischaemia. Nature 438, 1162-1166.

Káradóttir, R., Hamilton, N.B., Bakiri, Y., Attwell, D., 2008. Spiking and nonspiking classes of oligodendrocyte precursor glia in cns white matter. Nat. Neurosci. 11, 450-456.

Karim, S.A., Barrie, J.A., McCulloch, M.C., Montague, P., Edgar, J.M., Kirkham, D., Anderson, T.J., Nave, K.A., Griffiths, I.R., 2007. PLP overexpression perturbs myelin protein composition and myelination in a mouse model of Pelizaeus-Merzbacher disease. Glia $55,341-351$.

Kato, S., Shinozawa, T., Takikawa, M., Kato, M., Hirano, A., Awaya, A., Ohama, E., 2000. Midkine, a new neurotrophic factor, is present in glial cytoplasmic inclusions of multiple system atrophy brains. Acta Neuropathol. 100, 481-489.

Kawamoto, Y., Akiguchi, I., Nakamura, S., Budka, H., 2002. Accumulation of 14-3-3 proteins in glial cytoplasmic inclusions in multiple system atrophy. Ann. Neurol. 52, 722-731.

Kawamoto, Y., Kobayashi, Y., Suzuki, Y., Inoue, H., Tomimoto, H., Akiguchi, I., Budka, H., Martins, L.M., Downward, J., Takahashi, R., 2008. Accumulation of HtrA2/Omi in neuronal and glial inclusions in brains with $\alpha$-synucleinopathies. J. Neuropathol. Exp. Neurol. 67, 984-993.

Kawamoto, Y., Ito, H., Ihara, M., Takahashi, R., 2014. XIAP immunoreactivity in glial and neuronal cytoplasmic inclusions in multiple system atrophy. Clin. Neuropathol. 33, 76-83.

Kessaris, N., Fogarty, M., Iannarelli, P., Grist, M., Wegner, M., Richardson, W.D., 2006. Competing waves of oligodendrocytes in the forebrain and postnatal elimination of an embryonic lineage. Nat. Neurosci. 9, 173-179.

Kim, J.Y., Shen, S., Dietz, K., He, Y., Howell, O., Reynolds, R., Casaccia, P., 2010. HDAC1 nuclear export induced by pathological conditions is essential for the onset of axonal damage. Nat. Neurosci. 13, 180-189.

Kirby, B.B., Takada, N., Latimer, A.J., Shin, J., Carney, T.J., Kelsh, R.N., Appel, B., 2006. In vivo time-lapse imaging shows dynamic oligodendrocyte progenitor behavior during zebrafish development. Nat. Neurosci. 9, 1506-1511.

Kisos, H., Pukass, K., Ben-Hur, T., Richter-Landsberg, C., Sharon, R., 2012. Increased neuronal $\alpha$-synuclein pathology associates with its accumulation in oligodendrocytes in mice modeling alpha-synucleinopathies. PLoS One 7, e46817.

Klambt, C., 2009. Modes and regulation of glial migration in vertebrates and invertebrates. Nat. Rev. Neurosci. 10, 769-779.

Klein, C., Kramer, E.M., Cardine, A.M., Schraven, B., Brandt, R., Trotter, J., 2002. Process outgrowth of oligodendrocytes is promoted by interaction of fyn kinase with the cytoskeletal protein tau. J. Neurosci. 22, 698-707.

Knapp, P.E., Maderspach, K., Hauser, K.F., 1998. Endogenous opioid system in developing normal and jimpy oligodendrocytes: mu and kappa opioid receptors mediate differential mitogenic and growth responses. Glia 22, 189-201.

Knapp, P.E., Itkis, O.S., Zhang, L., Spruce, B.A., Bakalkin, G., Hauser, K.F., 2011. Endogenous opioids and oligodendroglial function: possible autocrine/paracrine effects on cell survival and development. Glia 35, 156-165.

Kneynsberg, A., Combs, B., Christensen, K., Morfini, G., Kanaan, N.M., 2017. Axonal degeneration in tauopathies: disease relevance and underlying mechanisms. Front. Neurosci. $11,572$.

Koenning, M., Jackson, S., Hay, C.M., Faux, C., Kilpatrick, T.J., Willingham, M., Emery, B., 2012. Myelin gene regulatory factor is required for maintenance of myelin and mature oligodendrocyte identity in the adult CNS. J. Neurosci. 32, 12528-12542.

Komori, T., 1999. Tau-positive glial inclusions in progressive supranuclear palsy, corticobasal degeneration and Pick's disease. Brain Pathol. 9, 663-679.

Komori, T., 2017. Pathology of oligodendroglia: an overview. Neuropathology 37, 465-474.

Konno, M., Hasegawa, T., Baba, T., Miura, E., Sugeno, N., Kikuchi, A., Fiesel, F.C., Sasaki, T., Aoki, M., Itoyama, Y., Takeda, A., 2012. Suppression of dynamin GTPase decreases $\alpha$-synuclein uptake by neuronal and oligodendroglial cells: a potent therapeutic target for synucleinopathy. Mol. Neurodegener. 7, 38.

Kotter, M.R., Li, W.W., Zhao, C., Franklin, R.J., 2006. Myelin impairs CNS remyelination by inhibiting oligodendrocyte precursor cell differentiation. J. Neurosci. 26, 328-332.

Koudelka, S., Voas, M.G., Almeida, R.G., Baraban, M., Soetaert, J., Meyer, M.P., Talbot, W.S., Lyons, D.A., 2016. Individual neuronal subtypes exhibit diversity in CNS myelination mediated by synaptic vesicle release. Curr. Biol. 26, 1447-1455.

Kovacs, G.G., 2015. Invited review: neuropathology of tauopathies: principles and practice. Neuropathol. Appl. Neurobiol. 41, 3-23.
Kovacs, G.G., 2015. Tauopathies. In: Kovacs, GG (Ed.), Neuropathology of Neurodegenerative Diseases: a Practical Guide. Cambridge University Press, Cambridge, pp. 109-148.

Kovács, G.G., László, L., Kovács, J., Jensen, P.H., Lindersson, E., Botond, G., Molnár, T., Perczel, A., Hudecz, F., Mezo, G., Erdei, A., Tirián, L., Lehotzky, A., Gelpi, E., Budka, H., Ovádi, J., 2004. Natively unfolded tubulin polymerization promoting protein TPPP/p25 is a common marker of $\alpha$-synucleinopathies. Neurobiol. Dis. 17, 155-162.

Kovács, G.G., Gelpi, E., Lehotzky, A., Höftberger, R., Erdei, A., Budka, H., Ovádi, J., 2007. The brain-specific protein TPPP/p25 in pathological protein deposits of neurodegenerative diseases. Acta Neuropathol. 113, 153-161.

Kovacs, G.G., Majtenyi, K., Spina, S., Murrell, J.R., Gelpi, E., Hoftberger, R., Fraser, G., Crowther, R.A., Goedert, M., Budka, H., Ghetti, B., 2008. White matter tauopathy with globular glial inclusions: a distinct sporadic frontotemporal lobar degeneration. J. Neuropathol. Exp. Neurol. 67, 963-975.

Kovacs, G.G., Ferrer, I., Grinberg, L.T., Alafuzoff, I., Attems, J., Budka, H., Cairns, N.J., Crary, J.F., Duyckaerts, C., Ghetti, B., Halliday, G.M., Ironside, J.W., Love, S., Mackenzie, I.R., Munoz, D.G., Murray, M.E., Nelson, P.T., Takahashi, H., Trojanowski, J.Q., Ansorge, O., Arzberger, T., Baborie, A., Beach, T.G., Bieniek, K.F., Bigio, E.H., Bodi, I., Dugger, B.N., Feany, M., Gelpi, E., Gentleman, S.M., Giaccone, G., Hatanpaa, K.J., Heale, R., Hof, P.R., Hofer, M., Hortobágyi, T., Jellinger, K., Jicha, G.A., Ince, P., Kofler, J., Kövari, E., Kril, J.J., Mann, D.M., Matej, R., McKee, A.C., McLean, C., Milenkovic, I., Montine, T.J., Murayama, S., Lee, E.B., Rahimi, J., Rodriguez, R.D., Rozemüller, A., Schneider, J.A., Schultz, C., Seeley, W., Seilhean, D., Smith, C., Tagliavini, F., Takao, M., Thal, D.R., Toledo, J.B., Tolnay, M., Troncoso, J.C., Vinters, H.V., Weis, S., Wharton, S.B., White 3rd, C.L., Wisniewski, T., Woulfe, J.M., Yamada, M., Dickson, D.W., 2016. Aging-related tau astrogliopathy (ARTAG): harmonized evaluation strategy. Acta Neuropathol. 131, 87-102.

Kovacs, G.G., Robinson, J.L., Xie, S.X., Lee, E.B., Grossman, M., Wolk, D.A., Irwin, D.J., Weintraub, D., Kim, C.F., Schuck, T., Yousef, A., Wagner, S.T., Suh, E., Van Deerlin, V.M., Lee, V.M., Trojanowski, J.Q., 2017. Evaluating the patterns of aging-related tau astrogliopathy unravels novel insights into brain aging and neurodegenerative diseases. J. Neuropathol. Exp. Neurol. 76, 270-288.

Kovacs, G.G., Kwong, L.K., Grossman, M., Irwin, D.J., Lee, E.B., Robinson, J.L., Suh, E., Van Deerlin, V.M., Lee, V.M., Trojanowski, J.Q., 2018. Tauopathy with hippocampal 4-repeat tau immunoreactive spherical inclusions: a report of three cases. Brain Pathol. 28, 274-283.

Kragh, C.L., Lund, L.B., Febbraro, F., Hansen, H.D., Wei-Ping, G., El-Agnaf, O., Richter-Landsberg, C., Jensen, P.H., 2009. $\alpha$-synuclein aggregation and Ser-129 phosphorylation-dependent cell death in oligodendroglial cells. J. Biol. Chem. 284, 10211-10222.

Kuhlbrodt, K., Herbarth, B., Sock, E., Hermans-Borgmeyer, I., Wegner, M., 1988. Sox10, a novel transcriptional modulator in glial cells. J. Neurosci. 18, 237-250.

Kukley, M., Capetillo-Zarate, E., Dietrich, D., 2007. Vesicular glutamate release from axons in white matter. Nat. Neurosci. 10, 311-320.

Kukley, M., Nishiyama, A., Dietrich, D., 2010. The fate of synaptic input to NG2 glial cells: neurons specifically downregulate transmitter release onto differentiating oligodendroglial cells. J. Neurosci. 30, 8320-8331.

Kursula, P., 2001. The current status of structural studies on proteins of the myelin sheath. Int. J. Mol. Med. 8, 475-479.

Kursula, P., 2008. Structural properties of proteins specific to the myelin sheath. Amino Acids 34, 175-185.

Kuzdas, D., Stemberger, S., Gaburro, S., Stefanova, N., Singewald, N., Wenning, G.K., 2013. Oligodendroglial $\alpha$-synucleinopathy and MSA-like cardiovascular autonomic failure: experimental evidence. Exp. Neurol. 1247, 531-536.

La Manno, G., Gyllborg, D., Codeluppi, S., Nishimura, K., Salto, C., Zeisel, A., Borm, L.E., Stott, S.R.W., Toledo, E.M., Villaescusa, J.C., Lönnerberg, P., Ryge, J., Barker, R.A., Arenas, E., Linnarsson, S., 2016. Molecular diversity of midbrain development in mouse, human, and stem cells. Cell 167, 566-580, e519.

Lake, B.B., Chen, S., Sos, B.C., Fan, J., Kaeser, G.E., Yung, Y.C., Duong, T.E., Gao, D., Chun, J., Kharchenko, P.V., Zhang, K., Integrative single-cell analysis by transcriptional and epigenetic states in human adult brain. bioRxiv 2017; 128520. Nat Biotechnol. 2017 December 11. 10.1038/nbt.4038. (Epub ahead of print)

Lappe-Siefke, C., Goebbels, S., Gravel, M., Nicksch, E., Lee, J., Braun, P.E., Griffiths, I.R., Nave, K.A., 2003. Disruption of Cnp1 uncouples oligodendroglial functions in axonal support and myelination. Nat. Genet. 33, 366-374.

Larsen, P.H., DaSilva, A.G., Conant, K., Yong, V.W., 2006. Myelin formation during development of the CNS is delayed in matrix metalloproteinase- 9 and -12 null mice. J. Neurosci. 26, 2207-2214.

Larson, V.A., Mironova, Y., Vanderpool, K.G., Waisman, A., Rash, J.E., Agarwal, A., Bergles, D.E., 2018. Oligodendrocytes control potassium accumulation in white matter and seizure susceptibility. Elife 7, e34829.

Lasiene, J., Matsui, A., Sawa, Y., Wong, F., Horner, P.J., 2009. Age-related myelin dynamics revealed by increased oligodendrogenesis and short internodes. Aging Cell 8, 201-213.

Lassmann, H., Bartsch, U., Montag, D., Schachner, M., 1997. Dying-back oligodendrogliopathy: a late sequel of myelin-associated glycoprotein deficiency. Glia 19, $104-110$. 
Lee, Y., Morrison, B.M., Li, Y., Lengacher, S., Farah, M.H., Hoffman, P.N., Liu, Y., Tsingalia, A., Jin, L., Zhang, P.W., Pellerin, L., Magistretti, P.J., Rothstein, J.D., 2012. Oligodendroglia metabolically support axons and contribute to neurodegeneration. Nature 487, 443-448.

Leey, Y.J., Baskakov, I.V., 2014. The cellular form of the prion protein guides the differentiation of human embryonic stem cells into neuron-, oligodendrocyte-, and astrocyte-committed lineages. Prion 8, 266-275.

Levine, J.M., Reynolds, R., Fawcett, J.W., 2001. The oligodendrocyte precursor cell in health and disease. Trends Neurosci. 24, 39-47.

Lewis, J., Dickson, D.W., 2016. Propagation of tau pathology: hypotheses, discoveries, and yet unresolved questions from experimental and human brain studies. Acta Neuropathol. 131, 27-48.

Leyk, J., Goldbaum, O., Noack, M., Richter-Landsberg, C., 2015. Inhibition of HDAC6 modifies tau inclusion body formation and impairs autophagic clearance. J. Mol. Neurosci. 55, 1031-1046.

Li, H., Richardson, W.D., 2016. Evolution of the CNS myelin gene regulatory program. Brain Res. 1641, 111-121.

Liberski, P.P., Yanagihara, R., Wells, G.A., Gibbs, C.J., Jr, Gajdusek, D.C., 1992. Ultrastructural pathology of axons and myelin in experimental scrapie in hamsters and bovine spongiform encephalopathy in cattle and a comparison with the panencephalopathic type of Creutzfeldt-Jakob disease. J. Comp. Pathol. 106, 383-398.

Liberski, P.P., Brown, P., Cervenakova, L., Gajdusek, D.C., 1997. Interactions between astrocytes and oligodendroglia in human and experimental Creutzfeldt-Jakob disease and scrapie. Exp. Neurol. 144, 227-234.

Lin, W.L., Lewis, J., Yen, S.H., Hutton, M., Dickson, D.W., 2003. Filamentous tau oligodendrocytes and astrocytes of transgenic mice expressing the human tau isoform with the P301L mutation. Am. J. Pathol. 162, 213-218.

Lin, S.C., Huck, J.H., Roberst, J.D., Macklin, W.B., Somogyi, P., Bergles, D.E., 2005. Climbing fiber innervation of NG2-expressing glia in the mammalian cerebellum. Neuron 46, 773-785.

Lin, W.L., Zehr, C., Lewis, J., Hutton, M., Yen, S.H., Dickson, D.W., 2005. Progressive white matter pathology in the spinal cord of transgenic mice expressing mutant (P301L) human tau. J. Neurocytol. 34, 397-410.

Lindersson, E., Lundvig, D., Petersen, C., Madsen, P., Nyengaard, J.R., Hojrup, P., Moos, T., Otzen, D., Gai, W.P., Blumbergs, P.C., Jensen, P.H., 2005. p25alpha stimulates $\alpha$-synuclein aggregation and is co-localized with aggregated $\alpha$-synuclein in $\alpha$-synucleinopathies. J. Biol. Chem. 280, 5703-5715.

Lindström, V., Gustafsson, G., Sanders, L.H., Howlett, E.H., Sigvardson, J., Kasrayan, A., Ingelsson, M., Bergström, J., Erlandsson, A., 2017. Extensive uptake of $\alpha$-synuclein oligomers in astrocytes results in sustained intracellular deposits and mitochondrial damage. Mol. Cell. Neurosci. 82, 143-156.

Ling, H., Neal, J.W., Revesz, T., 2017. Evolving concepts of chronic traumatic encephalopathy as a neuropathological entity. Neuropathol. Appl. Neurobiol. 43, 467-476.

Liu, A., Han, Y.R., Li, J., Sun, D., Ouyang, M., Plummer, M.R., Casaccia-Bonnefil, P., 2007. The glial or neuronal fate choice of oligodendrocyte progenitors is modulated by their ability to acquire an epigenetic memory. J. Neurosci. 27, 7339-7343.

Liu, Z., Hu, X., Cai, J., Liu, B., Peng, X., Wegner, M., Qiu, M., 2007. Induction of oligodendrocyte differentiation by Olig2 and Sox10: evidence for reciprocal interactions and dosage-dependent mechanisms. Dev. Biol. 302, 683-693.

Liu, J., Magri, L., Zhang, F., Marsh, N.O., Albrecht, S., Huynh, J.L., Kaur, J., Kuhlmann, T., Zhang, W., Slesinger, P.A., Casaccia, P., 2015. Chromatin landscape defined by repressive histone methylation during oligodendrocyte differentiation. J. Neurosci. 35, 352-365.

Liu, H., Yang, Y., Xia, Y., Zhu, W., Leak, R.K., Wei, Z., Wang, J., Hu, X., 2017. Aging of cerebral white matter. Ageing Res. Rev. 34, 64-76.

Liu, Z., Xu, D., Wang, S., Chen, Y., Gao, X., Jiang, L., Tang, Y., Peng, Y., 2017. Astrocytes induce proliferation of oligodendrocyte progenitor cells via connexin 47-mediated activation of the ERK/Id4 pathway. Cell Cycle 16, 714-722.

Livesey, M.R., Magnani, D., Cleary, E.M., Vasistha, N.A., James, O.T., Selvaraj, B.T., Burr, K., Story, D., Shaw, C.E., Kind, P.C., Hardingham, G.E., Wyllie, D.J., Chandran, S., 2016. Maturation and electrophysiological properties of human pluripotent stem cell-erived oligodendrocytes. Stem Cells 34, 1040-1053.

Llorens, F., Gil, V., del Río, J.A., 2011. Emerging functions of myelin-associated proteins during development, neuronal plasticity, and neurodegeneration. FASEB J. 25, 463-475.

López-González, I., Carmona, M., Arregui, L., Kovacs, G.G., Ferrer, I., 2014. $\alpha$ B-crystallin and HSP27 in glial cells in tauopathies. Neuropathology 34, 517-526.

Lowe, J, Kalaria, R., 2015. Dementia. In: Love, S, Budka, H, Ironside, J, Perry, A (Eds.), Greenfield'S Neuropathology, ninth edition CRC Press, Boca Raton, Florida, pp. 858-973.

Lu, Q.R., Yuk, D.-I., Alberta, J.A., Zhu, Z., Pawlitzky, I., Chan, J., McMahon, A.P., Stiles, C.D., Rowitch, D.H., 2000. Sonic hedgehog-regulated oligodendrocyte lineage genes encoding bHLH proteins in the mammalian central nervous system. Neuron 25, 317-329.

Ludwin, S.K., 1979. The perineuronal satellite oligodendrocyte. A role in remyelination. Acta Neuropathol. 47, 49-53.

Luyt, K., Slade, T.P., Dorward, J.J., Durant, C.F., Wu, Y., Shigemoto, R., Mundell, S.J., Váradi, A., Molnár, E., 2007. Developing oligodendro- cytes express functional $\mathrm{GABA}_{\mathrm{B}}$ receptors that stimulate cell proliferation and migration. J. Neurochem. 100, 822-840.

Mackenzie, I.R., Neumann, M., 2011. Frontotempopral lobar degeneration with TDP-43 pathology. In: Dickson, DW, Weller, RO (Eds.), Neurodegeneration: the Molecular Pathology of Dementia and Movement Disorders, second edition Willey-Blackwell, Chichester, West Sussex, pp. 393-403.

Mackenzie, I.R., Neumann, M., 2017. Fused in sarcoma neuropathology in neurodegenerative disease. Cold Spring Harb. Perspect. Med. 7 (12).

Mackenzie, I.R., Neumann, M., Bigio, E.H., Cairns, N.J., Alafuzoff, I., Kril, J., Kovacs, G.G., Ghetti, B., Halliday, G., Holm, I.E., Ince, P.G., Kamphorst, W., Revesz, T., Rozemuller, A.J., Kumar-Singh, S., Akiyama, H., Baborie, A., Spina, S., Dickson, D.W., Trojanowski, J.Q., Mann, D.M., 2009. Nomenclature for neuropathological subtypes of frontotemporal degeneration: consensus recommendations. Acta Neuropathol. 117, 15-18.

MacKenzie, I.R., Bigio, E.H., Ince, P.G., Geser, F., Neumann, M., Cairns, N.J., Kwong, L.K., Forman, M.S., Ravits, J., Stewart, H., Eisen, A., McClusky, L., Kretzschmar, H.A., Monoranu, C.M., Highley, J.R., Kirby, J., Siddique, T., Shaw, P.J., Lee, V.M., Trojanowski, J.Q., 2007. Pathological TDP-43 distinguishes sporadic amyotrophic lateral sclerosis from amyotrophic lateral sclerosis with SOD1 mutations. Ann. Neurol. 61, 427-434.

Maekawa, S., Leigh, P.N., King, A., Jones, E., Steele, J.C., Bodi, I., Shaw, C.E., Hortobagyi, T., Al-Sarraj, S., 2009. TDP-43 is consistently co-localized with ubiquitinated inclusions in sporadic and Guam amyotrophic lateral sclerosis but not in familial amyotrophic lateral sclerosis with and without SOD1mutations. Neuropathology $29672-29683$.

Magri, L., Gacias, M., Wu, M., Swiss, V.A., Janssen, W.G., Casaccia, P., 2014. c-Myc-dependent transcriptional regulation of cell cycle and nucleosomal histones during oligodendrocyte differentiation. Neuroscience 27672-27686.

Makioka, K., Yamazaki, T., Fujita, Y., Takatama, M., Nakazato, Y., Okamoto, K., 2010. Involvement of endoplasmic reticulum stress defined by activated unfolded protein response in multiple system atrophy. J. Neurol. Sci. 29760-29765.

Mandel, R.J., Marmion, D.J., Kirik, D., Chu, Y., Heindel, C., McCown, T., Gray, S.J., Kordower, J.H., 2017. Novel oligodendroglial alpha synuclein viral vector models of multiple system atrophystudies in rodents and nonhuman primates. Acta Neuropathol Commun. 5, 47.

Mangin, J.M., Li, P., Scafidi, J., Gallo, V., 2012. Experience-dependent regulation of NG2 progenitors in the developing barrel cortex. Nat. Neurosci. 151192-151194.

Marinelli, C., Bertalot, T., Zusso, M., Skaper, S.D., Giusti, P., 2016. Systematic review of pharmacological properties of the oligodendrocyte lineage. Front. Cell. Neurosci. 1027.

Marin-Husstege, M., Muggironi, M., Liu, A., Casaccia-Bonnefil, P., 2002. Histone deacetylase activity is necessary for oligodendrocyte lineage progression. J. Neurosci. 2210333-2210345.

Marques, S., Zeisel, A., Codeluppi, S., van Bruggen, D., Mendanha Falcao, A., Xiao, L., Li, H., Haring, M., Hochgerner, H., Romanov, R.A., Gyllborg, D., Muñoz Manchado, A., La Manno, G., Lönnerberg, P., Floriddia, E.M., Rezayee, F., Ernfors, P., Arenas, E., Hjerling-Leffler, J., Harkany, T., Richardson, W.D., Linnarsson, S., Castelo-Branco, G., 2016. Oligodendrocyte heterogeneity in the mouse juvenile and adult central nervous system. Science 3521326-3521329.

Martin-Lannere, S., Halliez, S., Hirsch, T., Hernández-Rapp, J., Passet, B., Tomkiewicz, C., Villa-Diaz, A., Torres, J.M., Launa, J.M., Beringue, V., Vilotte, J.L., Mouillet-Richardf, S., 2017. The cellular prion protein controls Notch signaling in neural stem/progenitor cells. Stem Cells 35754-35765.

Matsuo, A., Akiguchi, I., Lee, G.C., McGeer, E.G., McGeer, P.L., Kimura, J., 1998. Myelin degeneration in multiple system atrophy detected by unique antibodies. Am. J. Pathol. 153735-153744.

May, V.E., Ettle, B., Poehler, A.M., Nuber, S., Ubhi, K., Rockenstein, E., Winner, B., Wegner, M., Masliah, E., Winkler, J., 2014. $\alpha$-synuclein impairs oligodendrocyte progenitor maturation in multiple system atrophy. Neurobiol. Aging 352357-352368.

Mayer, J.A., Larsen, E.C., Kondo, Y., Duncan, I.D., 2011. Characterization of a PLP-overexpressing transgenic rat, a model for the connatal form of Pelizaeus-Merzbacher disease. Neurobiol. Dis. 44231-44238.

McKenzie, I.A., Ohayon, D., Li, H., de Faria, J.P., Emery, B., Tohyama, K., Richardson, W.D., 2014. Motor skill learning requires active central myelination. Science 346318-346322.

McKerracher, L., Rosen, K.M., 2015. MAG, myelin and overcoming growth inhibition in the CNS. Front. Mol. Neurosci. 851.

McTigue, D.M., Horner, P.J., Stokes, B.T., Gage, F.H., 1998. Neurotrophin-3 and brain-derived neurotrophic factor induce oligodendrocyte proliferation and myelination of regenerating axons in the contused adult rat spinal cord. J. Neurosci. 185354-185365.

Meijer, D.H., KaneMF, Mehta S., Liu, H., Harrington, E., Taylor, C.M., Stiles, C.D., Rowitch, D.H., 2012. Separated at birth? The functional and molecular divergence of OLIG1 and OLIG2. Nat. Rev. Neurosci. 13819-13831.

Menichella, D.M., Goodenough, D.A., Sirkowski, E., Scherer, S.S., Paul, D.L., 2003. Con nexins are critical for normal myelination in the CNS. J. Neurosci. 235963-235973.

Mensch, S., Baraban, M., Almeida, R., Czopka, T., Ausborn, J., El Manira, A., Lyons, D.A., 2015. Synaptic vesicle release regulates myelin sheath 
number of individual oligodendrocytes in vivo. Nat. Neurosci. 18628-18630.

Meyer, J.S., Kawamura, J., Terayama, Y., 1992. White matter lesions in the elderly. J. Neurol. Sci. 1101-1107.

Mi, S., Miller, R.H., Lee, X., Scott, M.L., Shulag-Morskaya, S., Shao, Z., Chang, J., Thill, G., Levesque, M., Zhang, M., Hession, C., Sah, D., Trapp, B.D., He, Z., Jung, V., McCoy, J.M., Pepinsky, R.B., 2005. LINGO-1 negatively regulates myelination by oligodendrocytes. Nat. Neurosci. 8745-8751.

Micheva, K.D., Wolman, D., Mensh, B.D., Pax, E., Buchanan, J., Smith, S.J., Bock, D.D., 2016. A large fraction of neocortical myelin ensheathes axons of local inhibitory neurons. Elife 5.

Micu, I., Jiang, Q., Coderre, E., Ridsdale, A., Zhang, L., Woulfe, J., Yin, X., Trapp, B.D., McRory, J.E., Rehak, R., Zamponi, G.W., Wang, W., Stys, P.K., 2006. NMDA receptors mediate calcium accumulation in myelin during chemical ischaemia. Nature 439988-439992.

Miki, Y., Tanji, K., Mori, F., Tatara, Y., Utsumi, J., Sasaki, H., Kakita, A., Takahashi, H., Fimia, G.M., Wakabayashi, K., 2018. AMBRA1, a novel $\alpha$-synuclein-binding protein, is implicated in the pathogenesis of multiple system atrophy. Brain Pathol. 2828-2842.

Miller, R.H., 2002. Regulation of oligodendrocyte development in the vertebrate CNS. Prog. Neurobiol. 67451-67467.

Miller, R.H., Mi, S., 2007. Dissecting demyelination. Nat. Neurosci. 101351-101354.

Miller, D.W., Johnson, J.M., Solano, S.M., Hollingsworth, Z.R., Standaert, D.G., Young, A.B., 2005. Absence of $\alpha$-synuclein mRNA expression in normal and multiple system atrophy oligodendroglia. J. Neural Transm. 1121613-1121624.

Mimuro, M., Yoshida, M., Miyao, S., Harada, T., Ishiguro, K., Hashizume, Y., 2010. Neuronal and glial tau pathology in early frontotemporal lobar degeneration-tau, Pick's disease subtype. J. Neurol. Sci. 290177-290182.

Min, S.W., Cho, S.H., Zhou, Y., Schroeder, S., Haroutunian, V., Seeley, W.W., Huang, E.J., Shen, Y., Masliah, E., Mukherjee, C., Meyers, D., Cole, P.A., Ott, M., Gan, L., 2010. Acetylation of tau inhibits its degradation and contributes to tauopathy. Neuron 67953-67966

Mitew, S., Hay, C.M., Peckham, H., Xiao, J., Koenning, M., Emery, B., 2014. Mechanisms regulating the development of oligodendrocytes and central nervous system myelin. Neuroscience 27629-27647.

Miyata, S., Hattori, T., Shimizu, S., Ito, A., Tohyama, M., 2015. Disturbance of oligodendrocyte function plays a key role in the pathogenesis of schizophrenia and major depressive disorder. Biomed Res. Int.492367.

Mobius, W., Cooper, B., Kaufmann, W.A., Imig, C., Ruhwedel, T., Snaidero, N., Saab, A.S., Varoqueaux, F., 2008. Electron mi croscopy of the mouse central nervous system. Methods Cell Biol. 96475-96512.

Molina, J.A., Probst, A., Villanueva, C., Jimenez-Jimenez, F.J., Madero, S., Torres, N., Bermejo, F., 1998. Primary progressive aphasia with glial cytoplasmic inclusions. Eur. Neurol. 4071-4077.

Morita, K., Sasaki, H., Fujimoto, K., Furuse, M., Tsukita, S., 1999. Claudin-11/OSP-based tight junctions of myelin sheaths in brain and Sertoli cells in testis. J. Cell Biol. 145579-145588.

Morland, C., Henjum, S., Iversen, E.G., Skrede, K.K., Hassel, B., 2007. Evidence for a higher glycolytic than oxidative metabolic activity in white matter of rat brain. Neurochem. Int. 50703-50709.

Moroni, R.F., Inverardi, F., Regondi, M.C., Pennacchio, P., Frassoni, C., 2015. Developmental expression of Kir4.1 in astrocytes and oligodendrocytes of rat somatosensory cortex and hippocampus. Int. J. Dev. Neurosci. 47198-47205.

Morrison, B.M., Lee, Y., Rothstein, J.D., 2013. Oligodendroglia metabolically support axons and maintain structural integrity. Trends Cell Biol. 23644-23651.

Moser, M., Colello, R.J., Pott, U., Oesch, B., 1995. Developmental expression of the prion protein gene in glial cells. Neuron 14509-14517.

Moshrefi-Ravasdjani, B, Dublin, P., Seifert, G., Jennissen, K., Steinhauser, C., Kafitz, K.W., Rose, C.R., 2017. Changes in the proliferative capacity of NG2 cell subpopulations during postnatal development of the mouse hippocampus. Brain Struct. Funct. 222831-222847.

Moyon, S., Dubessy, A.L., Aigrot, M.S., Trotter, M., Huang, J.K., Dauphinot, L., Potier, M.C., Kerninon, C., Melik Parsadaniantz, S., Franklin, R.J., Lubetzki, C., 2015. Demyelination causes adult CNS progenitors to revert to an immature state and express immune cues that support their migration. J. Neurosci.354-20.

Muñoz, D.G., Morris, H.R., Rossor, M., 2011. Pick's disease. In: Dickson, DW, Weller, RO (Eds.), Neurodegeneration: the Molecular Pathology of Dementia and Movement Disorders, second edition Willey-Blackwell, Chichester, West Sussex, pp. 156-164.

Murayama, S., Arima, K., Nakazato, Y., Satoh, J., Oda, M., Inose, T., 1992. Immunocytochemical and ultrastructural studies of neuronal and oligodendroglial cytoplasmic inclusions in multiple system atrophy. 2. Oligodendroglial cytoplasmic inclusions. Acta Neuropathol. 8432-8438.

Nagaishi, M., Yokoo, H., Nakazato, Y., 2011. Tau-positive glial cytoplasmic granules in multiple system atrophy. Neuropathology 31299-31305.

Nagy, J.I., Lynn, B.D., Tress, O., Willecke, K., Rash, J.E., 2011. Connexin26 expression in brain parenchymal cells demonstrated by targeted connexin ablation in transgenic mice. Eur. J. Neurosci. 34263-34271.

Nakamura, S., Kawamoto, Y., Nakano, S., Akiguchi, I., Kimura, J., 1998. Cyclin-dependent kinase 5 and mitogen-activated protein kinase in glial cytoplasmic inclusions inmultiple system atrophy. J. Neuropathol. Exp. Neurol. 57690-57698.

Nakamura, S., Kawamoto, Y., Nakano, S., Akiguchi, I., 2000. Expression of the endocytosis regulatory proteins Rab5 and Rabaptin-5 in glial cytoplasmic inclusions from brains with multiple system atrophy. Clin. Neuropathol. 1951-1956.

Nakayama, K., Suzuki, Y., Yazawa, I., 2009. Microtubule depolymerization suppresses $\alpha$-synuclein accumulation in a mouse model of multiple system atrophy. Am. J. Pathol. 1741471-1741480.

Nakayama, K., Suzuki, Y., Yazawa, I., 2012. Binding of neuronal $\alpha$-synuclein to $\beta$-III tubulin and accumulation in a model of multiple system atrophy. Biochem. Biophys. Res. Commun. 4171170-4171175.

Narasimhan, S., Guo, J.L., Changolkar, L., Stieber, A., McBride, J.D., Silva, L.V., He, Z., Zhang, B., Gathagan, R.J., Trojanowski, J.Q., Lee, V.M.Y., 2017. Pathological tau strains from human brains recapitulate the diversity of tauopathies in non-transgenic mouse brain. J. Neurosci. 3711406-3711423.

Naruse, M., Ishizaki, Y., Ikenaka, K., Tanaka, A., 2017. Origin of oligodendrocytes in mammalian forebrainsa revised perspective. J. Physiol. Sci. 67, 63-70.

Nave, K.A., 2010. Myelination and the trophic support of long axons. Nat. Rev. Neurosci. 11275-11283.

Nave, K.A., Trapp, B.D., 2008. Axon-glial signaling and the glial support of axon function. Annu. Rev. Neurosci. 31535-31561.

Nave, K.A., Werner, H.B., 2014. Myelination of the nervous systemmechanisms and functions. Annu. Rev. Cell Dev. Biol. 30503-30533.

Nedelska, Z., Schwarz, C.G., Boeve, B.F., Lowe, V.J., Reid, R.I., Przybelski, S.A., Lesnick, T.G., Gunter, J.L., Senjem, M.L., Ferman, T.J., Smith, G.E., Geda, Y.E., Knopman, D.S., Petersen, R.C., Jack Jr, C.R., Kantarci, K., 2015. White matter integrity in dementia with Lewy bodiesa voxel-based analysis of diffusion tensor imaging. Neurobiol. Aging $36,2010-2017$.

Nery, S., Wichterle, H., Fishell, G., 2001. Sonic hedgehog contributes to oligodendrocyte specification in the mammalian forebrain. Development 128527-128540.

Neumann, M., Sampathu, D.M., Kwong, L.K., Truax, A.C., Micsenyi, M.C., Chou, T.T., Bruce, J., Schuck, T., Grossman, M., Clark, C.M., McCluskey, L.F., Miller, B.L., Masliah, E., Mackenzie, I.R., Feldman, H., Feiden, W., Kretzschmar, H.A., Trojanowski, J.Q., Lee, V.M., 2006. Ubiquitinated TDP-43 in frontotemporal lobar degeneration and amyotrophic lateral sclerosis. Science 314130-314133.

Neumann, M., Kwong, L.K., Truax, A.C., Vanmassenhove, B., Kretzschmar, H.A., Van Deerlin, V.M., Clark, C.M., Grossman, M., Miller, B.L., Trojanowski, J.Q., Lee, V.M., 2007. TDP-43-positive white matter pathology in frontotemporal lobar degeneration with ubiquitin-positive inclusions. J. Neuropathol. Exp. Neurol. 66177-66183.

Neumann, M., Rademakers, R., Roeber, S., Baker, M., Kretzschmar, H.A., Mackenzie, I.R., 2009. A new subtype of frontotemporal lobar degeneration with FUS pathology. Brain1322922-132231.

Nielsen, H.M., Ek, D., Avdic, U., Orbjorn, C., Hansson, O., Netherlands Brain, B., Veerhuis, R., Rozemuller, A.J., Brun, A., Minthon, L., Wennstrom, M., 2013. NG2 cells, a new trail for Alzheimer's disease mechanisms?. Acta Neuropathol. Commun. 17.

Nishimura, T., Ikeda, K., Akiyama, H., Kondo, H., Kato, M., Li, F., Iseki, E., Kosaka, K., 1995. Immunohistochemical investigation of tau-positive structures in the cerebral cortex of patients with progressive supranuclear palsy. Neurosci. Lett. 201123-201126.

Nishimura, T., Ikeda, K., Akiyama, H., Arai, T., Kondo, H., Okochi, M., Furiya, Y., Mori, H., Oda, T., Kato, M., Iseki, E., 1997. Glial tau-positive structures lack the sequence encoded by exon 3 of the tau protein gene. Neurosci. Lett. 224169-224172.

Nishimura, A.L., Zupunski, V., Troakes, C., Kathe, C., Fratta, P., Howell, M., Gallo, J.M., Hortobágyi, T., Shaw, C.E., Rogelj, B., 2010. Nuclear import impairment causes cytoplasmic trans-activation response DNA-binding protein accumulation and is associated with frontotemporal lobar degeneration. Brain 1331763-1331771.

Noack, M., Leyk, J., Richter-Landsberg, C., 2014. HDAC6 inhibition results in tau acetylation and modulates tau phosphorylation and degradation in oligodendrocytes. Glia 62535-62547.

Noble, M., Murray, K., Stroobant, P., Waterfield, M.D., Riddle, P., 1988. Platelet-derived growth factor promotes division and motility and inhibits premature differentiation of the oligodendrocyte/type-2 astrocyte progenitor cell. Nature 333560-333562.

Nonneman, A., Robberecht, W., Van Den Bosch, L., 2014. The role of oligodendroglial dysfunction in amyotrophic lateral sclerosis. Neurodegener. Dis. Manage. 4223-4239.

Nualart-Marti, A., Solsona, C., Fields, R.D., 2013. Gap junction communication in myelinating glia. Biochim. Biophys. Acta 182869-182878.

Nunes, M.C., Roy, N.S., Keyoung, H.M., Goodman, R.R., McKhann, G., Jiang, L., Kang, J., Nedergaard, M., Goldman, S.A., 2003. Identification and isolation of multipotential neural progenitor cells from the subcortical white matter of the adult human brain. Nat. Med. 9439-9447.

Nykjaer, C.H., Brudek, T., Salvesen, L., Pakkenberg, B., 2017. Changes in the cell population in brain white matter in multiple system atrophy. Mov. Disord. 321074-321082.

Odagiri, S., Tanji, K., Mori, F., Kakita, A., Takahashi, H., Wakabayashi, K., 2012. Autophagic adapter protein NBR1 is localized in Lewy bodies and glial cytoplasmic inclusions and is involved in aggregate formation in $\alpha$-synucleinopathy. Acta Neuropathol. 124173-124186. 
Oikawa, N., Kimura, N., Yanagisawa, K., 2010. Alzheimer-type tau pathology in advanced aged nonhuman primate brains harboring substantial amyloid deposition. Brain Res. 1315137-1315149.

Okamoto, Y., Ihara, M., Urushitani, M., Yamashita, H., Kondo, T., Tanigaki, A., Oono, M., Kawamata, J., Ikemoto, A., Kawamoto, Y., Takahashi, R., Ito, H., 2011. An autopsy case of SOD1-related ALS with TDP-43 positive inclusions. Neurology 771993-771995.

Oluich, L.J., Stratton, J.A., Xing, Y.L., Ng, S.W., Cate, H.S., Sah, P., Windels, F., Kilpatrick, T.J., Merson, T.D., 2012. Targeted ablation of oligodendrocytes induces axonal pathology independent of overt demyelination. J. Neurosci. 328317-328330.

Orentas, D.M., Hayes, J.E., Dyer, K.L., Miller, R.H., 1999. Sonic hedgehog signaling is required during the appearance of spinal cord oligodendrocyte precursors. Development 1262419-1262429.

Ornelas, I.M., McLane, L., Saliu, A., Evangelou, A.V., Khandker, L., Wood, T.L., 2016. Heterogeneity in oligodendrogliais it relevant to mouse models and human disease?. J. Neurosci. Res. 94, 1421-1433.

Orthmann-Murphy, J.L., Freidin, M., Fischer, E., Scherer, S.S., Abrams, C.K., 2007. Two distinct heterotypic channels mediate gap junction coupling between astrocyte and oligodendrocyte connexins. J. Neurosci. 2713949-2713957.

Osborn, L.M., Kamphuis, W., Wadman, W.J., Hol, E.M., 2016. Astrogliosisan integral player in the pathogenesis of Alzheimer's disease. Prog. Neurobiol. 144, 121-141.

Ossola, B., Zhao, C., Compston, A., Pluchino, S., Franklin, R.J., Spillantini, M.G., 2016 Neuronal expression of pathological tau accelerates oligodendrocyte progenitor cell differentiation. Glia 64457-64471.

Ota, K., Obayashi, M., Ozaki, K., Ichinose, S., Kakita, A., Tada, M., Takahashi, H., Ando, N., Eishi, Y., Mizusawa, H., Ishikawa, K., 2014. Relocation of p25 $\alpha$ /tubulin polymerization promoting protein from the nucleus to the perinuclear cytoplasm in the oligodendroglia of sporadic and COQ2 mutant multiple system atrophy. Acta Neuropathol. Commun. 2136.

Overk, C., Rockenstein, E., Valera, E., Stefanova, N., Wenning, G., Masliah, E., 2018. Multiple system atrophyexperimental models and reality. Acta Neuropathol. 135, 33-47.

Oyanagi, K., Tsuchiya, K., Yamazaki, M., Ikeda, K., 2001. Substantia nigra in progressive supranuclear palsy, corticobasal degeneration, and parkinsonism-dementia complex of Guamspecific pathological features. J. Neuropathol. Exp. Neurol. 60, 393-402.

Ozawa, T., Okuizumi, K., Ikeuchi, T., Wakabayashi, K., Takahashi, H., Tsuji, S., 2001. Analysis of the expression level of $\alpha$-synuclein mRNA using postmortem brain samples from pathologically confirmed cases of multiple system atrophy. Acta Neuropathol. 102188-102190.

Ozawa, T., Paviour, D., Quinn, N.P., Josephs, K.A., Sangha, H., Kilford, L., Healy, D.G., Wood, N.W., Lees, A.J., Holton, J.L., Revesz, T., 2004. The spectrum of pathological involvement of the striatonigral and olivopontocerebellar systems in multiple system atrophyclinicopathological correlations. Brain 127, 2657-2671.

Ozerdem, U., Grako, K.A., Dahlin-Huppe, K., Monosov, E., Stallcup, W.B., 2001. NG2 proteoglycan is expressed exclusively by mural cells during vascular morphogenesis. Dev. Dyn. 222218-222227.

Ozgen, H., Baron, W., Hoekstra, D., Kahya, N., 2016. Oligodendroglial membrane dynamics in relation to myelin biogenesis. Cell. Mol. Life Sci. 733291-733310.

Pan, S., Chan, J.R., 2017. Regulation and dysregulation of axon infrastructure by myelinating glia. J. Cell Biol. 2163903-2163916.

Pan, B., Fromholt, S.E., Hess, E.J., Crawford, T.O., Griffin, J.W., Sheikh, K.A., Schnaar, R.L., 2005. Myelin-associated glycoprotein and complementary axonal ligands, gangliosides, mediate axon stability in the CNS and PNSneuropathology and behavioral deficits in single- and double-null mice. Exp. Neurol. 195, 208-217.

Pang, Y., Campbell, L., Zheng, B., Fan, L., Cai, Z., Rhodes, P., 2010. Lipopolysaccharideactivated microglia induce death of oligodendrocyte progenitor cells and impede their development. Neuroscience 166464-166475.

Papma, J.M., Jiskoot, L.C., Panman, J.L., Dopper, E.G., den Heijer, T., Donker Kaat, L., Pijnenburg, Y.A.L., Meeter, L.H., van Minkelen, R., Rombouts, S.A.R.B., van Swieten, J.C., 2017. Cognition and gray and white matter characteristics of presymptomatic C9orf72 repeat expansion. Neurology 891256-891264.

Papp, M.I., Lantos, P.L., 1992. Accumulation of tubular structures in oligodendroglial and neuronal cells as the basic alteration in multiple system atrophy. J. Neurol. Sci. 107172-107182.

Papp, M.I., Lantos, P.L., 1994. The distribution of oligodendroglial inclusions in multiple system atrophy and its relevance to clinical symptomatology. Brain J. Neurol. 117235-117243.

Papp, M.I., Kahn, J.E., Lantos, P.L., 1989. Glial cytoplasmic inclusions in the CNS of patients with multiple system atrophy (striatonigral degeneration, olivopontocerebellar atrophy and Shy-Drager syndrome). J. Neurol. Sci.9479-100.

Papuć, E., Wilczyńska, B., Rejdak, K., 2016. Humoral response against myelin associated glycoprotein reflects oligodendroglial degeneration in Parkinson's disease. Ann. Agric. Environ. Med. 23390-23393.

Parchi, P., Gambetti, P., Capellari, S., 2011. Genetic creutzfeldt-jakob disease. In: Dickson, DW, Weller, RO (Eds.), Neurodegeneration: the Molecular Pathology of Dementia and Movement Disorders, second edition Willey-Blackwell, Chichester, West Sussex, pp. 336-345.

Paviour, D.C., Thornton, J.S., Lees, A.J., Jager, H.R., 2007. Diffusion weighted magnetic resonance imaging differentiates Parkinsonian vari- ant of multiple-system atrophy from progressive supranuclear palsy. Mov. Disord. 2268-2274.

Pedraza, L., Huang, J.K., Colman, D.R., 2001. Organizing principles of the axoglial apparatus. Neuron 30335-30344.

Pekny, M, Pekna, M., 2014. Astrocyte reactivity and reactive astrogliosiscosts and benefits. Physiol. Rev. 94, 1077-1098.

Pekny, M., Pekna, M., Messing, A., Steinh€auser, C., Lee, J.M., Parpura, V., Hol, E.M., Sofroniew, M.V., Verkhratsky, A., 2016. Astrocytesa central element in neurological diseases. Acta Neuropathol. 131, 323-345.

Pelvig, D.P., Pakkenberg, H., Stark, A.K., Pakkenberg, B., 2008. Neocortical glial cell numbers in human brains. Neurobiol. Aging 291754-291762.

Penfield, W., 1924. Oligodendroglia and its relation to classical neuroglia. Brain $47430-47452$.

Perez, S.E., Raghanti, M.A., Hof, P.R., Kramer, L., Ikonomovic, M.D., Lacor, P.N., Erwin, J.M., Sherwood, C.C., Mufson, E.J., 2013. Alzheimer's disease pathology in the neocortex and hippocampus of the western lowland gorilla (Gorilla gorilla gorilla). J. Comp. Neurol. 5214318-5214338.

Perez, S.E., Sherwood, C.C., Cranfield, M.R., Erwin, J.M., Mudakikwa, A., Hof, P.R., Mufson, E.J., 2016. Early Alzheimer's disease-type pathology in the frontal cortex of wild mountain gorillas (Gorilla beringei beringei). Neurobiol. Aging 39195-39201.

Perez-Cerda, F., Sanchez-Gomez, M.V., Matute, C., 2015. Pio del Rio Hortega and the discovery of the oligodendrocytes. Front. Neuroanat. 992.

Persico, A.M., Altamura, C., Calia, E., Puglisi-Allegra, S., Ventura, R., Lucchese, F., Keller, F., 2000. Serotonin depletion and barrel cortex developmentimpact of growth impairment vs. Serotonin effects on thalamocortical endings. Cereb. Cortex 10, 181-191.

Peters, A., 2004. A fourth type of neuroglial cell in the adult central nervous system. J. Neurocytol. 33345-33357.

Pham, C.T., de Silva, R., Haïk, S., Verny, M., Sachet, A., Forette, B., Lees, A., Hauw, J.J., Duyckaerts, C., 2011. Tau-positive grains are constant in centenarians' hippocampus. Neurobiol. Aging 321296-321303.

Philips, T., Bento-Abreu, A., Nonneman, A., Haeck, W., Staats, K., Geelen, V., Hersmus, N., Kusters, B., Van Den Bosch, L., Van Damme, P., Richardson, W.D., Robberecht, W., 2013. Oligodendrocyte dysfunction in the pathogenesis of amyotrophic lateral sclerosis. Brain 136471-136482.

Piao, Y.S., Hayashi, S., Hasegawa, M., Wakabayashi, K., Yamada, M., Yoshimoto, M., Ishikawa, A., Iwatsubo, T., et al., 2001. Colocalization of alpha-synuclein and phosphorylated tau in neuronal and glial cytoplasmic inclusions in a patient with multiple system atrophy of long duration. Acta Neuropathol. 101285-101293.

Piao, Y.S., Tan, C.F., Iwanaga, K., Kakita, A., Takano, H., Nishizawa, M., Lashley, T., Revesz, T., Lees, A., de Silva, R., Tsujihata, M., Takahashi, H., 2005. Sporadic four-repeat tauopathy with frontotemporal degeneration, parkinsonism and motor neuron disease. Acta Neuropathol. 110600-110609.

Piaton, G., Gould, R.M., Lubetzki, C., 2010. Axon-oligodendrocyte interactions during developmental myelination, demyelination and repair. J. Neurochem. 1141243-1141260.

Pierre, K, Pellerin, L., 2005. Monocarboxylate transporters in the central nervous systemdistribution, regulation and function. J. Neurochem. 94, 1-14.

Pohl, H.B., Porcheri, C., Mueggler, T., Bachmann, L.C., Martino, G., Riethmacher, D., Franklin, R.J., Rudin, M., Suter, U., 2011. Genetically induced adult oligodendrocyte cell death is associated with poor myelin clearance, reduced remyelination, and axonal damage. J. Neurosci. 311069-311080.

Poliak, S, Peles, E., 2003. The local differentiation of myelinated axons at nodes of Ranvier. Nat. Rev. Neurosci. 4968.

Polymenidou, M., Cleveland, D.W., 2011. The seeds of neurodegenerationprion-like spreading in ALS. Cell 147, 498-508.

Pountney, D.L., Lowe, R., Quilty, M., Vickers, J.C., Voelcker, N.H., Gai, W.P., 2004. Annular $\alpha$-synuclein species from purified multiple system atrophy inclusions. J. Neurochem. 90502-90512.

Pountney, D.L., Chegini, F., Shen, X., Blumbergs, P.C., Gai, W.P., 2005. SUMO-1 marks subdomains within glial cytoplasmic inclusions of multiple system atrophy. Neurosci. Lett.38174-38179.

Pountney, D.L., Treweek, T.M., Chataway, T., Huang, Y., Chegini, F., Blumbergs, P.C. Raftery, M.J., Gai, W.P., 2005. $\alpha$ B-crystallin is a major component of glial cytoplasmic inclusions in multiple system atrophy. Neurotox. Res.777-785.

Pountney, D.L., Dickson, T.C., Power, J.H., Vickers, J.C., West, A.J., Gai, W.P., 2011. Association of metallothionein-III with oligodendroglial cytoplasmic inclusions in multiple system atrophy. Neurotox. Res. 19115-19122.

Powers, J.M., Byrne, N.P., Ito, M., Takao, M., Yankopoulou, D., Spillantini, M.G., Ghetti, B., 2003. A novel leukoencephalopathy associated with tau deposits primarily in white matter glia. Acta Neuropathol. 106181-106187.

Prinz, M., Montrasio, F., Furukawa, H., van der Haar, M.E., Schwarz, P., Rülicke, T., Giger, O.T., Häusler, K.G., Perez, D., Glatzel, M., Aguzzi, A., 2004. Intrinsic resistance of oligodendrocytes to prion infection. J. Neurosci. 245974-245981.

Privat, A., Valat, J., Fulcrand, J., 1981. Proliferation of neuroglial cell lines in the degenerating optic nerve of young rats. A radioautographic study. J. Neuropathol. Exp. Neurol. 4046-4060. 
Prodoehl, J., Li, H., Planetta, P.J., Goetz, C.G., Shannon, K.M., Tangonan, R., Comella, C.L., Simuni, T., Zhou, X.J., Leurgans, S., Corcos, D.M., Vaillancourt, D.E., 2013. Diffusion tensor imaging of Parkinson's disease, atypical parkinsonism, and essential tremor. Mov. Disord. 281816-281822.

Prusiner, S.B., 1982. Novel proteinaceous particles cause scrapie. Science 216136-216144.

Prusiner, S.B., 2004. An introduction to prion biology and diseases. In: Prusiner (Ed.), Prion Biology and Diseases, 2nd edition Cold Spring Harbor Laboratory, New Yoprk, pp. 1-87.

Prusiner, S.B., Scott, M.R., DeArmond, S.J., Cohen, F.E., 1998. Prion protein biology. Cell 93337-93348.

Prusiner, S.B., Woerman, A.L., Mordes, D.A., Watts, J.C., Rampersaud, R., Berry, D.B., Patel, S., Oehler, A., Lowe, J.K., Kravitz, S.N., Geschwind, D.H., Glidden, D.V., Halliday, G.M., Middleton, L.T., Gentleman, S.M., Grinberg, L.T., Giles, K., 2015. Evidence for $\alpha$-synuclein prions causing multiple system atrophy in humans with parkinsonism. Proc. Natl. Acad. Sci. U. S. A. 112, E5308-5317.

Psachoulia, K., Jamen, F., Young, K.M., Richardson, W.D., 2009. Cell cycle dynamics of NG2 cells in the postnatal and ageing brain. Neuron Glia Biol. 557-567.

Pukaß, K., Goldbaum, O., Richter-Landsberg, C., 2015. Mitochondrial impairment and oxidative stress compromise autophagosomal degradation of $\alpha$-synuclein in oligodendroglial cells. J. Neurochem. 135194-135205.

Pukaß, K, Richter-Landsberg, C., 2014. Oxidative stress promotes uptake, accumulation, and oligomerization of extracellular $\alpha$-synuclein in oligodendrocytes. J. Mol. Neurosci. 52339-52352.

Raasakka, A, Kursula, P., 2014. The myelin membrane-associated enzyme 2',3'-cyclic nucleotide 3'-phosphodiesteraseon a highway to structure and function. Neurosci. Bull. 30, 956-966.

Radanovic, M., Pereira, F.R., Stella, F., Aprahamian, I., Ferreira, L.K., Forlenza, O.V., Busatto, G.F., 2013. White matter abnormalities associated with Alzheimer's disease and mild cognitive impairmenta critical review of MRI studies. Expert Rev. Neurother. 13, 483-493.

Raff, M.C., Abney, E.R., Fok-Seang, J., 1985. Reconstitution of a developmental clock in vitroa critical role for astrocytes in the timing of oligodendrocyte differentiation. Cell $4261-4269$.

Raff, M.C., Barres, B.A., Burne, J.F., Coles, H.S., Ishizaki, Y., Jacobson, M.D., 1993. Programmed cell death and the control of cell survivalLessons from the nervous system. Science 262, 695-700.

Rahimi, J., Kovacs, G.G., 2014. Prevalence of mixed pathologies in the aging brain. Alzheimers Res. Ther. 682.

Raine, C.S., 1984. In: InMyelin, Morrell, P (Eds.), Morphology of Myelin and Myelination. Springer, pp. $1-50$

Rajani, R.M., Williams, A., 2017. Endothelial cell-oligodendrocyte interactions in small vessel disease and aging. Clin. Sci. 131369-131379.

Rasband, M.N., 2011. Composition, assembly, and maintenance of excitable membrane domains in myelinated axons. Semin. Cell Dev. Biol. 22178-22184.

Rasband, M.N., Trimmer, J.S., Peles, E., Levinson, S.R., Shrager, P., 1999. K + channel distribution and clustering in developing and hypomyelinated axons of the optic nerve. J. Neurocytol. 28319-28331.

Rasband, M.N., Tayler, J., Kaga, Y., Yang, Y., Lappe-Siefke, C., Nave, K.A., Bansal, R., 2005. CNP is required for maintenance of axon-glia interactions at nodes of Ranvier in the CNS. Glia 5086-5090.

Regenold, W.T., Phatak, P., Marano, C.M., Gearhart, L., Viens, C.H., Hisley, K.C., 2007. Myelin staining of deep white matter in the dorsolateral prefrontal cortex in schizophrenia, bipolar disorder and unipolar major depression. Psychiatry Res. 151179-151188.

Ren, Y., Lin, W.L., Sanchez, L., Ceballos, C., Polydoro, M., Spires-Jones, T.L., Hyman, B.T., Dickson, D.W., Sahara, N., 2014. Endogenous tau aggregates in oligodendrocytes of rTg4510 mice induced by human P301 L tau. J. Alzheimers Dis. 38589-38600.

Revesz, T, Clark, H.B., Holton, J.L., Houlden, H.H., Ince, P.G., HallidayGM, 2015. Extrapyramidal diseases of movement. In: Love, S, Budka, H, Ironside, J, Perry, A (Eds.), Greenfield's Neuropathology, ninth edition CRC Press, Boca Raton, Florida, pp. 740-798.

Rey, N.L., George, S., Brundin, P., 2016. ReviewSpreading the word: precise animal models and validated methods are vital when evaluating prion-like behaviour of $\alpha$-synuclein. Neuropathol. Appl. Neurobiol. 42, 51-76.

Reyes, J.F., Rey, N.L., Bousset, L., Melki, R., Brundin, P., Angot, E., 2014. $\alpha$-synuclein transfers from neurons to oligodendrocytes. Glia 62387-62398.

Richardson, W.D., Pringle, N., Mosley, M.J., Westermark, B., Dubois-Dalcg, M., 1988. Role for platelet-derived growth factor in normal gliogenesis in the central nervous system. Cell 53309-53319.

Richter-Landsberg, C., 2000. The oligodendroglial cytoskeleton in health and disease. J. Neurosci. Res. 5911-5918.

Richter-Landsberg, C., 2008. The cytoskeleton in oligodendrocytes. Microtubule dynamics in health and disease. J. Mol. Neurosci. 3555-3563.

Richter-Landsberg, C., 2016. Protein aggregate formation in oligodendrocytestau and the cytoskeleton at the intersection of neuroprotection and neurodegeneration. Biol. Chem. 397, 185-194.

Richter-Landsberg, C, Bauer, N.G., 2004. Tau-inclusion body formation in opligodendrogliathe role of stress poroteins and proteasome inhibition. Int. J. Dev. Neurosci. 22, 443-451.
Richter-Landsberg, C, Gorath, M., Trojanowski, J.Q., Lee, V.M., 2000. $\alpha$-synuclein is developmentally expressed in cultured rat brain oligodendrocytes. J. Neurosci. Res.629-14.

Riedel, M., Goldbaum, O., Richter-Landsberg, C., 2009. $\alpha$-synuclein promotes the recruitment of tau to protein inclusions in oligodendroglial cellseffects of oxidative and proteolytic stress. J. Mol. Neurosci. 39, 226-234.

Riedel, M., Goldbaum, O., Wille, M., Richter-Landsberg, C., 2011. Membrane lipid modification by docosahexaenoic acid (DHA) promotes the formation of $\alpha$-synuclein in clusion bodies immunopositive for SUMO-1 in oligodendroglial cells after oxidative stress. J. Mol. Neurosci. 43290-43302.

Rinholm, J.E., Hamilton, N.B., Kessaris, N., Richardson, W.D., Bergersen, L.H., Attwell, D., 2011. Regulation of oligodendrocyte development and myelination by glucose and lactate. J. Neurosci. 31538-31548.

Rios, J.C., Rubin, M., St Martin, M., Downey, R.T., Einheber, S., Rosenbluth, J., Levinson, S.R., Bhat, M., Salzer, J.L., 2003. Paranodal interactions regulate expression of sodium channel subtypes and provide a diffusion barrier for the node of Ranvier. J. Neurosci. 237001-237011.

Rivers, L.E., Young, K.M., Rizzi, M., Jamen, F., Psachoulia, K., Wade, A., Kessaris, N., Richardson, W.D., 2008. PDGFRA/NG2 glia generate myelinating oligodendrocytes and piriform projection neurons in adult mice. Nat. Neurosci. 11, 1392-1401.

Rockenstein, E., Ubhi, K., Inglis, C., Mante, M., Patrick, C., Adame, A., Masliah, E., 2012. Neuronal to oligodendroglial $\alpha$-synuclein redistribution in a double-transgenic model of multiple system atrophy. Neuroreport 23259.

Rodriguez-Peña, A., Ibarrola, N., Iñiguez, M.A., Muñoz, A., Bernal, J., 1993. Neonatal hypothyroidism affects the timely expression of myelin-associated glycoprotein in the rat brain. J. Clin. Invest. 91812-91818.

Rohan, Z., Matej, R., Rusina, R., Kovacs, G.G., 2014. Oligodendroglial response in the spinal cord in TDP-43 proteinopathy with motor neuron involvement. Neurodegener. Dis. $14117-14124$

Rohan, Z., Milenkovic, I., Lutz, M.I., Matej, R., Kovacs, G.G., 2016. Shared and distinct patterns of oligodendroglial response in $\alpha$-synucleinopathies and tauopathies. J. Neuropathol. Exp. Neurol. 751100-751109.

Roher, A.E., Weiss, N., Kokjohn, T.A., Kuo, Y.M., Kalback, W., Anthony, J., Watson, D. Luehrs, D.C., Sue, L., Walker, D., Emmerling, M., Goux, W., Beach, T., 2002. Increased $\mathrm{A} \beta$ peptides and reduced cholesterol and myelin proteins characterize white matter degeneration in Alzheimer's disease. Biochemistry 4111080-4111090.

Rone, M.B., Cui, Q.L., Fang, J., Wang, L.C., Zhang, J., Khan, D., Bedard, M., Almazan, G., Ludwin, S.K., Jones, R., Kennedy, T.E., Antel, J.P., 2016. Oligodendrogliopathy in multiple sclerosislow glycolytic metabolic rate promotes oligodendrocyte survival. J. Neurosci. 36, 4698-4707.

Roseborough, A., Ramirez, J., Black, S.E., Edwards, J.D., 2017. Associations between amyloid $\beta$ and white matter hyperintensitiesA systematic review. Alzheimers Dement. 13, 1154-1167.

Rosenbluth, J., 1976. Intramembranous particle distribution at the node of Ranvier and adjacent axolemma in myelinated axons of the frog brain. J. Neurocytol. 5731-5745.

Rosenbluth, J., 2009. Multiple functions of the paranodal junction of myelinated nerve fibers. J. Neurosci. Res. 873250-873258.

Rosin, C., Colombo, S., Calver, A., Bates, T.E., Skaper, S.D., 2005. Dopamine D2 and D3 receptor agonists limit oligodendrocyte injury caused by glutamate oxidative stress and oxygen/glucose deprivation. Glia 52336-52343.

Roth, A.D., Núñez, M.T., 2016. Oligodendrocytesfunctioning in a delicate balance between high metabolic requirements and oxidative damage. Glial cells in health and disease. Advances in Experimental Medicine and Biology 949, Von Bernhardi, R., (edit) Springer Int Publish Switzerland, pp: 167-181.

Rowitch, D.H., Kriegstein, A.R., 2010. Developmental genetics of vertebrate glial-cell specification. Nature 468214-468222.

Roy, N.S., Wang, S., Harrison-Restelli, C., Benraiss, A., Fraser, R.A., Gravel, M., Braun, P.E., Goldman, S.A., 1999. Identification, isolation, and promoter-defined separation of mitotic oligodendrocyte progenitor cells from the adult human subcortical white matter. J. Neurosci. 199986-199995.

Saab, A.S., Tzvetanova, I.D., Nave, K.-A., 2013. The role of myelin and oligodendrocytes in axonal energy metabolism. Curr. Opin. Neurobiol. 231065-231072.

Saher, G., Stumpf, S.K., 2015. Cholesterol in myelin biogenesis and hypomyelinating disorders. Biochim. Biophys. Acta 18511083-18511094.

Saifetiarova, J., Taylor, A.M., Bhat, M.A., 2017. Early and late loss of the cytoskeletal scaffolding protein, ankyrin $\mathrm{G}$ reveals its role in maturation and maintenance of nodes of Ranvier in myelinated axons. J. Neurosci. 372524-372538.

Saing, T., Dick, M., Nelson, P.T., Kim, R.C., Cribbs, D.H., Head, E., 2012. Frontal cortex neuropathology in dementia pugilistica. J. Neurotrauma 291054-291070.

Sakry, D., Karram, K., Trotter, J., 2011. Synapses between NG2 glia and neurons. J. Anat. 2192-2197.

Salter, M.G., Fern, R., 2005. NMDA receptors are expressed in developing oligodendrocyte processes and mediate injury. Nature 4381167-4381171.

Sasaki, K., Doh-ura, K., Wakisaka, Y., Iwaki, T., 2002. Clusterin/apolipoprotein J is associated with cortical Lewy bodiesimmunohisto- 
chemical study in cases with $\alpha$-synucleinopathies. Acta Neuropathol. 104, 225-230.

Schmitt, S., Castelvetri, L.C., Simons, M., 2015. Metabolism and functions of lipids in myelin. Biochim. Biophys. Acta1851999-1005.

Schneider, A., Montague, P., Griffiths, I., Fanarraga, M., Kennedy, P., Brophy, P., Nave, K.A., 1992. Uncoupling of hypomyelination and glial cell death by a mutation in the proteolipid protein gene. Nature 358758-358761.

Schocke, M.F., Seppi, K., Esterhammer, R., Kremser, C., Jaschke, W., Poewe, W., Wenning, G.K., 2002. Diffusion-weighted MRI differentiates the Parkinson variant of multiple system atrophy from PD. Neurology 58575-58580.

Schultz, C., Dehghani, F., Hubbard, G.B., Thal, D.R., Struckhoff, G., Braak, E., Braak, H., 2000. Filamentous tau pathology in nerve cells, astrocytes, and oligodendrocytes of aged baboons. J. Neuropathol. Exp. Neurol. 5939-5952.

Schwarz, L., Goldbaum, O., Bergmann, M., Probst-Cousin, S., Richter-Landsberg, C., 2012. Involvement of macroautophagy in multiple system atrophy and protein aggregate formation in oligodendrocytes. J. Mol. Neurosci. 47256-47266.

Scolding, N., Franklin, R., Stevens, S., Heldin, C.H., Compston, A., Newcombe, J., 1998. Oligodendrocyte progenitors are present in the normal adult human CNS and in the lesions of multiple sclerosis. Brain 1212221-1212228.

Seidel, K., Mahlke, J., Siswanto, S., Krüger, R., Heinsen, H., Auburger, G., Bourzrou, M., Grinberg, L.T., Wicht, H., Korf, H.W., den Dunnen, W., Rüb, U., 2015. The brainstem pathologies of Parkinson's disease and dementia with Lewy bodies. Brain Pathol. 25, 121-135.

Seifert, G., Schilling, K., Steinhauser, C., 2006. Astrocyte dysfunction in neurological disordersa molecular perspective. Nat. Rev. Neurosci. 7, 194-206.

Serwanski, D.R., Jukkola, P., Nishiyama, A., 2017. Heterogeneity of astrocyte and NG2 cell insertion at the node of Ranvier. J. Comp. Neurol. 525535-525552.

Shan, X., Vocadlo, D., Krieger, C., 2009. Mislocalization of TDP-43 in the G93 A mutant SOD1 transgenic mouse model of ALS. Neurosci. Lett. 45870-45874.

Shen, S., Li, J., Casaccia-Bonnefil, P., 2005. Histone modifications affect timing of oligodendrocyte progenitor differentiation in the developing rat brain. J. Cell Biol. 169577-169589.

Shen, S., Liu, A., Li, J., Wolubah, C., Casaccia-Bonnefil, P., 2008. Epigenetic memory loss in aging oligodendrocytes in the corpus callosum. Neurobiol. Aging29452-29463.

Shen, S., Sandoval, J., Swiss, V.A., Li, J., Dupree, J., Franklin, R.J., Casaccia-Bonnefil, P., 2008. Age-dependent epigenetic control of differentiation inhibitors is critical for remyelination efficiency. Nat. Neurosci.111024-111034.

Sherman, D.L., Brophy, P.J., 2005. Mechanisms of axon ensheathment and myelin growth. Nat. Rev. Neurosci. 6683-6690.

Shiga, K., Yamada, K., Yoshikawa, K., Mizuno, T., Nishimura, T., Nakagawa, M., 2005. Local tissue anisotropy decreases in cerebellopetal fibers and pyramidal tract in multiple system atrophy. J. Neurol. 252589-252596.

Shimozawa, A., Ono, M., Takahara, D., Tarutani, A., Imura, S., Masuda-Suzukake, M., Higuchi, M., Yanai, K., Hisanaga, S.I., 2017. Hasegawa M· Propagation of pathological $\alpha$-synuclein in marmoset brain. Acta Neuropathol. Commun. 512.

Shintaku, M, Yutani, C., 2004. Oligodendrocytes within astrocytes ("emperipolesis") in the white matter in Creutzfeldt-Jakob disease. Acta Neuropathol. 108201-108206.

Shults, C.W., Rockenstein, E., Crews, L., Adame, A., Mante, M., Larrea, G., Hashimoto, M., Song, D., Iwatsubo, T., Tsuboi, K., Masliah, E., 2005. Neurological and neurodegenerative alterations in a transgenic mouse model expressing human $\alpha$-synuclein under oligodendrocyte promoterimplications for multiple system atrophy. J. Neurosci. 25, 10689-10699.

Sidman, R.L., Dickie, M.M., Appel, S.H., 1964. Mutant mice (quaking and jimpy) with deficient myelination in the central nervous system. Science 144309-144311.

Sim, F.J., Lang, J.K., Waldau, B., Roy, N.S., Schwartz, T.E., Pilcher, W.H., Chandross, K.J., Natesan, S., Merrill, J.E., Goldman, S.A., 2006. Complementary patterns of gene expression by human oligodendrocyte progenitors and their environment predict determinants of progenitor maintenance and differentiation. Ann. Neurol. 59763-59779.

Sim, F.J., McClain, C.R., Schanz, S.J., Protack, T.L., Windrem, M.S., 2011. Goldman SACd140a identifies a population of highly myelinogenic, migration-competent and efficiently engrafting human oligodendrocyte progenitor cells. Nat. Biotechnol. 29, 934-941.

Simon, C., Gotz, M., Dimou, L., 2011. Progenitors in the adult cerebral cortexcell cycle properties and regulation by physiological stimuli and injury. Glia 59, 869-881.

Simons, M, Trajkovic, K., 2006. Neuron-glia communication in the control of oligodendrocyte function and myelin biogenesis. J. Cell. Biochem. 1194381-1194389.

Simons, M, Trotter, J., 2007. Wrapping it upthe cell biology of myelination. Curr. Opin. Neurobiol. 17, 533-540.

Simons, M., Nave, K.-A., 2016. Oligodendrocytes. Myelination and axonal supprt. Cold Spring Harbor Perspect. Biol. 80240479.

Simón-Sánchez, J., Dopper, E.G., Cohn-Hokke, P.E., Hukema, R.K., Nicolaou, N., Seelaar, H., de Graaf, J.R., de Koning, I., van Schoor, N.M.,
Deeg, D.J., Smits, M., Raaphorst, J., van den Berg, L.H., Schelhaas, H.J., De Die-Smulders, C.E., Majoor-Krakauer, D, Rozemuller, A.J., Willemsen, R., Pijnenburg, Y.A., Heutink, P., van Swieten, J.C., 2012. The clinical and pathological phenotype of C9ORF72 hexanucleotide repeat expansions. Brain 135723-135735.

Snaidero, N., Möbius, W., Czopka, T., Hekking, L.H.P., Mathisen, C., Verkleij, D., Goebbels, S., Edgar, J., Merkler, D., Lyons, D.A., Nave, K.A., Simons, M., 2014. Myelin membrane wrapping of CNS axons by $\mathrm{PI}(3,4,5) \mathrm{P} 3$-dependent polarized growth at the inner tongue. Cell 156277-156290.

Solano, S.M., Miller, D.W., Augood, S.J., Young, A.B., Penney Jr, J.B., 2000. Expression of $\alpha$-synuclein, parkin, and ubiquitin carboxy-terminal hydrolase L1 mRNA in human braingenes associated with familial Parkinson's disease. Ann. Neurol. 47, 201-210.

Song, Y.J., Lundvig, D.M., Huang, Y., Gai, W.P., Blumbergs, P.C., Hojrup, P., Otzen, D., Halliday, G.M., Jensen, P.H., 2007. p25 $\alpha$ relocalizes in oligodendroglia frommyelin to cytoplasmic inclusions in multiple system atrophy. Am. J. Pathol. 1711291-1711303.

Sottejeau, Y., Bretteville, A., Cantrelle, F.X., Malmanche, N., Demiaute, F., Mendes, T., Delay, C., Alves Dos Alves, H., Flaig, A., Davies, P., Dourlen, P., Dermaut, B., Laporte, J., Amouyel, P., Lippens, G., Chapuis, J., Landrieu, I., Lambert, J.C., 2015. Tau phosphorylation regulates the interaction between BIN1's SH3 domain and Tau's proline-rich domain. Acta Neuropathol. Commun. 358.

Spaethling, J.M., Na, Y.-J., Lee, J., Ulyanova, A.V., Baltuch, G.H., Bell, T.J., Brem, S., Chen, H.I., Dueck, H., Fisher, S.A., Garcia, M.P., Khaladkar, M., Kung, D.K., Lucas Jr, T.H., O’Rourke, D.M., Stefanik, D., Wang, J., Wolf, J.A., Bartfai, T., Grady, M.S., Sul, J.Y., Kim, J., Eberwine, J.H., 2017. Primary cell culture of live neurosurgically-resected aged adult human brain cells and single cell transcriptomics. Cell Rep. 18791-18803.

Sperling, R., Mormino, E., Johnson, K., 2014. The evolution of preclinical Alzheimer's diseaseimplications for prevention trials. Neuron 84, 608-622.

Spillantini, M.G., Goedert, M., Crowther, R.A., Murrell, J.R., Farlow, M.R., Ghetti, B., 1997. Familial multiple system tauopathy with presenile dementiaa disease with abundant neuronal and glial tau filaments. Proc. Natl. Acad. Sci. U. S. A. 94, 4113-4118.

Spillantini, M.G., Crowther, R.A., Jakes, R., Cairns, N.J., Lantos, P.L., Goedert, M., 1998. Filamentous alpha-synuclein inclusions link multiple system atrophy with Parkinson's disease and dementia with Lewy bodies. Neurosci. Lett. 251205-251208.

Spina, S., Farlow, M.R., Unverzagt, F.W., Kareken, D.A., Murrell, J.R., Fraser, G., Epperson, F., Crowther, R.A., Spillantini, M.G., Goedert, M., Ghetti, B., 2008. The tauopathy associated with mutation +3 in intron 10 of Taucharacterization of the MSTD family. Brain 131, 72-89.

Stefanova, N., Reindl, M., Neumann, M., Haass, C., Poewe, W., Kahle, P.J., Wenning, G.K., 2005. Oxidative stress in transgenic mice with oligodendroglial $\alpha$-synuclein overexpression replicates the characteristic neuropathology of multiple system atrophy. Am. J. Pathol. 166869-166876.

Stefanova, N., Kaufmann, W.A., Humpel, C., Poewe, W., Wenning, G.K., 2012. Systemic proteasome inhibition triggers neurodegeneration in a transgenic mouse model expressing human $\alpha$-synuclein under oligodendrocyte promoterimplications for multiple system atrophy. Acta Neuropathol. 124, 51-65.

Stemberger, S., Poewe, W., Wenning, G.K., Stefanova, N., 2010. Targeted overexpression of human $\alpha$-synuclein in oligodendroglia induces lesions linked to MSA-like progressive autonomic failure. Exp. Neurol. 224459-224464.

Stolt, C.C., Rehberg, S., Ader, M., Lommes, P., Riethmacher, D., Schachner, M., Bartsch, U., Wegner, M., 2002. Terminal differentiation of myelinforming oligodendrocytes depends on the transcription factor Sox10. Genes Dev. 16165-16170.

Sudre, C.H., Bocchetta, M., Cash, D., Thomas, D.L., Woollacott, I., Dick, K.M., van Swieten, J., Borroni, B., Galimberti, D., Masellis, M., Tartaglia, M.C., Rowe, J.B., Graff, C., Tagliavini, F., Frisoni, G., Laforce, R., Jr, Finger, E., de Mendonça, A., Sorbi, S., Ourselin, S., Cardoso, M.J., Rohrer, J.D., Genetic, F.T.D., Initiative, G.E.N.F.I., 2017 White matter hyperintensities are seen only in GRN mutation carriers in the GENFI cohort. Neuroimage Clin. 15171-15180.

Sugimori, M., Nagao, M., Parras, C.M., Nakatani, H., Lebel, M., Guillemot, F., Nakafuku, M., 2008. Ascl1 is required for oligodendrocyte development in the spinal cord. Development 1351271-1351281.

Sun, W, Dietrich, D., 2013. Synaptic integration by NG2 cells. Front. Cell. Neurosci. 7255

Susuki, K., Chang, K.J., Zollinger, D.R., Liu, Y., Ogawa, Y., Eshed-Eisenbach, Y., Dours-Zimmermann, M.T., Oses-Prieto, J.A., Burlingame, A.L., Seidenbecher, C.I., Zimmermann, D.R., Oohashi, T., Peles, E., Rasband, M.N., 2013. Three mechanisms assemble central nervous system nodes of Ranvier. Neuron 78469-78482.

Tacik, P., DeTure, M., Lin, W.L., Sanchez Contreras, M., Wojtas, A., Hinkle, K.M., Fujioka, S., Baker, M.C., Walton, R.L., Carlomagno, Y., Brown, P.H., Strongosky, A.J., Kouri, N., Murray, M.E., Petrucelli, L., Josephs, K.A., Rademakers, R., Ross, O.A., Wszolek, Z.K., Dickson, D.W., 2015. A novel tau mutation, p.K317 N, causes globular glial tauopathy. Acta Neuropathol. 130199-130214.

Tacik, P., Sanchez-Contreras, M., Rademakers, R., Dickson, D.W., Wszolek, Z.K., 2016. Genetic disorders with tau pathologya review of the litera- 
ture and report of two patients with tauopathy and positive family histories. Neurodegener. Dis. 16, 12-21.

Takao, T., Flint, N., Lee, L., Ying, X., Merrill, J., Chandross, K.J., 2004. 17beta-estradiol protects oligodendrocytes from cytotoxicity induced cell death. J. Neurochem. 89660-89673.

Takeda, A., Arai, N., Komori, T., Iseki, E., Kato, S., Oda, M., 1997. Tau immunoreactivity in glial cytoplasmic inclusions in multiple system atrophy. Neurosci. Lett. 23463-23466.

Tan, A.M., Zhang, W., Levine, J.M., 2005. NG2a component of the glial scar that inhibits axon growth. J. Anat. 207, 717-725.

Tan, C.F., Eguchi, H., Tagawa, A., Onodera, O., Iwasaki, T., Tsujino, A., Nishizawa, M., Kakita, A., Takahashi, H., 2007. TDP-43 immunoreactivity in neuronal inclusions in familial amyotrophic lateral sclerosis with or without SOD1 gene mutation. Acta Neuropathol. 113535-113542.

Tanji, K., Mori, F., Kakita, A., Zhang, H., Kito, K., Kamitani, T., Takahashi, H., Wakabayashi, K., 2007. Immunohistochemical localization of NUB1, a synphilin-1-binding protein, in neurodegenerative disorders. Acta Neuropathol. 114365-114371.

Tank, J., da Costa-Goncalves, A.C., Kamer, I., Qadri, F., Ubhi, K., Rockenstein, E., Diedrich, A., Masliah, E., Gross, V., Jordan, J., 2014. Preserved functional autonomic phenotype in adult mice overexpressing moderate levels of human $\alpha$-synuclein in oligodendrocytes. Physiol. Rep. 2 (11).

Tasic, B., Menon, V., Nguyen, T.N., Kim, T.K., Jarsky, T., Yao, Z., Levi, B., Gray, L.T., Sorensen, S.A., Dolbeare, T., Bertagnolli, D., Goldy, J., Shapovalova, N., Parry, S., Lee, C., Smith, K., Bernard, A., Madisen, L., Sunkin, S.M., Hawrylycz, M., Koch, C., Zeng, H., 2016. Adult mouse cortical cell taxonomy revealed by single cell transcriptomics. Nat. Neurosci. 19335-19346.

Tauber, H., Waehneldt, T.V., Neuhoff, V., 1980. Myelination in rabbit optic nerves is accelerated by artificial eye opening. Neurosci. Lett. 1980, 16235-16238.

Taveggia, C., Feltri, M.L., Wrabetz, L., 2010. Signals to promote myelin formation and repair. Nat. Rev. Neurol. 6276-6287.

Tawk, M., Makoukji, J., Belle, M., Fonte, C., Trousson, A., Hawkins, T., Li, H., Ghandour, S., Schumacher, M., Massaad, C., 2011. Wnt/b-catenin signaling is an essential and direct driver of myelin gene expression andmyelinogenesis. J. Neurosci. 313729-313742.

Taylor, J.M., Song, Y.J., HuangY, Farrer M.J., Delatycki, M.B., Halliday, G.M., Lockhart, P.J., 2007. Parkin Co-Regulated Gene (PACRG) is regulated by the ubiquitin-proteasomal systemand is present in the pathological features of Parkinsonian diseases. Neurobiol. Dis. 27238-27247.

Tekki-Kessaris, N., Woodruff, R., Hall, A.C., Gaffield, W., Kimura, S., Stiles, C.D., Rowitch, D.H., Richardson, W.D., 2001. Hedgehog-dependent oligodendrocyte lineage specification in the telencephalon. Development 1282545-1282554.

Thal, D., Rüb, U., Orantes, M., Braak, H., 2002. Phases of A $\beta$-deposition in the human brain and its relevance for the development of AD. Neurology 581791-581800.

Thaxton, C., Pillai, A.M., Pribisko, A.L., Dupree, J.L., Bhat, M.A., 2011. Nodes of Ranvier act as barriers to restrict invasion of flanking paranodal domains in myelinated axons. Neuron 69244-69257.

Tognata, R., Miller, R.H., 2016. Contribution of the oligodendrocyte lineage to CNS repair and neurodegenerative pathologies. Neuropharmacology 110539-110547.

Tolnay, M, Braak, H., 2011. In: Dickson, DW, Weller, RO (Eds.), Argyrophilic Grain Disease. InNeurodegeneration: the Molecular Pathology of Dementia and Movement Disorders, second edition Willey-Blackwell, Chichester, West Sussex, pp. 165-170.

Tolnay, M., Spillantini, M.G., Goedert, M., Ulrich, J., Langui, D., Probst, A., 1997. Argyrophilic grain diseasewidespread hyperphosphorylation of tau protein in limbic neurons. Acta Neuropathol. 93, 477-484.

Tomassy, G.S., Berger, D.R., Chen, H.H., Kasthuri, N., Hayworth, K.J., Vercelli, A., Seung, H.S., Lichtman, J.W., Arlotta, P., 2014. Distinct profiles of myelin distribution along single axons of pyramidal neurons in the neocortex. Science 344319-344324.

Tong, X.P., Li, X.Y., Zhou, B., Shen, W., Zhang, Z.J., Xu, T.L., Duan, S., 2009. Ca(2+) signaling evoked by activation of $\mathrm{Na}(+)$ channels and $\mathrm{Na}(+) / \mathrm{Ca}(2+)$ exchangers is required for GABA-induced NG2 cell migration. J. Cell Biol. 186113-186128.

Tong, J., Wong, H., Guttman, M., Ang, L.C., Forno, L.S., Shimadzu, M., Rajput, A.H., Muenter, M.D., Kish, S.J., Hornykiewicz, O., Furukawa, Y., 2010. Brain $\alpha$-synuclein accumulation in multiple system atrophy, Parkinson's disease and progressive supranuclear palsya comparative investigation. Brain 133, 172-188.

Tosic, M., Torch, S., Comte, V., Dolivo, M., Honegger, P., Matthieu, J.M., 1992. Tri-iodothyronine has diverse and multiple stimulating effects on expression of the major myelin protein genes. J. Neurochem. 591770-591777.

Toyama, B.H., Savas, J.N., Park, S.K., Harris, M.S., Ingolia, N.T., Yates 3rd, J.R., Hetzer, M.W., 2013. Identification of long-lived proteins reveals exceptional stability of essential cellular structures. Cell 154971-154982.

Trajkovic, K., Dhaunchak, A.S., Goncalves, J.T., Wenzel, D., Schneider, A., Bunt, G., Nave, K.A., Simons, M., 2006. Neuron to glia signaling triggers myelin membrane exocytosis from endosomal storage sites. J. Cell Biol. 172937-172948.

Traka, M., Dupree, J.L., Popko, B., Karagogeos, D., 2002. The neuronal adhesion protein TAG-1 is expressed by Schwann cells and oligoden- drocytes and is localized to the juxtaparanodal region of myelinated fibers. J. Neurosci. 223016-223024.

Trapp, B.D., Nishiyama, A., Cheng, D., Macklin, W., 1997. Differentiation and death of premyelinating oligodendrocytes in developing rodent brain. J. Cell Biol. 137459-137468.

Tress, O., Maglione, M., May, D., Pivneva, T., Richter, N., Seyfarth, J., Binder, S., Zlomuz ica, A., Seifert, G., Theis, M., Dere, E., Kettenmann, H., Willecke, K., 2012. Panglial gap junctional communication is essential for maintenance of myelin in the CNS. J. Neurosci. 327499-327518.

Tripathi, R.B., Rivers, L.E., Young, K.M., Jamen, F., Richardson, W.D., 2010. NG2 glia generate new oligodendrocytes but few astrocytes in a murine experimental autoimmune encephalomyelitis model of demyelinating disease. J. Neurosci. 3016383-3016390.

Tripathi, R.B., Clarke, L.E., Burzomato, V., Kessaris, N., Anderson, P.N., Attwell, D., Richardson, W.D., 2011. Dorsally and ventrally derived oligodendrocytes have similar electrical properties but myelinate preferred tracts. J. Neurosci. 316809-316819.

Tse, K.H., Herrup, K., 2017. DNA damage in the oligodendrocyte lineage and its role in brain aging. Mech. Ageing Dev. 16137-16150.

Tu, P.H., Galvin, J.E., Baba, M., Giasson, B., Tomita, T., Leight, S., Nakajo, S., Iwatsubo, T. Trojanowski, J.Q., Lee, V.M., 1998. Glial cytoplasmic inclusions in white matter oligodendrocytes of multiple system atrophy brains contain insoluble $\alpha$-synuclein. Ann. Neurol. 44415-44422.

Turner, B.J., Bäumer, D., Parkinson, N.J., Scaber, J., Ansorge, O., Talbot, K., 2008. TDP-43 expression in mouse models of amyotrophic lateral sclerosis and spinal muscular atrophy. BMC Neurosci. 9104

Ubhi, K., Lee, P.H., Adame, A., Inglis, C., Mante, M., Rockenstein, E., Stefanova, N., Wenning, G.K., Masliah, E., 2009. Mitochondrial inhibitor 3-nitroproprionic acid enhances oxidative modification of $\alpha$-synuclein in a transgenic mouse model of multiple system atrophy. J. Neurosci. Res. 872728-872739.

Ubhi, K., Rockenstein, E., Mante, M., Inglis, C., Adame, A., Patrick, C., Whitney, K., Masliah, E., 2010. Neurodegeneration in a transgenic mouse model of multiple system atrophy is associated with altered expression of oligodendroglial-derived neurotrophic factors. J. Neurosci. 306236-306246.

Ubhi, K., Low, P., Masliah, E., 2011. Multiple system atrophya clinical and neuropathological perspective. Trends Neurosci. 34, 581-590.

Ubhi, K., Inglis, C., Mante, M., Patrick, C., Adame, A., Spencer, B., Rockenstein, E., May, V., Winkler, J., Masliah, E., 2012. Fluoxetine ameliorates behavioural and neuropathological deficits in a transgenic model mouse of $\alpha$-synucleinopathy. Exp. Neurol. 234405-234416.

Ulusoy, A., Musgrove, R.E., Rusconi, R., Klinkenberg, M., Helwig, M., Schneider, A., Di Monte, D.A., 2015. Neuron-to-neuron $\alpha$-synuclein propagation in vivo is independent of neuronal injury. Acta Neuropathol. Commun. 313.

Urushitani, M., Sato, T., Bamba, H., Hisa, Y., Tooyama, I., 2010. Synergistic effect between proteasome and autophagosome in the clearance of polyubiquitinated TDP-43. J. Neurosci. Res. 88784-88797.

Urwin, H., Josephs, K.A., Rohrer, J.D., Mackenzie, I.R., Neumann, M., Authier, A., Seelaar, H., Van Swieten, J.C., Brown, J.M., Johannsen, P., Nielsen, J.E., Holm, I.E., FReJA Consortium, Dickson, D.W., Rademakers, R., Graff-Radford, N.R., Parisi, J.E., Petersen, R.C., Hatanpaa, K.J., White 3rd, C.L., Weiner, M.F., Geser, F., Van Deerlin, V.M., Trojanowski, J.Q., Miller, B.L., Seeley, W.W., van der Zee, J., Kumar-Singh, S., Engelborghs, S., De Deyn, P.P., Van Broeckhoven, C., Bigio, E.H., Deng, H.X., Halliday, G.M., Kril, J.J., Munoz, D.G., Mann, D.M., Pickering-Brown, S.M., Doodeman, V., Adamson, G., Ghazi-Noori, S., Fisher, E.M., Holton, J.L., Revesz, T., Rossor, M.N., Collinge, J., Mead, S., Isaacs, A.M., 2010. FUS pathology defines the majority of tau- and TDP-43-negative frontotemporal lobar degeneration. Acta Neuropathol. 12033-12041.

Uyama, N., Uchihara, T., Mochizuki, Y., Nakamura, A., Takahashi, R., Mizutani, T., 2009. Selective nuclear shrinkage of oligodendrocytes lacking glial cytoplasmic inclusions in multiple system atrophya 3-dimensional volumetric study. J. Neuropathol. Exp. Neurol. 68, 1084-1091.

Valat, J., Privat, A., Fulcrand, J., 1988. Experimental modifications of postnatal differentiation and fate of glial cells related to axo-glial relationships. Int. J. Dev. Neurosci. 6245-6260.

Valerio, A., Ferrario, M., Dreano, M., Garotta, G., Spano, P., Pizzi, M., 2002. Soluble interleukin-6 (IL-6) receptor/IL-6 fusion protein enhances in vitro differentiation of purified rat oligodendroglial lineage cells. Mol. Cell. Neurosci. 21602-21615.

Vallstedt, A, Kullander, K., 2013. Dorsally derived spinal interneurons in locomotor circuits. Ann. N. Y. Acad. Sci. 127932-127942.

Vallstedt, A., Klos, J.M., Ericson, J., 2005. Multiple dorsoventral origins of oligodendrocyte generation in the spinal cord and hindbrain. Neuron 4555-4567.

Van Bruggen, D., Aguirre, E., Castelo-Branco, G., 2017. Single-cell transcriptomic analysis of oligodendrocyte. Curr. Opin. Neurobiol. 47168-47175.

Van Eersel, J., Ke, Y.D., Gladbach, A., Bi, M., Götz, J., Kril, J.J., Ittner, L.M., 2011. Cytoplasmic accumulation and aggregation of TDP-43 upon proteasome inhibition in cultured neurons. PLoS One6e22850.

Velumian, A.A., Samoilova, M., Fehlings, M.G., 2011. Visualization of cytoplasmic diffusion within living myelin sheaths of CNS white matter axons using microinjection of the fluorescent dye Lucifer Yellow. Neuroimage 5627-5634. 
Verkhratsky, A.N., Trotter, J., Kettenmann, H., 1990. Cultured glial precursor cells from mouse cortex express two types of calcium currents. Neurosci. Lett. 112194-112198.

Verkhratsky, A., Zorec, R., Parpura, V., 2017. Stratification of astrocytes in healthy and diseased brain. Brain Pathol.27629-27644.

Verkhratsky, A., Zorec, R., Rodriguez, J.J., Parpura, V., 2017. Neurogliafunctional paralysis and reactivity in Alzheimer's disease and other neurodegenerative pathologies. Adv. Neurobiol. 15, 427-449.

Vestal-Laborde, A.A., Eschenroeder, A.C., Bigbee, J.W., Robinson, S.E., Sato-Bigbee, C., 2014. The opioid system and brain developmenteffects of methadone on the OL lineage and the early stages of myelination. Dev. Neurosci. 36, 409-421.

Victoria, G.S., Arkhipenko, A., Zhu, S., Syan, S., Zurzolo, C., 2016. Astrocyte-to-neuron intercellular prion transfer is mediated by cell-cell contact. Sci. Rep.620762.

Vigano, F, Dimou, L., 2016. The heterogeneous nature of NG2-glia. Brain Res. 1638129-1638137.

Vigano, F., Mobius, W., Gotz, M., 2013. Dimou LTransplantation reveals regional differences in oligodendrocyte differentiation in the adult brain. Nat. Neurosci. 16, 1370-1372.

Vigano, F., Schneider, S., Cimino, M., Bonfanti, E., Gelosa, P., Sironi, L., Abbracchio, M.P., Dimou, L., 2016. GPR17 expressing NG2 gliaoligodendrocyte progenitors serving as a reserve pool after injury. Glia 64, 287-299.

Vlkolinsky, R., Cairns, N., Fountoulakis, M., Lubec, G., 2001. Decreased brain levels of 2',3'-cyclic nucleotide-3'-phosphodiesterase in Down syndrome and Alzheimer's disease. Neurobiol. Aging 22547-22553.

Wakabayashi, K., Oyanagi, K., Makifuchi, T., Ikuta, F., Homma, A., Homma, Y., Horikawa, Y., Tokiguchi, S., 1994. Corticobasal degenerationetiopathological significance of the cytoskeletal alterations. Acta Neuropathol. 87, 545-553.

Wakabayashi, K., Yoshimoto, M., Tsuji, S., Takahashi, H., 1998. $\alpha$-synuclein immunoreactivity in glial cytoplasmic inclusions in multiple system atrophy. Neurosci. Lett. 249180-249182.

Wakabayashi, K., Hayashi, S., Yoshimoto, M., Kudo, H., Takahashi, H., 2000. $\mathrm{NACP} / \alpha$-synuclein-positive filamentous inclusions in astrocytes and oligodendrocytes of Parkinson's disease brains. Acta Neuropathol. 9914-9920.

Wakabayashi, K., Engelender, S., Tanaka, Y., Yoshimoto, M., Mori, F., Tsuji, S., Ross, C.A., Takahashi, H., 2002. Immunocytochemical localization of synphilin-1, an alpha-synuclein-associated protein, in neurodegenerative disorders. Acta Neuropathol. 103209-103214.

Wang, S., Sdrulla, A.D., diSibio, G., Bush, G., Nofziger, D., Hicks, C., Weinmaster, G., Barres, B.A., 1998. Notch receptor activation inhibits oligodendrocyte differentiation. Neuron 2163-2175.

Wang, X., Fan, H., Ying, Z., Li, B., Wang, H., Wang, G., 2010. Degradation of TDP-43 and its pathogenic form by autophagy and the ubiquitin-proteasome system. Neurosci. Lett. 469112-469116.

Wang, W., Gao, X.F., Xiao, L., Xiang, Z.H., He, C., 2011. K(V)7/KCNQ channels are functionally expressed in oligodendrocyte progenitor cells. PLoS ONE6e21792.

Wang, J., Pol, S.U., Haberman, A.K., Wang, C., O’Bara, M.A., Sim, F.J., 2014. Transcription factor induction of human oligodendrocyte progenitor fate and differentiation. Proc. Natl. Acad. Sci. U. S. A. 111, E2885-E2894.

Watts, J.C., Giles, K., Oehler, A., Middleton, L., Dexter, D.T., Gentleman, S.M., Dearmond, S.J., Prusiner, S.B., 2013. Transmission of multiple system atrophy prions to transgenic mice. Proc. Natl. Acad. Sci. U.S.A. 11019555-11019560.

Wegner, M., Stolt, C.S., 2005. From stem cells to neurons and gliaa Soxist's view of neural development. Trends Neurosci. 28, 583-588.

Wender, M., Kozik, M., Goncerzewicz, A., Mularek, O., 1980. Neuroglia of the developing optic nerve in the course of Wallerian degeneration. J. Hirnforsch. 21417-21428.

Wenning, G.K., Jellinger, K.A., 2005. The role of alpha-synuclein in the pathogenesis of multiple system atrophy. Acta Neuropathol. 109129-109140.

Wenning, G.K., Stefanova, N., Jellinger, K.A., Poewe, W., Schlossmacher, M.G., 2008. Multiple system atrophya primary oligodendrogliopathy. Ann. Neurol. 64, 239-246.

Wharton, S.B., Simpson, J.E., Brayne, C., Ince, P.G., 2015. Age-associated white matter lesionsthe MRC cognitive function and ageing study. Brain Pathol. 25, 35-43.

White, R., Krämer-Albers, E.M., 2014. Axon-glia interaction and membrane traffic in myelin formation. Front. Cell Neurosci. 7284

Wilkins, A., Majed, H., Layfield, R., Compston, A., Chandran, S., 2003. Oligodendrocytes promote neuronal survival and axonal length by distinct intracellular mechanismsa novel role for oligodendrocyte-derived glial cell line-derived neurotrophic factor. J. Neurosci. 23, 4967-4974.

Williams, D.R., 2006. Tauopathiesclassification and clinical update on neurodegenerative diseases associated with microtubule-associated protein tau. Intern. Med. J. 36, 652-660.

Williamson, A.V., Mellor, J.R., Grant, A.L., 1998. Randall AD Properties of GABA(A) receptors in cultured rat oligodendrocyte progenitor cells. Neuropharmacology 37859-37873.

Windrem, M.S., Nunes, M.C., Rashbaum, W.K., Schwartz, T.H., Goodman, R.A., McKhann 2nd, G., Roy, N.S., Goldman, S.A., 2004. Fetal and adult human oligodendrocyte progenitor cell isolates myelinate the congenitally dysmyelinated brain. Nat. Med. 1093-1097.
Winton, M.J., Igaz, L.M., Wong, M.M., Kwong, L.K., Trojanowski, J.Q., Lee, V.M., 2008. Disturbance of nuclear and cytoplasmic TAR DNA-binding protein (TDP-43) induces disease-like redistribution, sequestration, and aggregate formation. J. Biol. Chem. 8313302-8313309.

Woerman, A.L., Stöhr, J., Aoyagi, A., Rampersaud, R., Krejciova, Z., Watts, J.C., Ohyama, T., Patel, S., Widjaja, K., Oehler, A., Sanders, D.W., Diamond, M.I., Seeley, W.W., Middleton, L.T., Gentleman, S.M., Mordes, D.A., Südhof, T.C., Giles, K., Prusiner, S.B. 2015. Propagation of prions causing synucleinopathies in cultured cells. Proc. Natl. Acad. Sci. U. S. A. 112, E4949-4958.

Woerman, A.L., Watts, J.C., Aoyagi, A., Giles, K., Middleton, L.T., Prusiner, S.B., 2017. $\alpha$-synucleinmultiple system atrophy prions. Cold Spring Harb. Perspect. Med. (February (17)), a024588. https://doi.org/10.1101/cshperspect.a024588, (Epub ahead of print)

Wolswijk, G, Noble, M., 1989. Identification of an adult-specific glial progenitor cell. Development 105387-105400

Wong, M.B., Goodwin, J., Nozarit, A., Meedeniya, A.C., Richter-Landsberg, C., Gai, W.P., Pountney, D.L., 2013. SUMO-1 is associated with a subset of lysosomes in glial protein aggregate diseases. Neurotox. Res.231-21.

Wulf, M.A., Senatore, A., Aguzzi, A., 2017. The biological function of the cellular prion proteinan update. BMC Biol. 15, 34.

Xu, J., Chen, S., Ahmed, S.H., Chen, H., Ku, G., Goldberg, M.P., Hsu, C.Y., 2001. Amyloid-beta peptides are cytotoxic to oligodendrocytes. J. Neurosci.21RC.

Xu, D., Liu, Z., Wang, S., Peng, Y., Sun, X., 2017. Astrocytes regulate the expression of Sp1R3 on oligodendrocyte progenitor cells through Cx47 and promote their proliferation. Biochem. Biophys. Res. Commun. 490670-490675.

Yamazaki, Y., Hozumi, Y., Kaneko, K., Sugihara, T., Fujii, S., Goto, K., Kato, H., 2007. Modulatory effects of oligodendrocytes on the conduction velocity of action potentials along axons in the alveus of rat CA1 hippocampal region. Neuron Glia Biol. 3325-3334.

Yang, C., Tan, W., Whittle, C., Qiu, L., Cao, L., Akbarian, S., Xu, Z., 2010. The C-terminal TDP-43 fragments have a high aggregation propensity and harm neurons by a dominant-negative mechanism. PLoS One5e15878.

Yang, N., Zuchero, J.B., Ahlenius, H., Marro, S., Ng, Y.H., Vierbuchen, T., Hawkins, J.S., Geissler, R., Barres, B.A., Wernig, M., 2013. Generation of oligodendroglial cells by direct lineage conversion. Nat. Biotechnol. 31434-31439.

Yazawa, I., Giasson, B.I., Sasaki, R., Zhang, B., Joyce, S., Uryu, K., Trojanowski, J.Q., Lee, V.M., 2005. Mouse model of multiple system atrophy $\alpha$-synuclein expression in oligodendrocytes causes glial and neuronal degeneration. Neuron 45847-45859.

Yin, X., Crawford, T.O., Griffin, J.W., Ph, Tu, Lee, V.M., Li, C., Roder, J., Trapp, B.D., 1998. Myelin-associated glycoprotein is a myelin signal that modulates the caliber of myelinated axons. J. Neurosci. 181953-181962.

Yin, X., Kidd, G.J., Ohno, N., Perkins, G.A., Ellisman, M.H., Bastian, C., Brunet, S., Baltan, S., Trapp, B.D., 2016. Proteolipid protein-deficient myelin promotes axonal mitochondrial dysfunction via altered metabolic coupling. J. Cell Biol. 215531-215542.

Young, V.G., Halliday, G.M., Kril, J.J., 2008. Neuropathologic correlates of white matter hyperintensities. Neurology 71804-71811.

Young, K.M., Psachoulia, K., Tripathi, R.B., Dunn, S.J., Cossell, L., Attwell, D., Tohyama, K., Richardson, W.D., 2013. Oligodendrocyte dynamics in the healthy adult CNSevidence for myelin remodeling. Neuron 77, 873-885.

Yu, Y., Casaccia, P., Lu, Q.R., 2010. Shaping the oligodendrocyte identity by epigenetic control. Epigenetics 5124-5128.

Yu, Y., Chen, Y., Kim, B., Wang, H., Zhao, C., He, X., Liu, L., Liu, W., Wu, L.M., Mao, M., Chan, J.R., Wu, J., Lu, Q.R., 2013. Olig2 targets chromatin remodelers to enhancers to initiate oligodendrocyte differentiation. Cell 152248-152261.

Zarranz, J.J., Ferrer, I., Lezcano, E., Forcadas, M.I., Eizaguirre, B., Atares, B., Puig, B., Gomez-Esteban, J.C., Fernandez-Maiztegui, C., Rouco, I., Perez-Concha, T., Fernandez, M., Rodriguez, O., Rodriguez-Martinez, A.B., de Pancorbo, M.M., Pastor, P., Perez-Tur, J., 2005. A novel mutation (K317 M) in the MAPT gene causes FTDP and motor neuron disease. Neurology 641578-641585.

Zawadzka, M., Rivers, L.E., Fancy, S.P., Zhao, C., Tripathi, R., Jamen, F., Young, K., Goncharevich, A., Pohl, H., Rizzi, M., Rowitch, D.H., Kessaris, N., Suter, U., Richardson, W.D., Franklin, R.J., 2010. CNS-resident glial progenitor/stem cells produce Schwann cells as well as oligodendrocytes during repair of CNS demyelination. Cell Stem Cell 6578-6590.

Zehr, C., Lewis, J., McGowan, E., Crook, J., Lin, W.L., Godwin, K., Knight, J., Dickson, D.W., Hutton, M., 2004. Apoptosis in oligodendrocytes is associated with axonal degeneration in P301 L tau mice. Neurobiol. Dis. 15553-15562.

Zeisel, A., Manchado, A.B.M., Codeluppi, S., Lönnerberg, P., Manno, G.L., Jure' us, A., Marques, S., Munguba, H., He, L., Betsholtz, C., Rolny, C., Castelo-Branco, G., Hjerling-Leffler, J., Linnarsson, S., 2015. Cell types in the mouse cortex and hippocampus revealed by single-cell RNA-seq. Science 3471138-3471142.

Zhang, Y.J., Xu, Y.F., Cook, C., Gendron, T.F., Roettges, P., Link, C.D., Lin, W.L., Tong, J., Castanedes-Casey, M., Ash, P., Gass, J., Rangachari, V., Buratti, E., Baralle, F., Golde, T.E., Dickson, D.W., Petrucelli, L., 2009. Aberrant cleavage of TDP-43 enhances aggregation and cellular toxicity. Proc. Natl. Acad. Sci. U. S. A. 1067607-1067612. 
Zhang, F., Yao, S.Y., Whetsell, W.O., Jr, Sriram, S., 2013. Astrogliopathy and oligodendrogliopathy are early events in CNS demyelination. Glia 611261-611273.

Zhang, Y., Chen, K., Sloan, S.A., Bennett, M.L., Scholze, A.R., O'Keeffe, S., Phatnani, H.P., Guarnieri, P., Caneda, C., Ruderisch, N., Deng, S., Liddelow, S.A., Zhang, C., Daneman, R., Maniatis, T., Barres, B.A., Wu, J.Q., 2014. An RNA-sequencing transcriptome and splicing database of glia, neurons, and vascular cells of the cerebral cortex. J. Neurosci. 3411929-3411947.

Zhao, X., He, X., Han, X., Yu, Y., Ye, F., Chen, Y., Hoang, T., Xu, X., Mi, Q.S., Xin, M., Wang, F., Appel, B., Lu, Q.R., 2010. MicroRNA-mediated control of oligodendrocyte differentiation. Neuron 65612-65626.

Zhao, T., Severijnen, L.A., van derWeiden, M., Zheng, P.P., Oostra, B.A., Hukema, R.K., Willemsen, R., Kros, J.M., et al., 2013. FBXO7 immunore- activity in alpha-synuclein-containing inclusions in Parkinson disease and multiple system atrophy. J. Neuropathol. Exp. Neurol. 72482-72488.

Zhu, X., Bergles, D.E., Nishiyama, A., 2008. NG2 cells generate both oligodendrocytes and gray matter astrocytes. Development 135145-135157.

Zhu, X., Hill, R.A., Dietrich, D., Komitova, M., Suzuki, R., Nishiyama, A., 2011. Age-dependent fate and lineage restriction of single NG2 cells. Development 138745-138753.

Ziskin, J.L., Nishiyama, A., Rubio, M., Fukaya, M., Bergles, D.E., 2007. Vesicular release of glutamate from unmyelinated axons in white matter. Nat. Neurosci. 10321-10330. 